\title{
Manual for Building Capacity of Trainers and Program Managers in Emergency Contraception
}

\author{
Sharif M.I. Hossain \\ Population Council \\ M.E. Khan \\ Population Council \\ Mary Philip Sebastian \\ Population Council \\ Sohini Roychowdhury \\ Population Council
}

Follow this and additional works at: https://knowledgecommons.popcouncil.org/departments_sbsr-rh

Part of the Community Health and Preventive Medicine Commons, Demography, Population, and Ecology Commons, Family, Life Course, and Society Commons, Gender and Sexuality Commons, International Public Health Commons, Maternal and Child Health Commons, Medicine and Health Commons, and the Women's Health Commons How does access to this work benefit you? Let us know!

\section{Recommended Citation}

Hossain, Sharif M.I., M.E. Khan, Mary Philip Sebastian, and Sohini Roychowdhury. 2008. "Manual for Building Capacity of Trainers and Program Managers in Emergency Contraception," FRONTIERS Report. New Delhi: Population Council. 



\title{
$M$ anual for B uilding C apacity of Trainer $s$ and Program M anager $s$ in E mergency Contraception
}

\author{
Sharif Md. Ismail Hossian \\ M. E. Khan \\ Mary Philip Sebastian \\ Sohini Roychowdhury
}
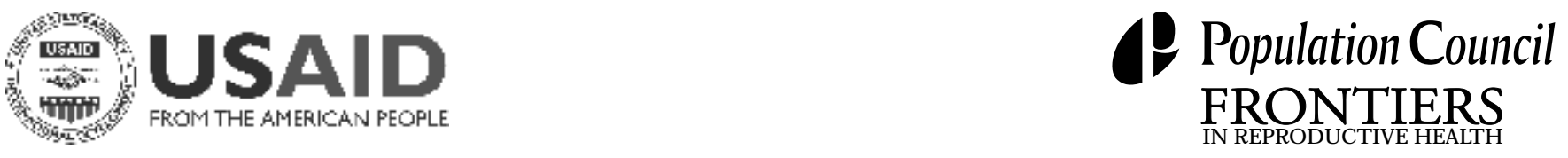

\section{April 2008}

This publication is made possible by the generous support of the American people through the United States Agency for International Development (USAID) under the terms of Cooperative Agreement No. HRN-A-00-98-00012-00. The contents are the responsibility of the FRONTIERS Program and do not necessarily reflect the views of USAID or the United States Government. 



\section{Contents}

About the Manual

iii

Status of Emergency Contraception: A Global Overview v

Session 1: Emergency Contraception Pills: A Reproductive Health Intervention 3

Session 2: Emergency Contraception and Emergency Contraceptive Pills 23

Session 3: Service Delivery Guidelines for Emergency Contraceptive Pills 49

Session 4: Counseling on Emergency Contraceptive Pills 67

Frequently Asked Questions About Emergency Contraceptive Pills and 72

Women's Concerns

Appendix 



\section{About the M anual}

This manual aims to equip trainers with appropriate knowledge on emergency contraceptive pills (ECPs). Emergency contraception refers to any method of contraception that can be used by a woman to prevent an unwanted pregnancy within three days of unprotected intercourse or a contraceptive accident such as condom leakage. This manual discusses emergency contraceptive pills and the provision of related services. It does not cover Intra-uterine Devices (IUDs).

Trainers will need a day's training to get acquainted with the training materials. After training, trainers will have the knowledge and skills necessary to train service providers and workers on emergency contraceptive pills. Clinicians and program managers who would like to provide services or information on emergency contraceptive pills would also benefit from the manual.

The manual is divided into four sessions. The first session provides an overview of the demographic and reproductive health situation in South and South East Asia and briefly discusses the role of emergency contraception as a reproductive health intervention. The second session defines emergency contraception, and discusses details of when and how emergency contraceptive pills should be taken. Service delivery guidelines are covered in the third session, particularly, what users should do in case of method failure. The fourth session covers counseling on emergency contraceptive pills and the frequently asked questions on emergency contraception.

Each session has a list of objectives that are detailed at the outset. Trainers should aim to achieve these objectives when training service providers and workers. A set of transparencies and all tools tested and used in Bangladesh, India and Nepal are provided with the manual to the trainers, which can be used for each session and evaluation of the program. These tools and presentations have been found effective in imparting the information and could be adopted in any setting. An informal questions and answers session should follow each presentation during which participants can clarify doubts. 



\section{Status of emer gency contraception: a global over view}

Invented in 1960 s, emergency contraception (EC) is now available to women in over 140 countries around the globe to prevent unwanted pregnancies that may result from unprotected sex. Previously it was known as the "morning-after pill". In 44 countries, ECP is available through over-the-counter (OTC) meaning that no medical prescription is required to purchase the pill (ICEC 2007, http://www.cecinfo.org). In most of the countries where ECP is approved and registered for use are available through the pharmacies, social marketing, private channels, non-governmental organization (NGO) clinics and physicians but not introduced in the public sector and not available through its service delivery system. In a number of countries, EC is still not registered and in some countries, it is still a prescription drug (Table 1). Lack of polices about the method makes the provider unclear about its legal status and ultimately women are deprived of the benefits of this important reproductive health intervention (ICEC 2007).

Although emergency contraception was innovated in the mid 1960s, when the Yuzpe method was first described, it has remained one of the least known and least used contraceptive methods in nearly all countries particularly, in the developing countries. Many developing countries are still not sure about the potentiality of the method or how to include this method in their family planning (FP) programs. Worldwide, there is a lack of awareness among both service providers and consumers of pregnancy prevention options available to women once unprotected intercourse has occurred. As a result, women use various ineffective and harmful methods to avoid unwanted pregnancy after unprotected intercourse (Khan et al., Tamang et al). Few service providers, those who are aware, offer it to women but many more experience problems due to lack of polices and protocols to deliver ECP services (ICEC 2007). This low knowledge creates little demand for the product and benefit to the needy women.

In many parts of the world, program managers and service providers, because of lack of correct information about the mode of action of ECP believe that ECP is an abortifacient. This misconception deters many governments to register and approve ECP introduction in their program. The fact is that ECPs, like other hormonal contraceptives, act in a variety of ways by inhibiting or delaying ovulation and preventing sperm and egg from uniting (Marions et al. 2002). Recent studies show that ECPs do not prevent implantation. It is also found that once implantation has taken place, ECPs are ineffective and will not abort or harm the embryo (Bacic et al 1970; FDA 1997). 


\section{Table 1: ECP Status and Availability in Asia}

\begin{tabular}{|c|c|c|c|c|c|c|c|}
\hline Country & $\begin{array}{l}\text { Registration } \\
\text { status }\end{array}$ & $\begin{array}{c}\text { Government } \\
\text { status \& } \\
\text { introduction in PS }\end{array}$ & $\begin{array}{l}\text { Available } \\
\text { pills type }\end{array}$ & $\begin{array}{l}\text { WhereEC } \\
\text { available }\end{array}$ & $\begin{array}{l}\text { Dedicated } \\
\text { EC available }\end{array}$ & $\begin{array}{l}\text { OTC } \\
\text { status }\end{array}$ & $\begin{array}{c}\text { Contributors } \\
\text { in introduction }\end{array}$ \\
\hline Afghanistan & N ot registered & $\begin{array}{c}\text { NIA or } \\
\text { Not approved }\end{array}$ & Fertilian & $\begin{array}{l}\text { IPPF's associates } \\
\text { clinics }\end{array}$ & No & $\begin{array}{l}\text { OTC not } \\
\text { available }\end{array}$ & IPPF Affiliate \\
\hline Bangladesh & Registered & $\begin{array}{c}\text { Approved in } 2001 \\
\text { by MOHFW \& } \\
\text { introduced in PS }\end{array}$ & $\begin{array}{l}\text { Postinor-2, } \\
\text { Emcon }\end{array}$ & $\begin{array}{c}\text { Public, private, NGO } \\
\text { clinics, pharmacies } \\
\& \text { physicians }\end{array}$ & Yes & $\begin{array}{c}\text { OTC } \\
\text { available }\end{array}$ & $\begin{array}{l}\text { G0, Population } \\
\text { Council, USAID, } \\
\text { Pathfinder, J SI }\end{array}$ \\
\hline Bhutan & NIA & NIA & NIA & NIA & NIA & $\mathrm{NIA}$ & NIA \\
\hline Myanmar & Registered & $\begin{array}{l}\text { Approved by National } \\
\text { Formulary in } 1995 . \\
\text { Not introduced in PS }\end{array}$ & Postinor-2 & $\begin{array}{l}\text { Clinics, private } \\
\text { providers \& } \\
\text { Pharmacies }\end{array}$ & Yes & $\begin{array}{l}\text { OTC not } \\
\text { available }\end{array}$ & PSI \\
\hline Cambodia & $\begin{array}{l}\text { Temporary } \\
\text { licensed }\end{array}$ & Not approved & NorLevo & $\begin{array}{c}\text { Physicians,IPPF } \\
\text { clinics \& Pharmacies }\end{array}$ & $\begin{array}{l}\text { Yes but not } \\
\text { available }\end{array}$ & $\begin{array}{l}\text { NIA upto } \\
2007\end{array}$ & $\begin{array}{c}\text { PSI,PATH, } \\
\text { Engender Health }\end{array}$ \\
\hline India & Registered & $\begin{array}{c}\text { Approved in } \\
2002 \& \text { introduced } \\
\text { in PS }\end{array}$ & $\begin{array}{l}\text { E pill, I pill, } \\
\text { Preventol }\end{array}$ & $\begin{array}{c}\text { Public, private, NGO } \\
\text { clinics, Pharmacies } \\
\text { \& Physicians }\end{array}$ & Yes & $\begin{array}{c}\text { OTC } \\
\text { available }\end{array}$ & $\begin{array}{l}\text { GO, WHO,AllMS, } \\
\text { ICMR, SEBA, FPAI, } \\
\text { Population Council }\end{array}$ \\
\hline Indonesia & Registered & $\begin{array}{c}\text { Approved by BKKBN } \\
\text { in } 2003 \& \text { introduced } \\
\text { in FP clinics }\end{array}$ & $\begin{array}{l}\text { Postinor-2, } \\
\text { Neogynon } \\
\text { (UR) }\end{array}$ & $\begin{array}{c}\text { GO \& NGO FP } \\
\text { clinics, pharmacies } \\
\text { \& Physicians }\end{array}$ & Yes & $\begin{array}{l}\text { Pharmacies with } \\
\text { prescription }\end{array}$ & $\begin{array}{c}\text { GO, PATH, Pacific } \\
\text { Institute, Pathfinder, } \\
\text { IPPF, M uhamaddiya }\end{array}$ \\
\hline Laos & Not registered & Not approved & $\mathrm{NIA}$ & Pharmacies & No & $\mathrm{NIA}$ & NIA \\
\hline$\overline{M a l a y s i a ~}$ & Registered & $\begin{array}{c}\text { Approved in } 1987 . \\
\text { Included in M OH FP } \\
\text { guidelines but not } \\
\text { introduced in PS }\end{array}$ & $\begin{array}{c}\text { Estinor, } \\
\text { Postinor 2, } \\
\text { NorLevo }\end{array}$ & Pharmacies & Yes & $\begin{array}{l}\text { Pharmacies with } \\
\text { prescription }\end{array}$ & $\overline{N I A}$ \\
\hline Maldives & NIA & NIA & NIA & NIA & NIA & $\mathrm{NIA}$ & NIA \\
\hline Nepal & Registered & $\begin{array}{l}\text { Included in NMS } \\
\text { in } 2001 \& \text { introduced } \\
\text { in PS in } 2005\end{array}$ & Postinor-2 & $\begin{array}{c}\text { GO, NGO, private } \\
\text { clinics, Pharmacies, } \\
\text { Physicians }\end{array}$ & Yes & $\begin{array}{c}\text { OTC } \\
\text { available }\end{array}$ & $\begin{array}{c}\text { PSI, Population } \\
\text { Council, NFCC, } \\
\text { FPAN }\end{array}$ \\
\hline Pakistan & Registered & $\begin{array}{l}\text { Approved in } 2003 \\
\text { but not introduced } \\
\text { in PS }\end{array}$ & $\begin{array}{l}\text { Postinor-2, } \\
\text { Emkit, ECP, } \\
\text { Emkit plus }\end{array}$ & $\begin{array}{c}\text { Green star FP \& } \\
\text { GO Clinics, } \\
\text { Pharmacies \& } \\
\text { Physicians }\end{array}$ & Yes & $\begin{array}{c}\text { OTC } \\
\text { available }\end{array}$ & $\begin{array}{l}\text { PSI, Population } \\
\text { Council, GO }\end{array}$ \\
\hline Philippines & $\begin{array}{l}\text { Registered but } \\
\text { delisted }\end{array}$ & $\begin{array}{l}\text { "Delisted Postinor" } \\
\text { by BFAD in } 2001 \\
\text { due to court order }\end{array}$ & No & $\begin{array}{c}\text { Not } \\
\text { available }\end{array}$ & Delisted & Not available & Pacific Institute \\
\hline Singapore & Registered & $\begin{array}{l}\text { Regulated, no MOH } \\
\text { guidelines \& not } \\
\text { introduced in PS }\end{array}$ & $\begin{array}{l}\text { Estinor, } \\
\text { NorLevo }\end{array}$ & Pharmacies & Yes & $\begin{array}{l}\text { Pharmacies with } \\
\text { prescription }\end{array}$ & $\mathrm{NIA}$ \\
\hline Sri Lanka & Registered & $\begin{array}{l}\text { Approved in } 1997 \\
\text { and introduced in } \\
\text { PS. FPAS L began } \\
\text { Yuzpe in } 1994 \text { \& } \\
\text { Postinor } 2 \text { in } 1998 \\
\end{array}$ & $\begin{array}{l}\text { NorLevo, } \\
\text { Postinor-2 }\end{array}$ & $\begin{array}{l}\text { Public, private, } \\
\text { NGO clinics, } \\
\text { pharmacies \& } \\
\text { Physicians }\end{array}$ & Yes & OTC available & G0, IPPF affiliates \\
\hline Thailand & Registered & $\begin{array}{l}\text { Approved in and } \\
\text { introduced in national } \\
\text { FP program }\end{array}$ & $\begin{array}{l}\text { Madonna, } \\
\text { Postinor } 2\end{array}$ & $\begin{array}{c}\text { Public hospitals, NGO } \\
\text { clinics, pharmacies } \\
\text { \& Physicians }\end{array}$ & Yes & OTC available & $\begin{array}{l}\text { G0, Population } \\
\text { Council,J SI }\end{array}$ \\
\hline Vietnam & Registered & $\begin{array}{c}\text { Approved in included } \\
\text { in Nat. RH Standards } \\
\& \text { Guidelines }\end{array}$ & NIA & $\begin{array}{l}\text { GO, NGO FP clinics } \\
\& \text { pharmacies }\end{array}$ & Yes & OTC available & GO and PATH \\
\hline East Timor & NIA & NIA & NIA & NIA & NIA & NIA & NIA \\
\hline $\begin{array}{l}\text { Brunei } \\
\text { Darussalam }\end{array}$ & NIA & NIA & NIA & NIA & NIA & NIA & NIA \\
\hline
\end{tabular}

$\mathrm{NIA}=\mathrm{N}$ o information available, $\mathrm{OTC}=0$ ver-the-counter, $\mathrm{GO}=$ Government, $\mathrm{M}$ OHFW $=$ M inistry of Health and Family Welfare, NTC $=\mathrm{N}$ ational Technical Committee, FPAI = Family Planning Association of India, M SCS =M arie Stopes Clinic Society, J SI = ohn Snow Inc., FPAN = Family Planning Association of N epal,IPPF=International Planned Parenthood Federation,PS=PublicSystem,Source:Adapted from ICEC,2007 
Millions of women around the globe are using oral contraceptive pill (OCP) as a means of contraception and procuring them from pharmacies without a prescription. ECP is an easy method to use after unprotected intercourse and no medical screening is warranted to provide the services. It is the same hormone women are using in OCP. In many parts of the world, ECP is still a prescription-only remedy which involves a third person to come into the picture after unprotected intercourse and deter women from using it. In many cases, this process unnecessarily delays the use of the method and decreases the efficacy of ECP. Previous studies have shown that women understand labeling on emergency contraception and have used it safely and effectively (Raymond et al. 2007). The established safety record of ECPs and the public health benefits from improved access at the point of sale justify a change in its regulatory status (Ellertson et al. 1998).

Besides a dedicated product with levonorgestrel-only hormone, the available existing oral contraceptive pills women use regularly (usually combined-hormone pills) can also be used as emergency contraception. The efficacy and side-effects are much less with dedicated products than combined-hormone pills. The number of pills to be taken in each dose is also less in case of dedicated products. Moreover, the new regime for emergency contraception becomes more simpler-single pill and single dose within 120 hours of unprotected intercourse. Pharmaceutical firms have also started producing single dose pill. Now, in most of the countries in the world, dedicated ECPs are available. It is suggested that where possible, single dose should be implemented as it greatly reduces the compliance problems.

In many parts of the world, access to ECP among the vulnerable groups such as youth, factory workers and students has remained extremely limited due to various reasons including, fear of policymakers that ECP use could lead to promiscuity or increased sexual activity. However, WHO and many other studies reveal that ECP does not increase promiscuity or risk-taking behaviors rather it establishes responsible sexual behaviors (ICEC 2007 and WHO 1998).

Emergency Contraception opens new windows for the family planning programs. Several studies show that provision of ECP could be used as a potential bridge to provide other reproductive health $(\mathrm{RH})$ services such as regular contraception, counseling on correct use of contraceptive methods, voluntary counseling and testing (VCT), medical treatment, legal services, and psychosocial care (Khan et al. 2007; ICEC 2007). Studies show that non-users of contraception can be brought into regular contraception by creating an opportunity for women to initiate a regular method and/or more reliable method of contraception by counseling while providing EC services. The family planning program should also expand this option to cater to unmet needs of the clients. 
While all this perplexity and programmatic vision remains major challenges for many nations in the world, lack of policies and initiatives act as deterrents for women to leverage benefit from this important reproductive health innovation. It is now established that improved access to EC has the potential to avert unwanted pregnancies and abortions worldwide and thereby, consequences of abortions and unwanted deliveries. It is recommended that to achieve this public health benefit, policymakers should include the method in the medical and legal protocols, providers should inform women about EC and women should have the ability to obtain the method without a medical prescription (ICEC 2007). To address the need of a large number of women in every country, the government should approve and introduce EC in the vertical system.

\section{References}

1. Bacic M, Wesselius de casparis A, Diczfalusy E. 1970. "Failure of Large Doses of Ethiny Estradiol to Interfere with Early Embryonic Development in the Human Spacies." American Journal of Obstetrics and Gynecology; 107 (4):531-534.

2. Ellertson C, Trussell J, Stewart F, Winikoff B. 1998. "Should Emergency Contraceptive Pills Be Available Without Prescription?"; Journal of American Women's Medical Association; 56; 5:226-229.

3. FDA. 1997. Prescription Drugs Products; Certain Combined oral Contraceptives for Use as Postcoital Emergency Contraception: Notice, Federal Register; 62 (37); 86108612 .

4. ICEC. 2007. Improving Access to Emergency Contraception: Policy Statements.

5. ICEC. 2007.http://www.cecinfo.org

6. Khan M. E., Mary Philip Sebastian, Shiv Kumar, Chander Shekhar, N. K. Gupta and Malabika Roy. 2006. "Studying the Utilization of Emergency Contraceptive Services through Paramedics in India." FRONTIERS Report. New Delhi: Population Council/FRONTIERS.

7. Marions L, Hultenby K, Lindell I, Sun X, Stabi B, Danilesson K. 2002. "Emergency Contraception with Mifepristone and Levonorgestrel: Machanism of Action"; 100; 1 : 65-71.

8. Raymond E, Chen P, dalebout, S. 2007. "Actual Use" Study of Emergency Contraception Pills Provided in a Simulated Over the Counter Manner. Obstetriccs and Gynecology (in press).

9. Tamang, Anand. 2005. "Emergency Contraception: Chemists and Paramedics Knowledge About ECP in Nepal." Policy Brief on Emergency Contraception. Nepal: CREHPA. 


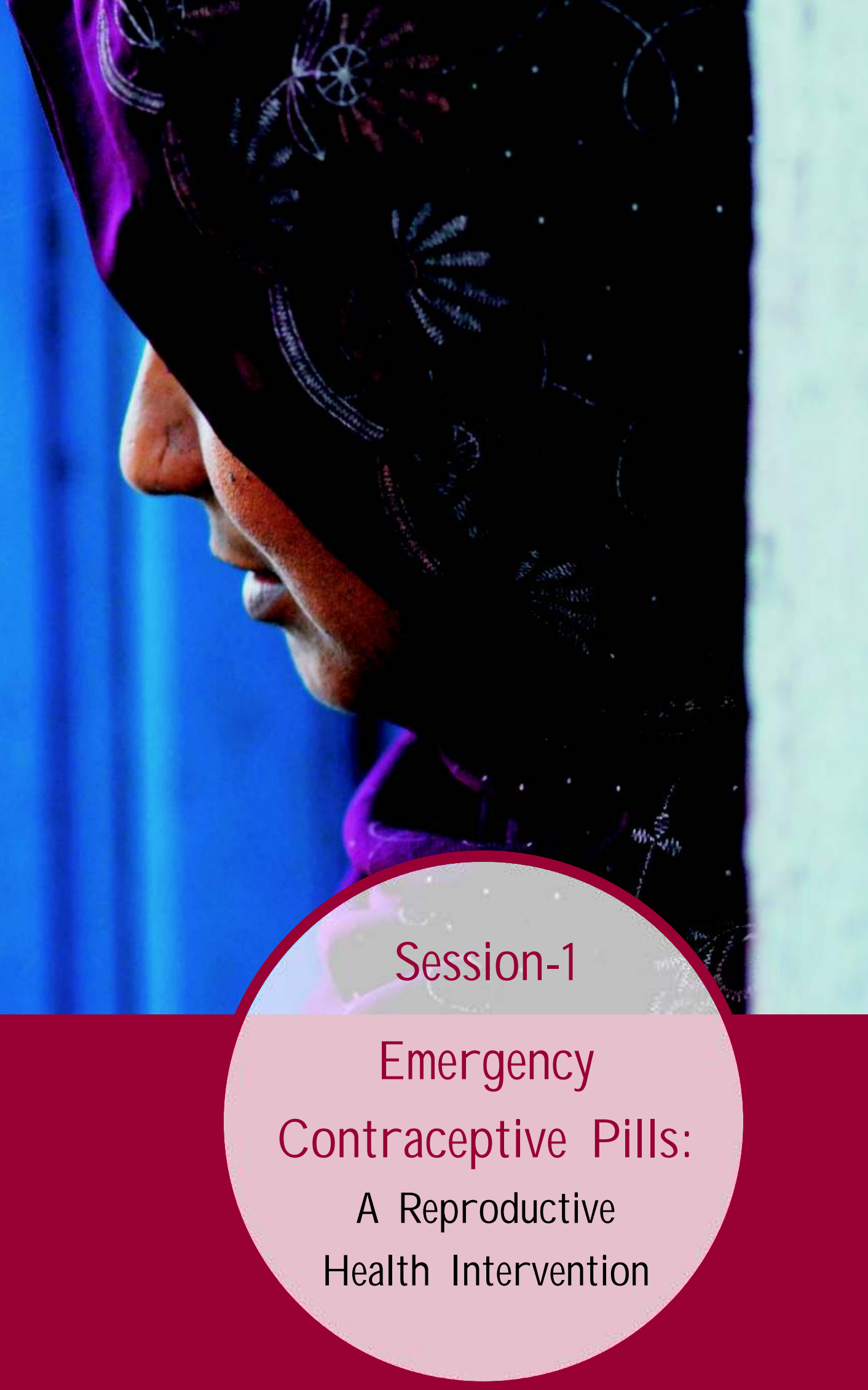





\section{E mergency Contraceptive Pills: A Reproductive Health Intervention}

\section{Objectives}

By the end of Session 1, participants will know:

- Population and fertility in South and South-East Asia

- Contraceptive use and unmet need in South and South-East Asia

- The levels and causes of maternal mortality worldwide

- The extent of menstrual regulations/abortions

- How to reduce the number of unwanted pregnancies, menstrual regulation/abortion and maternal deaths

- Role of emergency contraception in reproductive health programs.

\section{Methods/Presenting Session}

The following methods should be used:

a. An overhead projector for the transparencies

b. An informal discussion and question-answer session should follow where participants can clarify their doubts.

Time Needed for Session 1

Presentation: 30 minutes

Discussion and question-answer session: 30 minutes 



\section{E mergency Contraceptive Pills: A Reproductive Health Intervention}

Each year about 210 million women around the world become pregnant (CDC 2004, PRCH and AGI 2003, WHO/SEARO 2001, AGI 1999, and UNFPA 1997). Among them, about 80 million pregnancies (36 percent) are unplanned and/or unintended (WHO /SEARO 2004 and UNFPA 1997, PRB 2007). Most of these unplanned/unintended pregnancies are not carried to full term, but aborted often in unhygienic conditions leading to serious consequences. It is estimated that worldwide about 46 million pregnancies ( 22 percent of the total pregnancies and 61 percent of the unplanned/unintended pregnancies) are aborted. It is also estimated that among the total pregnancies each year in South and South-East Asia, about one-third are unplanned or unintended. For instance, 30 percent in Bangladesh, 21 percent in India and 35 percent in Nepal and 35 percent in Pakistan are unplanned pregnancies. While most of the unplanned pregnancies in developed countries occur outside the marital union (83 percent in USA) (PRCH and AGI 2003), in South and South-East Asia, it is mostly within marriage or in a stable family life. The reasons for such a huge number of unplanned pregnancies include low contraceptive use, method failure (both users and technological faults), and high unmet need for contraceptives. "Unmet need" means that women want to limit or space future pregnancies but are not using a contraceptive method or have no access to the method.

According to estimates, the increasing number in the total population of South and SouthEast Asia every year could be reduced by one-third if all unplanned or unintended births could be avoided. For example, it is estimated that if all unplanned births were avoided, the fertility rate in Bangladesh would fall from 3.3 to the replacement level of 2.2 children per woman (NIPORT, Mitra and Associates, and ORC Macro 2004).

\section{Population and Fertility in South and South- East Asia}

A projection of the world population shows that while the population of the most developed countries will decrease in 2050, it will increase in the developing countries. Developing countries in Africa and Asia will account for 90 percent of the increase (PRB 2004). It is estimated that about one-third of the world's population (2,135 million) live in South and SouthEast Asia (PRB 2004).

\begin{tabular}{|l|c|c|}
\hline \multicolumn{3}{|c|}{ Table 1: Fertility Trend in Selected } \\
Countries \\
\hline \multirow{2}{*}{ Country } & \multicolumn{2}{|c|}{ Total Fertility } \\
\cline { 2 - 3 } & $1960-70$ & 2006 \\
\hline Bangladesh & 6.3 & 2.7 \\
Bhutan & - & 2.9 \\
India & 5.0 & 2.9 \\
Nepal & 5.1 & 3.1 \\
Pakistan & - & 4.1 \\
Thailand & 6.4 & 1.7 \\
Myanmar & - & 2.3 \\
Sri Lanka & 5.0 & 2.0 \\
Maldives & - & 2.8 \\
Indonesia & 5.6 & 2.4 \\
Malaysia & - & 2.9 \\
Laos & - & 4.8 \\
Cambodia & - & 3.4 \\
Vietnam & - & 2.1 \\
\hline
\end{tabular}

Source: PRB 2006 and BDHS 2007 
While in Europe, the average birth rate has fallen below two children, in some countries of Africa and Middle East, women still have six to eight children. Although most of the South and South-East Asian countries have achieved a steep decline in fertility over the last three to four decades (Table 1), an estimate reveals that population in these countries will continue to grow over the next several decades as well and will have population almost double of what they presently have (PRB 2007). Figure 1 gives a comparative picture of birth rate in the world and selected large South Asian countries.

\section{Contraceptive Use}

Contraceptives are now being widely used in developing countries to avoid unwanted pregnancy. However, many countries are still far behind the world prevalence level. Even within the region there is wide variation in the level of contraceptive use. About 60 percent of the women and men

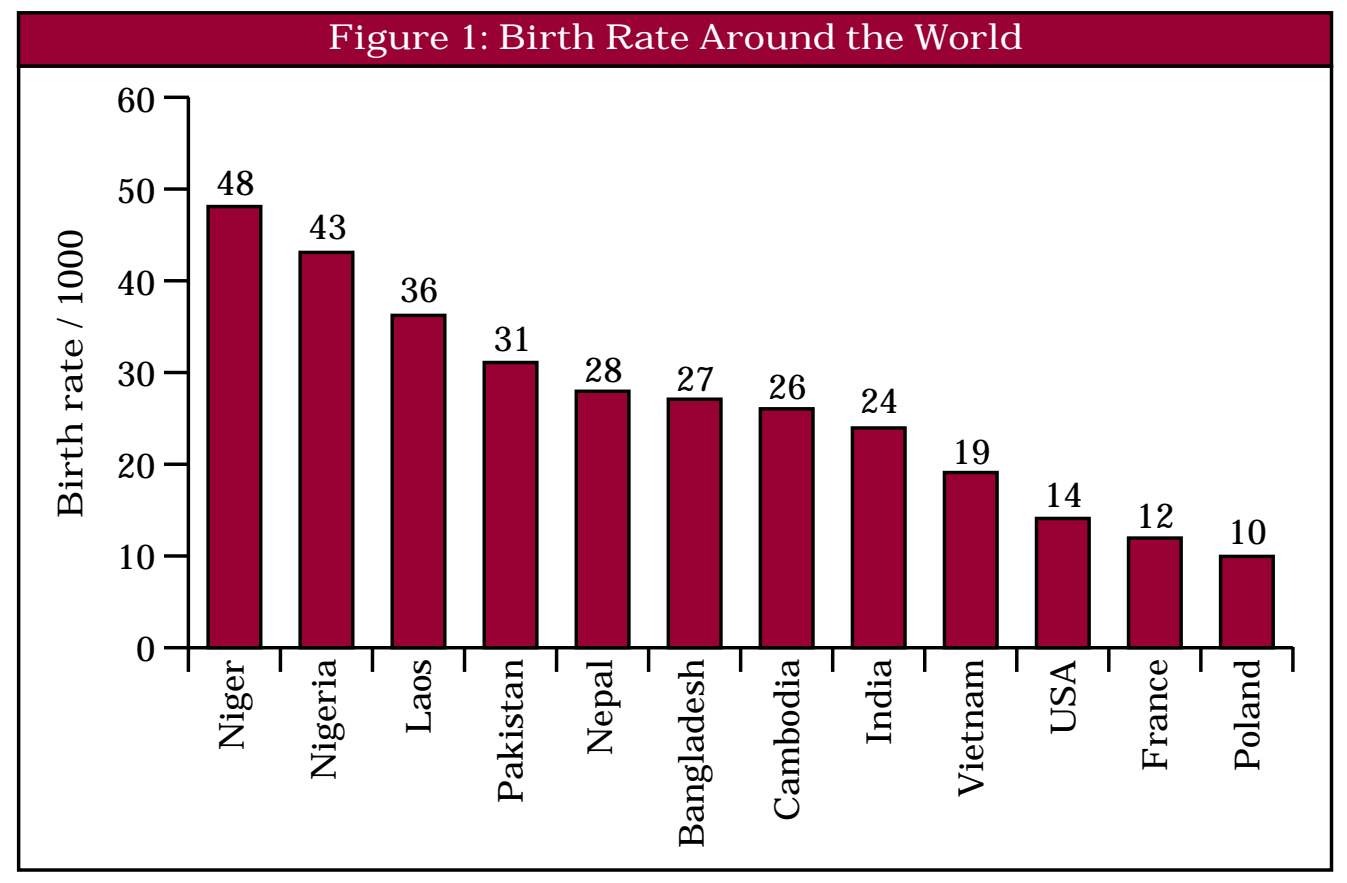
around the world are using modern contraceptive methods (PRB 2004). While more than 80 percent of women aged 15-49 living within stable relationship in developed countries use contraceptives, only about 21 percent in Africa and 51 percent in Asia do so.

Contraceptive methods, even the most effective in preventing pregnancy, may fail for a variety of reasons related to the technologies themselves and/or due to the way they are used. It is estimated that about 30 million pregnancies each year result from contraceptive failure either due to inconsistent or incorrect use or failure of the method itself (Segal et al. 1990; PRB 2007). In developing countries, however, errors in method use are the main cause for an overwhelming majority of unintended pregnancies. Such failure rate over a period of 12 months was much lower for methods like implants and injectables (2-4 percent) compared to condom (15 percent), periodic abstinence ( 22 percent) and withdrawal (26 percent) (Haishan et al 1999).

The unmet need for family planning in South and South-East Asia is presented in Table 2. It shows that a considerable number of women in South and South-East Asia have the desire to use family planning but they do not have the scope to use or lack resources to do so. Unmet 
need for family planning method in South and South-East Asia ranges from a low 9 percent for Indonesia to as high as 32 percent for Pakistan (WHO/SEARO 2002a). For many of these countries in South and South-East Asia, if "unmet need" could be met, the fertility rate in each country could be drastically brought down to the replacement level or to a level that is reasonable.

\section{The Extent and Causes of Maternal Mortality}

Each year worldwide, more than 20 million women experience ill health as a result of pregnancy (WHO/SEARO 2001). Many of these pregnant women experience permanent disabilities and/or deaths due to pregnancy and delivery related complications. According to WHO estimates, about 529, 000 women die annually from pregnancy-related causes worldwide (WHO/UNICEF/UNFPA 2004a). Ninety percent of these deaths occur in less developed countries (WHO 2004b). For every woman who dies, approximately 30 more suffer injury, infection or disability during pregnancy or childbirth, averaging approximately 15 million a year.

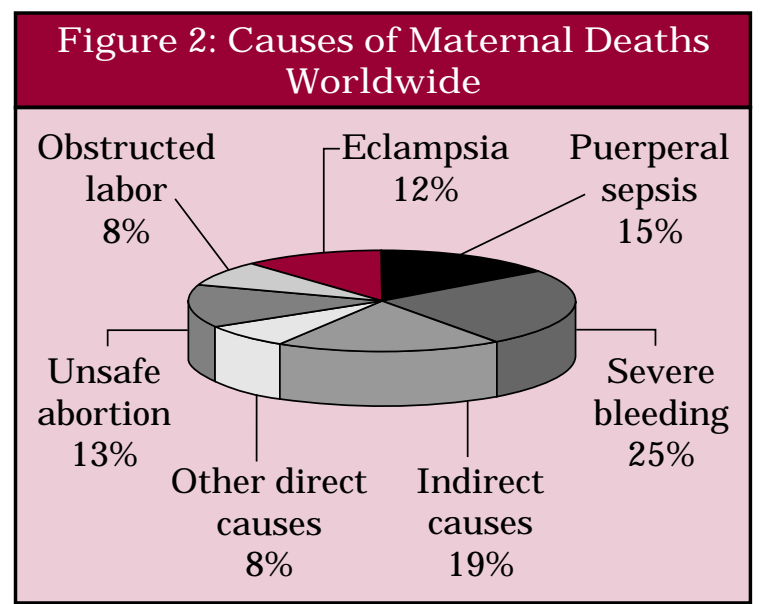

Other direct causes: Ectopic pregnancy, embolism, and anesthesia

Indirect causes: Malaria, anemia and heart diseases

Source: WHO/SEARO 2001

\begin{tabular}{|l|c|c|c|}
\hline \multicolumn{4}{|c|}{$\begin{array}{c}\text { Table 2: Prevalence of Contraceptive Use and } \\
\text { Unmet Need in Selected Countries }\end{array}$} \\
\hline Country & \multicolumn{2}{c|}{ Contraceptive use } & Unmet need \\
\hline & $\begin{array}{c}\text { All } \\
\text { methods }\end{array}$ & $\begin{array}{c}\text { Modern } \\
\text { methods }\end{array}$ & \\
\hline Bangladesh & 58 & 47 & 11 \\
\hline Bhutan & - & 31 & - \\
\hline India & 56 & 49 & 16 \\
\hline Nepal & 48 & 44 & 28 \\
\hline Pakistan & 30 & 22 & 32 \\
\hline Thailand & 72 & 70 & 23 \\
\hline Myanmar & 37 & 33 & - \\
\hline Sri Lanka & 70 & 50 & 25 \\
\hline Maldives & 40 & 35 & - \\
\hline Indonesia & 60 & 57 & 9 \\
\hline Malaysia & 55 & 30 & \\
\hline Laos & 32 & 29 & \\
\hline Cambodia & 40 & 27 & \\
\hline Vietnam & 77 & 66 & \\
\hline
\end{tabular}

Source: PRB 2007 and WHO/SEARO 2002a
Eighty percent of the pregnant women die due to direct causes of pregnancy (Figure 2). The indirect causes (Malaria, anemia and heart diseases) constitute about the remaining 20 percent of the maternal deaths (WHO/SEARO 2001). Studies have shown that abortion-related complications account for nearly 13 percent of the maternal deaths in the world (Figure 2). In the developing world, deaths due to abortion and its related complications is as high as 23 percent. (WHO/SEARO 2001 and PRB 2004). The wide variation in the level of maternal mortality in South Asia and East Asia is reflected in Table 3. For comparison, Maternal Mortality Rate (MMR) of selected developing countries is also given. 
One of the important and vulnerable subgroup of pregnant women is married and unmarried adolescents. A pregnant adolescent (10-19 years old) is two to five times more likely to die of pregnancy related complications than a woman of 20 to 25 years of age (WHO/SEARO 2002). Poor physical development, lack of access to essential reproductive health care and pregnancy termination are i m p or t a n t r e a s o n s contributed to the maternal deaths of adolescent girls. In some countries of South and SouthEast Asia such as India and Bangladesh 40-50 percent of the adolescents are married and become pregnant before they reach age 20. All these adolescents are at high risk of pregnancy and can face severe pregnancy complications (WHO 1997).

Although contraceptive use is increasing and birth rate is decreasing, maternal mortality ratio (maternal deaths per 1,000 live births) has declined only marginally. Unwanted pregnancy is one of the leading causes of maternal mortality and morbidity. Women do not want to keep unwanted pregnancies and many use unsafe methods and/or unhygienic services to terminate their pregnancies. In addition, unwanted pregnancy increases the possibility of women seeking menstrual regulation/abortion services. It is significant to note that many women who seek such services are married and in stable relationships having no objection to contraceptive use.

\section{Menstrual Regulation / Abortion Levels and Trends}

Globally, an average of 35 out of every 1,000 women of childbearing age have abortions each year (AGI 1999). In the year 2000, it is estimated that 19 million abortions were conducted in unsafe and unhygienic conditions. Thirteen percent of the maternal deaths worldwide are due to abortion-related complications. In absolute terms, every year around 68,000 women die of abortion-related complications (Table 4). According to unofficial estimates every year 


\begin{tabular}{|l|c|c|c|c|c|}
\hline \multicolumn{6}{|c|}{ Table 4: Global and Regional Estimates of the Number of Unsafe Abortions and Mortality } \\
& $\begin{array}{c}\text { Due to Unsafe Abortion, 2000 } \\
\text { unsafe abortions } \\
\text { (Thousands) }\end{array}$ & $\begin{array}{c}\text { Number of } \\
\text { maternal } \\
\text { deaths due to } \\
\text { unsafe abortion }\end{array}$ & $\begin{array}{c}\text { \% of all } \\
\text { maternal } \\
\text { deaths }\end{array}$ & $\begin{array}{c}\text { Case-fatality } \\
\text { rate (\%) }\end{array}$ & $\begin{array}{c}\text { Unsafe abortion } \\
\text { deaths to } \\
\mathbf{1 0 0 0 0 0 ~ l i v e ~} \\
\text { births }\end{array}$ \\
\hline World & 19000 & 67900 & 13 & 0.4 & 50 \\
\hline Developed Countries* & 500 & 300 & 14 & 0.1 & 3 \\
\hline Developing Countries & 18400 & 67500 & 13 & 0.4 & 60 \\
\hline Africa & 4200 & 29800 & 12 & 0.7 & 100 \\
\hline Asia* & 10500 & 34000 & 13 & 0.3 & 40 \\
\hline Europe & 500 & 300 & 20 & $<0.1$ & 5 \\
\hline $\begin{array}{l}\text { Latin America } \\
\text { and the Caribbean }\end{array}$ & 3700 & 3700 & 17 & 0.1 & 30 \\
\hline Oceania* & 30 & $<100$ & 7 & 0.1 & 20 \\
\hline
\end{tabular}

* Japan, Australia and New Zealand have been excluded from the regional estimates, but are included in the total for developed countries.

Source: WHO 2004

in India around 7 million abortions are conducted, the majority of them are unsafe and conducted under unhygienic conditions. Similarly in Bangladesh, it is estimated that about 800,000 abortions taken place every year. Among them, menstrual regulation accounts for 468,299 of the pregnancies that are terminated (Singh et al. 1997). Interestingly, the majority of them are unreported, unsafe and conducted under unhygienic conditions. Although the Nepal government has recently legalized abortion, because of the lack of facilities, the majority of the abortions are conducted by untrained providers under unhygienic conditions.

More than half of all unsafe abortions (10.5 million) are conducted in Asia. Among them, over 7 million unsafe abortions are conducted in South Asia alone (WHO 2004). This is a reflection of the high abortion incidence in the large population of reproductive age women in South Asia. The unsafe abortion rate for Asia is 13 per 1000 women aged 15 - 44 years (WHO 2004). About 14 percent of the unsafe abortions in developing countries are among women under 20 years. Table 4 shows that among the total number of maternal deaths due to unsafe abortions, 50 percent are from Asia.

Despite the wide availability of modern contraceptives, an increasing number of women continue to seek abortion and/or other pregnancy termination procedures such as menstrual regulation. In South and South-East Asia (SSEA), a number of abortions are conducted using traditional methods such as inserting roots that are unsafe and could have serious consequences for maternal health and even for life. Like maternal mortality, the extent of maternal morbidity in developing countries is extremely high. There are many women who have survived severe complications of pregnancy and childbirth to suffer from long-lasting conditions such as fistula, uterine prolapse, and urinary incontinence. 


\section{Table 5: Abortion Law Status is South and Southeast Asia}

\begin{tabular}{|l|l|}
\hline Abortion law & Countries \\
\hline $\begin{array}{l}\text { Abortion illegal in all circumstances or permitted only } \\
\text { to save a woman's life }\end{array}$ & $\begin{array}{l}\text { Afghanistan, Bangladesh***, Bhutan R/I, } \\
\text { Indonesia, Laos, Myanmar, Philippines, Sri Lanka }\end{array}$ \\
\hline $\begin{array}{l}\text { Abortion legally permitted only to save a woman's life or } \\
\text { protect her physical health }\end{array}$ & Maldives SA, Pakistan \\
\hline Abortion legally permitted only to protect mental health & Thailand R/F \\
\hline Abortion legally permitted on socioeconomic grounds & India PA/R/F, Nepal \\
\hline Without restriction as to reason (Abortion on request) & Cambodia*, Singapore $^{* *}$ \\
\hline
\end{tabular}

*- Gestational limit of 14 weeks, ** - Gestational limit of 24 weeks, ***- MR is permitted, $\mathrm{R}$ - Abortion permitted in cases of rape

R1 - Abortion permitted in the case of rape of a woman with a mental disability, I - Abortion permitted in cases of incest, F - Abortion permitted in cases of fetal impairment, SA - Spousal authorization required

PA - Parental authorization/notification required. Source: United Nations, World Abortion Policies 2007

Initial understanding about the family planning, EC and abortion law in a country is very important while thinking about registration and approval of a dedicated product particularly in those countries where misconceptions exists that EC is an abortive. However, for the registration and approval of a dedicated EC, abortion laws may not have any influence over the policy makers as it seen from SSEA countries. For example, in Bangladesh, Pakistan, Malaysia and Indonesia abortion is illegal; however, dedicated products have been registered in the country before the government has introduced it in their program (Table 5). One of the reasons for this could be that progesterone-only pills are already available in the country and women are using that. Other possible reason could be WHO approval of combined estrogenprogestin (Yuzpe) regimen to the WHO Model List of Essential Drugs in 1995, levonorgestrelonly EC regimen in this list in 1997 (ICEC 2003). The most important reason is that policy makers do not consider EC as an abortive. On these grounds, EC has been approved in most of the SSEA countries. Table 5 shows that although there are clear cut abortion laws in the countries, however, EC has been approved since all these countries do not consider EC as an abortive.

\section{How Can These Unwanted Deaths and Morbidities be Prevented?}

Many abortion-related deaths and morbidities can be averted by:

- Promoting the use of family planning methods so that women would need to go through fewer unwanted pregnancies and deliveries

- Strengthening post-abortion services in all clinics and making it widely and easily accessible to all women in need

- Informing women about the high risks of traditional methods of pregnancy termination

- Introducing and informing women about Emergency Contraceptive Pills (ECP) as a back-up support in case other family planning methods fail or is incorrectly used and the advantage if ECP is used within 3 days of unprotected intercourse. 


\section{The Role of Emergency Contraception in Reproductive Health Programs}

- Although effective methods of regular contraception are easily available, many pregnancies continue to be unplanned and unwanted. These pregnancies carry a higher risk of maternal morbidity and mortality, as women often attempt to abort these pregnancies through unsafe methods and/or in unhygienic conditions. ECP gives women a second chance to prevent any unplanned or unintended pregnancy

- Emergency contraceptive pills are needed because no contraceptive is 100 percent reliable. Moreover, not everyone uses a contraceptive method perfectly each time they have intercourse

- Emergency contraceptive pills offer women the chance to avoid unwanted pregnancy in cases where regular contraceptive methods have failed or incorrectly used. By preventing unintended pregnancies, emergency contraception can ensure that fewer women will need to seek an abortion or menstrual regulation which will eventually result in fewer pregnancy-related maternal deaths and morbidity

- Millions of women globally have used emergency contraceptive methods safely and effectively. A recent study in China reveals that emergency contraceptive pills can halve the number of induced abortions (UNDP/UNFPA/WHO 2001)

- By offering emergency contraceptive pills, family planning and reproductive health programs can improve the quality of reproductive health services and meet the needs of clients more effectively.

\section{Points to Remember about ECP}

- Emergency contraceptive pills are not intended for regular use. They are only for emergencies

- Emergency contraceptive pills are not as effective as regular pre-coital methods of contraception such as oral contraceptive pills or condoms and should be used only in emergencies when a regular contraceptive method has failed or incorrectly used

- It is important that women are informed in advance about the option of using emergency contraceptive pills and where they can get such services because emergency treatment has to be sought within a very short period of time (three days of unprotected intercourse)

- Providing women with a supply of emergency contraceptive pills at the time of a regular contraceptive visit (advance supply) is one way of ensuring that they are equipped to protect themselves from an unwanted pregnancy in the event of unprotected intercourse or contraceptive failure.

\section{Source:}

United Nations. 2007. World Abortion Polices. New York: United Nations.

Population Reference Bureau. 2008. World Population Data Sheet. New York: PRB. 



\section{Emergency Contraceptlon Is an RH Interventlon for South and Southeast Asian Countries}

South and Southeast Asia in the Context of Global

Demographic Scenarios

\section{Session Objectives}

After the session the participants will have

knowledge and able to:

- Describe demographic scenario of South and Southeast Asian countries in the global context

- Get idea about the rate of maternal mortality and its causes

- Get idea about the rate of unplanned pregnancy and its consequences

- Get idea about the number of unsafe ahortions/MR

- Rolc of ECP in reproductive health 


\section{Population and Rate of Natural Increase}

\begin{tabular}{|c|c|c|}
\hline Country & $\begin{array}{l}\text { Population } \\
\text { (Million) }\end{array}$ & $\begin{array}{c}\text { Rate of natural increase } \\
\text { (Pereentage) }\end{array}$ \\
\hline Bangladesh & 149 & 1.9 \\
\hline India & $1,131.9$ & 1.6 \\
\hline Nepal & 27.8 & 1.9 \\
\hline Pakistan & 169.3 & 2.3 \\
\hline Thailand & 65.7 & 0.7 \\
\hline Myanmar & 49.8 & 0.9 \\
\hline Srilanka & 20.1 & 1.2 \\
\hline Indonesia & 231.6 & 1.4 \\
\hline Malaysia & 27.2 & 1.8 \\
\hline Laos & 5.9 & 2.4 \\
\hline Cambodia & 14.4 & 1.7 \\
\hline Victnaum & 85.1 & 1.3 \\
\hline USAID & \multicolumn{2}{|c|}{ FRB 2008} \\
\hline
\end{tabular}

\section{Birth Rate Around the Globe}

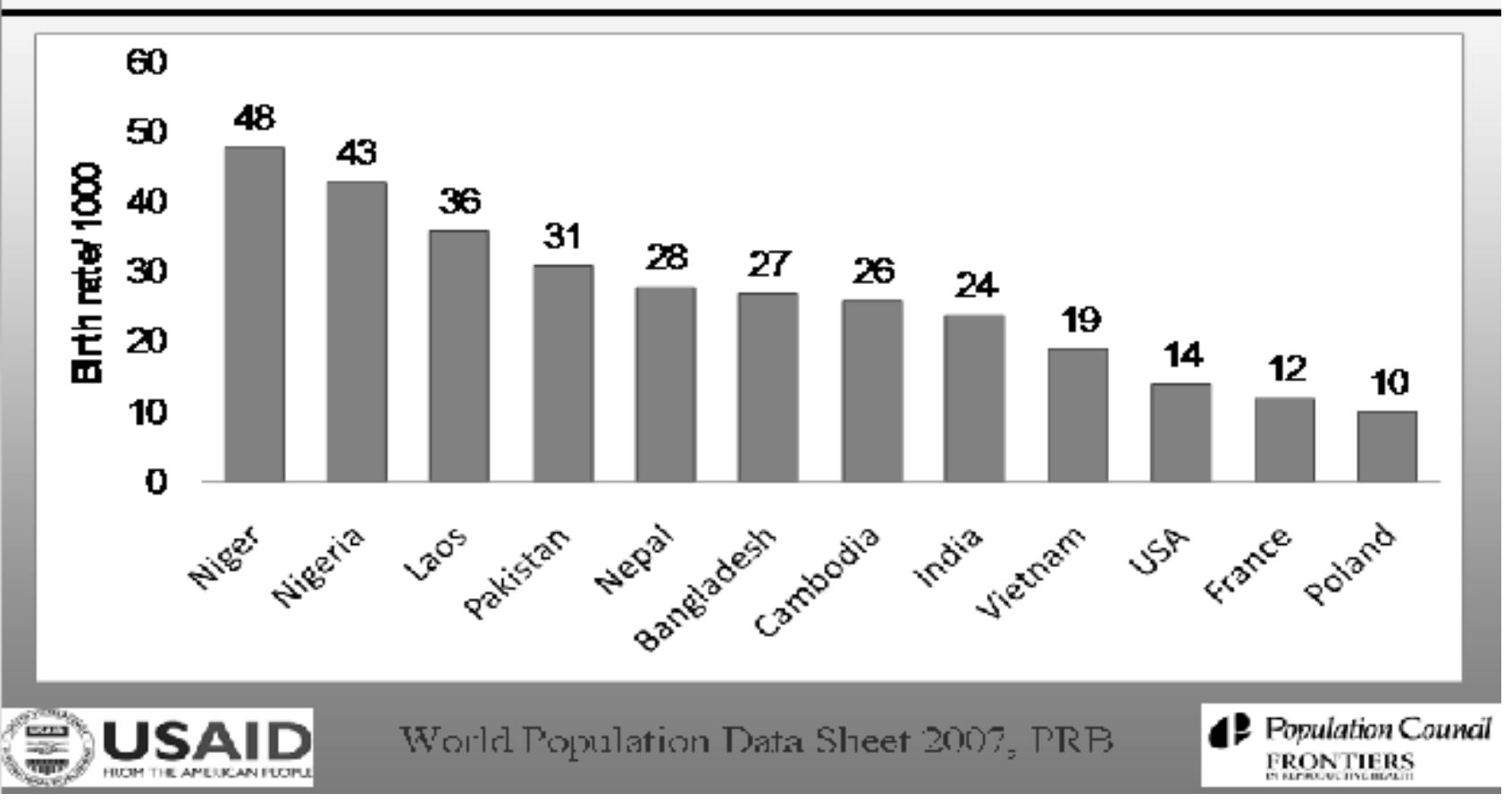




\section{Fertility Trend in Selected Asian Countries}

\begin{tabular}{lll}
\hline Country & \multicolumn{2}{c}{ Total Fertility } \\
& $1960-70$ & 2006 \\
Bangladesh & 6.3 & 2.7 \\
India & 5.0 & 2.9 \\
Thailand & 6.4 & 1.7 \\
Myanmar & - & 2.3 \\
Si Lanka & 5.0 & 2.0 \\
Indonesiat & 5.6 & 2.4 \\
Lans & - & 4.8 \\
Cambodita & - & 3.4 \\
Vietmam & - & 2.1
\end{tabular}

\section{Prevalence of Contraceptive Use and Unmet Need in Selected Countries}

\begin{tabular}{|c|c|c|c|}
\hline Country & $\begin{array}{l}\text { Contr: } \\
\text { All methods }\end{array}$ & $\begin{array}{l}\text { ceptive use } \\
\text { Modern methods }\end{array}$ & $\begin{array}{l}\text { Linmet: } \\
\text { need }\end{array}$ \\
\hline 13aungladesh & $5 \mathbf{B}$ & 47 & 11 \\
\hline India & 53 & 46 & 16 \\
\hline Mepal & 30 & 35 & $2 *$ \\
\hline l'skkistan & 28 & 20 & 32 \\
\hline Thtailand & 79 & 79 & 23 \\
\hline Myanmar & 37 & 33 & - \\
\hline Srilamka & $7 \|$ & 50 & 25 \\
\hline Indonesian & 611 & 57 & 9 \\
\hline Malaysia & 55 & 30 & - \\
\hline I alos & 32 & 29) & - \\
\hline Cambodian & 24 & 19) & \\
\hline Vietnam & 77 & 66 & 5.5 \\
\hline USA & \multicolumn{2}{|c|}{ PRB 2008} & $\begin{array}{l}\text { (2) Population Council } \\
\text { FRONTIERS }\end{array}$ \\
\hline
\end{tabular}




\section{Estimates of Number of Matemal Deaths, Lifetime Risk and Matemal Mortality Ratio by MDG Regions, 2000}

\begin{tabular}{|c|c|c|c|}
\hline MJ)(: region & $\begin{array}{l}\text { No. of } \\
\text { maternal } \\
\text { deaths }\end{array}$ & $\begin{array}{l}\text { I ifetime chance } \\
\text { of dying from } \\
\text { maternal cause }\end{array}$ & $\begin{array}{l}\text { MIM Ratio } \\
\text { (deaths/100,000 } \\
\text { live births) }\end{array}$ \\
\hline World & 529.000 & 1 in 74 & 400 \\
\hline $\begin{array}{l}\text { Developed } \\
\text { regions* }\end{array}$ & 2,500 & 1 in 2,800 & 20 \\
\hline Gurope & $\mathbf{1 , 7 0 0}$ & 1 in $2,4(x)$ & 24 \\
\hline $\begin{array}{l}\text { Developing } \\
\text { regions }\end{array}$ & 527,000 & 1 in 61 & 440 \\
\hline Africa & 251.000 & 1 in 20 & 830 \\
\hline LA/Caribbean & 22,000 & 1 in 160 & 190 \\
\hline Asia & 253,000 & 1 in 94 & 330 \\
\hline Oceania & $531)$ & 1 in 83 & 240 \\
\hline \multicolumn{4}{|c|}{$\begin{array}{l}\text { "Includes, in addiliun ta burople, Canida, I ISA, Japan, } \\
\text { Zealand which are excluded from the regional total. }\end{array}$} \\
\hline 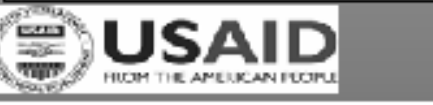 & WHO 20 & and PRB 2008 & 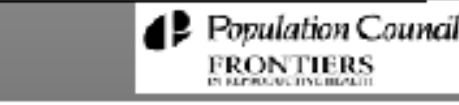 \\
\hline
\end{tabular}

\section{Major Causes of Matemal Death Worldwide}

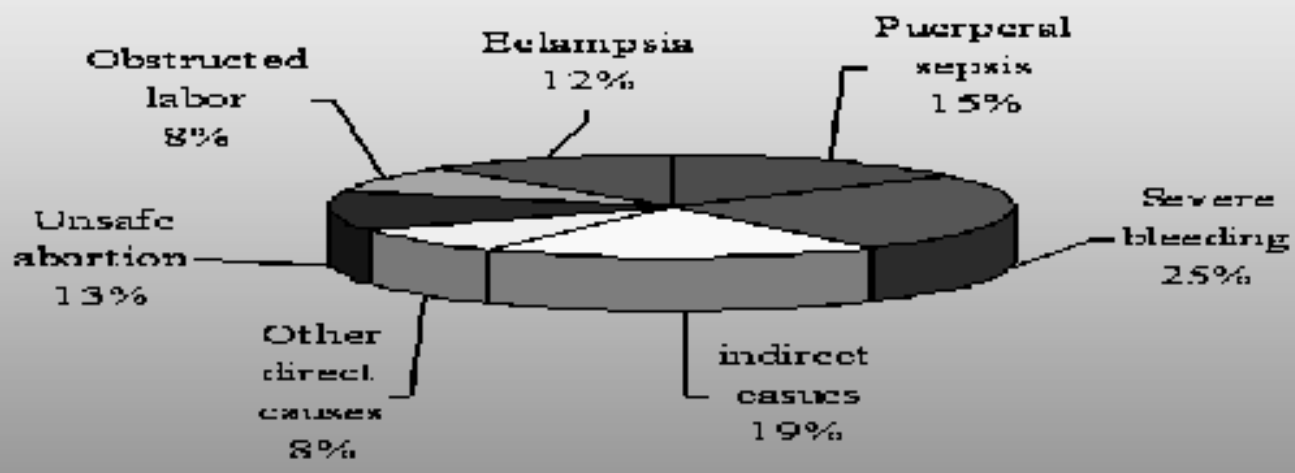




\section{Global and Regional Estimates of the Number of Unsafe Abortions and Mortality Due to Unsafe Abortion, 2000}

\begin{tabular}{|c|c|c|c|c|c|}
\hline VIDG region & $\begin{array}{l}\text { No.of unsafe } \\
\text { abortions } \\
\text { ("l'tollstirits) }\end{array}$ & 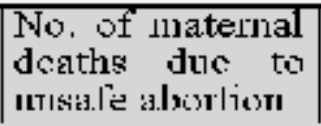 & $\begin{array}{l}9 \% \text { of all } \\
\text { matsrtial } \\
\text { clets.lfis: }\end{array}$ & $\begin{array}{l}\text { Case- } \\
\text { fatality: } \\
\text { rale }[\%]\end{array}$ & $\begin{array}{l}\text { Unsafe aboltion } \\
\text { deaths to } 100000 \\
\text { live liritis: }\end{array}$ \\
\hline World & 19000 & 67900 & 13 & 0.1 & 50 \\
\hline $\begin{array}{l}\text { Dereloped } \\
\text { Cauntries }\end{array}$ & 500 & 300 & 11 & 0.1 & 3 \\
\hline $\begin{array}{l}\text { Devcloping } \\
\text { Countries }\end{array}$ & 18400 & 67500 & 13 & 0.4 & 60 \\
\hline Africa & 4200 & 29800 & 12 & 0.7 & 100 \\
\hline Asia * & 10500 & 34000 & 13 & 0.3 & 40 \\
\hline Iliorope & 500 & .300 & 20 & 0.1 & 5 \\
\hline I,A/Cádribbestn & 3700 & 3700 & 17 & 0.1 & 30 \\
\hline (Xeanian" & 30 & $\because 100$ & 7 & 0.1 & 30 \\
\hline
\end{tabular}

* Japan, Australia aud Nes Zcaland lave becu cocluded fion the regional catienates, but are incluiled in the tostal for developed com untries.

\section{Abortion Law Status is South and Southeast Asia}

\begin{tabular}{|c|c|}
\hline Abortion lıw & Countriks \\
\hline $\begin{array}{l}\text { Abortion illegal in all circumstances or } \\
\text { permitted only to save a woman's life } \\
\text { Abortion legally permitted only to save a } \\
\text { woman's life or protect her physical health }\end{array}$ & 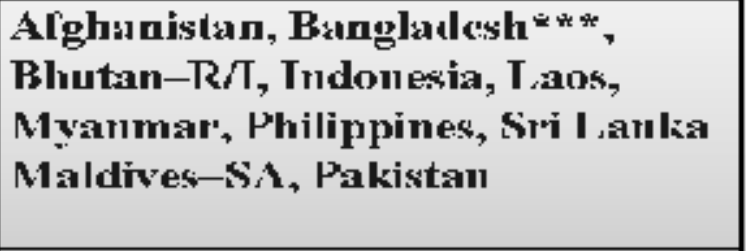 \\
\hline $\begin{array}{l}\text { Abortion legally permitical only to proiket } \\
\text { mentul heulth } \\
\text { Abortion legally permitted on } \\
\text { sncioeconnmic grounds } \\
\text { Without restriction as to reason (Abortion } \\
\text { on request) }\end{array}$ & $\begin{array}{l}\text { Thuiland-R/T } \\
\text { India-PAR/F, Nepal } \\
\text { Cambodia*, Singapore* }\end{array}$ \\
\hline \multicolumn{2}{|c|}{ 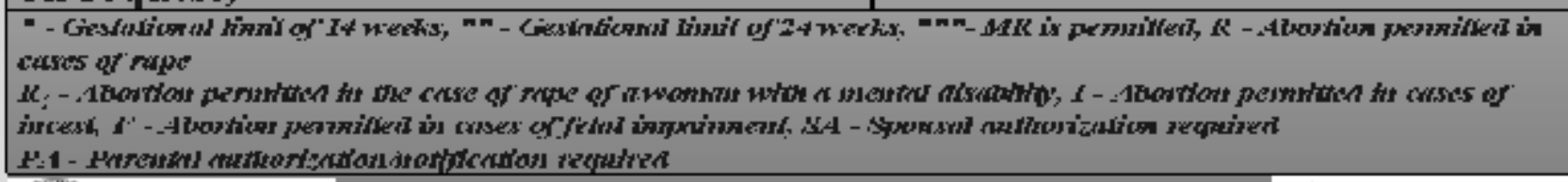 } \\
\hline 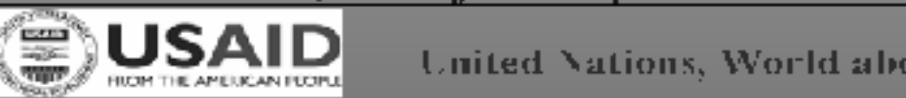 & $\begin{array}{l}\text { A Population Counail } \\
\text { FRONTIERS } \\
\text { Fin pulicies } 200(17\end{array}$ \\
\hline
\end{tabular}




\section{Worldwide Abortions Scenario and Consequences on Maternal Health}

Each year in the world-

- 210 million women become pregnant

‘ 133 million give live births

$>78$ million end in miscarriage, stillbirth or induced aburtion

- 46 million induesed abortions performed

$>19$ million performed in unsafe conditions

- 0.5 million maternal deaths occur due to pregnancy and delivery related causes

$>68,000$ women die ( 13 percent) due to abortions

\section{Worldwide Scenario of Unintended Pregnancies}

Each year in the world-

- 80 million unintended pregnancies vecur

$>26.5$ million (nearly one-third) resulted from incorreet use or thilure of contraceptives

$>40$ million ended in induced abortions 


\section{Many of These Sufferings/Deaths}

\section{Could be Avoided by}

- promoting family planning use to avoid unwanted pregnancy

- making safe and hygienic abortion/MR facilities widely and easily acessible

- educating women about the high risk of pregnancy termination by traditional methods

- introducing and educating women about ECP and its use to avoid unwanted pregnancy resulted from unprotected intercourse

\section{Role of Emergency Contracepti
Reproductive Health}

- A backup support for a very crucial time

- Expanded choice of women for preventing contraception failures

- ECP prevents possible unplanned pregnancy resulted from unprotected sex

- Do not need abortion/MR/traditional methods/ways for pregnancy termination

- Decrease maternal morbidity and mortality 




\section{E mer gency Contraception and Emer gency Contraceptive Pills}

\section{Objectives}

By the end of Session 2, participants will know/be able to define and discuss:

- Emergency contraception and emergency contraceptive pills

- When emergency contraception can be used

- Methods of emergency contraception

- How emergency contraceptive pills work

- The indications and contraindications of emergency contraceptive pills

- The characteristics of emergency contraceptive pills

- The suggested regimen for emergency contraceptive pills

- How emergency contraceptive pills should be taken

- How the three-day interval should be calculated

- The effectiveness of emergency contraceptive pills

- Whether emergency contraceptive pills are effective as a regular contraceptive method

- The side-effects of emergency contraceptive pills and their management.

\section{Methods/presenting session}

The following methods should be used:

a. An overhead projector for the transparencies

b. An informal discussion and question-answer should follow each session where participants can clarify their doubts.

\section{Time needed for Session 2}

Presentation: 60 minutes

Discussion and question-answer: 60 minutes 



\section{E mer gency Contraception and Emer gency Contraceptive Pills}

\section{What is Emergency Contraception and Emergency Contraceptive Pills?}

Emergency contraception (EC) refers to contraceptive methods that can be used by women in the first few days following unprotected intercourse or if she had a contraceptive accident such as leakage/slippage of condom to prevent an unwanted pregnancy. Emergency contraception should not be used as a regular family planning method but should be used only in an emergency as a back-up. Emergency contraception can be provided by emergency contraceptive pills or an intra-uterine device (IUD).

Emergency contraceptive pills are a hormonal method of contraception. These pills contain the hormones found in oral contraceptive pills but in higher doses. These pills are also called "morning-after" or "post-coital" pills. However, since emergency contraceptive pills can be used up to FIVE days after unprotected intercourse, these terms do not convey the correct timing of use. Moreover, these terms do not convey the important fact that emergency contraceptive pills are not a regular family planning method and are intended for "emergency" use only, which is why the name "emergency contraceptive pills" is more appropriate.

For centuries, women have followed a number of practices, or used a variety of devices and preparations to prevent pregnancy. These include washing the genitalia, standing up immediately after intercourse, passing urine, walking and jumping after intercourse. These traditional methods of contraception are generally used immediately after unprotected intercourse to avoid pregnancy. Many of these methods are being used by women, although none of these methods have been found to be effective in preventing pregnancy.

In the 1960s, the first human clinical trials of hormonal emergency contraceptives were conducted, using high-dose estrogen hormone. In the 1970s, high-dose combined oral contraceptives containing ethinyl estradiol and levonorgestrel (known as the Yuzpe method) was initiated.

As is the case with developing countries, most people are not familiar with emergency contraception. Even those who have heard of the method lack accurate information on how to use emergency contraceptive pills or where to obtain them. This lack of knowledge often results in unwanted pregnancies, many of which lead to menstrual regulation/abortions. These, in turn, can cause a number of adverse health consequences for women. 


\section{When Can Emergency Contraception be Used?}

Emergency contraception can be used after unprotected intercourse if a woman does not want to become pregnant from that sexual encounter. Unprotected intercourse includes the following:

- Where a contraceptive method has not been used in voluntary sex

- When the contraceptive method has failed or the method has been used incorrectly, for instance:

- Condom breakage, slippage or leakage

- Failure to take oral contraceptive pills on three consecutive days (combined hormone preparation)

- Delaying a contraceptive injection Depo-medroyprogesterone acetate (DMPA) by more than two weeks from the due date

- Partial or complete dislodgement of IUD

- Miscalculating the infertile period by those following periodic abstinence, or the failure to abstain from sexual intercourse during the fertile period

- Failed coitus interruptus, for instance, when ejaculation has occurred inside the vagina or on the external genitalia

- In cases of involuntary sex or sexual assault, such as rape.

\section{What are the Methods of Emergency Contraception?}

There are two methods of emergency contraception: emergency contraceptive pills and copper-releasing IUDs.

Emergency contraceptive pills are of two types:

- Increased dose of combined oral contraceptives containing ethinyl estradiol and levonorgestrel (the Yuzpe regimen)

- High dose progestin-only pills containing levonorgestrel

The first dose of combined emergency contraceptive pills and levonorgestrel pill should be taken within 72 hours of unprotected intercourse and the second dose 12 hours after the first dose. IUDs can be inserted up to 5 days following such an episode. Although there are pills specially packed for emergency use, most brands of biphasic oral contraceptive pills (OCPs) available in the national program or in the market for regular use can also be used for emergency contraception. Thus, low-cost emergency contraception is already available in most countries' family planning programs. However, the important thing is that most clients are not aware of the dose for taking these pills as emergency contraceptives, or how to switch to the regular cycle of oral contraceptive pills after using the pills as emergency contraceptives. It is critical and essential that women are told how oral contraceptive pills can be used as an emergency contraceptive and how to return to a regular contraceptive method after using emergency contraceptive pills. 
Previously, ECP was used in two divided doses and the time limit was 72 hours. Recently, WHO recommended that ECP could be used in a single dose of two pills (1.5mg levonorgestrel) within 120 hours of unprotected intercourse (Hertzen et al 2002).

\section{How Do Emergency Contraceptive Pills Work?}

The precise mechanism of action of emergency contraceptive pills has not been clearly established. However, a number of studies have mentioned that emergency contraceptive pills can inhibit or delay ovulation. It has also been suggested that emergency contraceptive pills may:

- Delay or prevent ovulation

- Prevent fertilization

- Prevent transport of the sperm and ovum

Which mechanism is active in a particular case depends on the time of the menstrual cycle when emergency contraceptive pills are used.

Emergency contraceptive pills do not interrupt or abort an established pregnancy. They can only help prevent an unwanted pregnancy. Once implantation (pregnancy) has occurred, emergency contraceptive pills are not any more effective. Emergency contraceptive pills, thus, do not cause any form of abortion or bring about menstrual bleeding. Recent Population Council study shows that ECP does not have any effect on post-fertilization process, does not prevent implantation (Population Council 2005).

\section{What are the Indications and Contraindications of Emergency Contraceptive Pills?}

The absolute indication of emergency contraceptive pills is after unprotected intercourse if the woman does not want to become pregnant. Unprotected intercourse can be explained as a situation when no contraceptive has been used pre-coitally, or the method used for contraception was not used correctly or assumed that the method used for contraception was not used correctly or doubts that the method used may fail to prevent pregnancy. In these situations, women may take emergency contraceptive pills to prevent an unwanted pregnancy.

The use of emergency contraceptive pills is not contraindicated unless the woman is already pregnant or there is a realistic suspicion of pregnancy. This is not because emergency contraceptive pills will harm the fetus but because they will not be effective, hence unnecessary.

There are no other known medical contraindications to the use of emergency contraceptive pills. The dose of hormones used in emergency contraception is relatively small and the pills 
are used for a short period of time, so that the contraindications associated with regular use of combined oral contraceptives and progestogen-only pills do not apply to emergency contraceptive pills.

\section{What are the Characteristics of Emergency Contraceptive Pills?}

Emergency contraceptive pills are:

- Safe and effective

- Easy to use and widely available

- First dose of emergency contraceptive pills must be taken within 72 hours of an unprotected intercourse and same dose should be repeated after 12 hours of the first dose

- More effective if taken early

- Can be taken at any time during the monthly cycle

- A physical examination is not required

- Can be given without a prescription depending on the medical regulations of the country

- Can be given to women who have not taken regular oral contraceptive pills for medical reasons, such as a history of heart disease, migraine and liver problems

- Not recommended as a regular method

- Do not prevent STI and HIV/AIDS.

\section{What is the Suggested Regimen for Emergency Contraceptive Pills?}

Several types of available biphasic oral contraceptive pills can be used as emergency contraceptive pills. However, irrespective of which pill is taken, the first dose must be taken within 72 hours of unprotected intercourse (earlier is better) and the second dose 12 hours after the first dose. The recent regimen is better than the previous one.

The number of pills to be taken in each dose depends on the formulation of the contraceptive pills. Two formulations are available: combined oral pills and progestin-only pills.

\section{Combined oral pills}

There are two types of combined oral pills:

- Standard/high-dose pills

These contain 50 micrograms or more of ethinyl estradiol and 250 micrograms of levonorgestrel, or 500 micrograms of dl-norgestrel.

- Low-dose pills

These contain 30-35 micrograms of ethinyl estradiol and 150 micrograms of levonorgestrel, or 300 micrograms of dl-norgestrel. 
Irrespective of whether standard/high dose pills or low dose pills are taken, each dose should contain at least $0.1 \mathrm{mg}$ (100 micrograms) of ethinyl estradiol and $0.5 \mathrm{mg}$ (500 micrograms) of levonorgestrel to be effective as an emergency contraceptive. Table 5 shows a list of few oral contraceptive pills available in Bangladesh, India and Nepal and the dosage for using them for emergency contraception.

\section{Progestin-only pills}

Pills containing only progestin hormone are an alternative to com bined or a l contraceptive pills. Progestin pills are more effective and are associated with fewer side-effects than combined emergency contraceptive pills. However, each dose should contain at least $0.75 \mathrm{mg}(750$ micrograms) of levonorgestrel (a derivative of the progestin hormone). Like combined oral pills, the first dose of progestin pills should be taken as soon as possible but within 72 hours after unprotected sex. The second dose should be taken 12 hours after the first dose. One pill should be taken in each dose. If single dose regimen is used, it has to be taken within five days of unprotected intercourse.

\section{How Should Emergency Contraceptive Pills be Taken?}

Like other tablets, emergency contraceptive pills should be swallowed with water. They should be taken preferably after a meal as they sometimes cause irritability of the stomach. The first dose should be timed so that the woman does not have to wake up in the middle of the night for the next dose (for example, the first dose could be taken at 8 a.m. and the second dose at 8 p.m.). It must be remembered, however, that any delay in starting treatment could decrease the efficacy of emergency contraceptive pills. 


\section{How Should the Three-Days (72 hours)/Five-Days Interval be Calculated?}

To date, most studies have only examined the effectiveness of emergency contraceptive pills after a single penetrative sexual act. However, it is possible that couples may have multiple sexual encounters prior to starting a course of emergency contraceptive pills. The calculation of 72 hours or 3 days/120 hours or five days should start from the first unprotected penetrative vaginal intercourse the woman has had during that particular menstrual cycle. There is no evidence that emergency contraceptive pills can work against unprotected sexual intercourse before or after this (120 hours) period, or during the period when the woman is taking emergency contraceptive pills. However, it is still possible that emergency contraceptive pills may work against multiple intercourses that have occurred within the 120-hour time period, but there is no study available to support this important event.

\section{How Effective are Emergency Contraceptive Pills?}

Emergency contraceptive pills are fairly effective in preventing pregnancy from unprotected sexual intercourse. However, it is important to recognize that not every woman will become pregnant after an unprotected intercourse even if she does not take any emergency contraceptive pills. Moreover, it is impossible to predict correctly who would become pregnant after an unprotected intercourse. Indeed, every woman has an equal chance of becoming pregnant after an unprotected intercourse.

It is estimated that if 100 women have unprotected sexual intercourse during the second or third week of their menstrual cycle, 8 would become pregnant.

- If the same 100 women use combined oral pills as ECPs, instead of 8 women only 2 women would become pregnant.

- If the same 100 women used progestin-only ECPs, instead of 8 women only 1 woman would become pregnant.

These estimates suggest that the use of emergency contraceptive pills could reduce the probability of becoming pregnant from unprotected sexual intercourse by roughly 75 percent in the case of combined oral contraceptive pills, and 85 percent in the case of progestin-only pills.

It should also be mentioned that even if emergency contraceptive pills are correctly used, a few women (15-25 percent) may become pregnant. Taking the results of the studies with highdose oral contraceptives (which are similar to emergency contraceptive pills) into account, experts believe there is no harm to a pregnant woman or fetus if emergency contraceptive pills are failed or inadvertently used during early pregnancy. Two factors influence the efficacy of emergency contraceptive pills: 
- The time gap between unprotected sexual intercourse and the start of the first dose of emergency contraceptive pills and

- The time in a woman's menstrual cycle when she has had unprotected sexual intercourse (whether it is in the fertile period)

Treatment with emergency contraceptive pills should be started as soon as possible after unprotected intercourse because the sooner a woman starts taking emergency contraceptive pills after unprotected intercourse, the more effective they are. Recent studies have indicated that efficacy declines substantially over time after intercourse. The closer the woman is to ovulation at the time of unprotected intercourse, the less likely is the method to succeed.

\section{Are Emergency Contraceptive Pills Effective as Regular Contraceptive Method?}

Emergency contraceptive pills are not effective as regular contraceptives and should be used only in emergencies. Using high-dose contraceptive pills regularly can cause a number of side-effects. Moreover, it is difficult to ascertain the time of ovulation and menstrual bleeding if emergency contraceptive pills are used frequently as they delay or prevent ovulation. As ovulation could occur very soon after emergency contraceptive treatment has ended, if other methods such as condoms are not used during further unprotected intercourses, there is a high possibility that a woman may become pregnant.

Further, as the pregnancy rate for emergency contraceptive pills is based on one-time use, it cannot be directly compared to failure rates of hormonal contraceptives used regularly, which represent the risk of failure during a one-year period of use. In fact, if emergency contraceptive pills were to be used frequently, the failure rate during a full year of use would be much higher than for regular hormonal contraceptives.

\section{Do Emergency Contraceptive Pills Have Any Side-Effects?}

Emergency contraceptive pills have some side-effects, many of which are similar to what women face in the first weeks of starting oral contraceptive pills. However, these side-effects generally do not last more than one to two days (or a maximum of 3 days for combined emergency contraceptive pills) after the second dose of pills.

Generally, progestin-only pills have fewer side-effects as compared to combined emergency contraceptive pills. While about 50 percent of women experience nausea and 20 percent vomiting in the case of combined emergency contraceptive pills, among women who use progestin-only pills, in contrast, 20 percent experience nausea and 6 percent vomiting (WHO 1998). 
Some side-effects that women could experience are:

- Nausea

- Vomiting

- Headache

- Dizziness

- Fatigue

- Breast tenderness

- Menstrual problems

Nausea and vomiting are the most commonly experienced side-effects. These symptoms are generally limited to three days and generally resolve within 24 hours after treatment. Other side-effects are less frequently reported among users of emergency contraceptive pills. If emergency contraceptive pills are frequently used, a woman's periods may become irregular and unpredictable (Knowles and Marcia 1998).

Although single dose regimen (1.5mg levonorgestrel) has higher hormone content, however, research revealed that there is no added side effect due to increased hormone. Moreover, the efficacy of single dose regimen remains same as divided dose.

\section{How Can Side-Effects be Managed?}

- Taking emergency contraceptive pills with food or at bedtime may help reduce nausea and vomiting. Recent study shows it may not help (CEC 2005).

- Women may have an anti-emetic an hour before taking emergency contraceptive pills to reduce nausea and vomiting. Anti-emetics are not effective once nausea begins. Meclizine Hydrochloride (available at the pharmacy under brand names such as Pregnidoxin, Ancolan, Postafen, Antivert, etc.) is the safest drug, although other antiemetics may be helpful. A single 25mg Meclizine Hydrochloride oral dose taken one hour before the first ECP dose reduces the chance of nausea and vomiting by about 30 percent. Women should be warned that this medicine might cause drowsiness. This can be repeated two to three times a day. Prophylactic anti-emetics are not routinely recommended because they may not help all women.

- Some clinicians recommend that if vomiting occurs within two hours of taking the first dose of emergency contraceptive pills, the dose of ECP should be repeated. In such cases, the woman should take an anti-emetic an hour before this dose of emergency contraceptive pills to prevent nausea and vomiting. If vomiting occurs after the second dose is taken, the dose need not be repeated. If the vomiting is severe, the repeated or the second dose can be used intra-vaginally.

- A few women may have irregular bleeding and spotting after treatment with emergency contraceptive pills. They should be told that this is normal and is nothing to worry about. This bleeding should not be confused with menstruation, which is the much-anticipated evidence/proof that the treatment has been successful. Clients 
should be told that emergency contraceptive pills do not necessarily bring on menses immediately (a common misconception among users of emergency contraceptive pills); most women will have their menstrual bleeding on time or slightly early or 2-3 days late than the expected date. However, if menstruation is delayed beyond one week, a pregnancy test should be conducted to exclude the possibility of pregnancy.

- In about 10-15 percent of women, emergency contraceptive pills change the amount, duration, and timing of the next menstrual period. These effects are usually minor and do not need any treatment.

Side-effects such as breast tenderness, headache, dizziness, and fatigue are not common and do not generally last more than 24 hours. Paracetamol or Aspirin or Ibuprofen can be safely recommended for breast tenderness and headache. 



\section{Emergency Contraception}

\section{What is Emergency Contraception (EC)?}

Emergency contraception (EC) refers to contraceptive methods that can be used by women in the first few days following unprotected intercourse to prevent an unwanted pregnancy. 


\section{Role of Emergency Contraceptive Pills in Reproductive Health}

- A backup support for a very crucial time

- Expanded choice of women who's contraceptives have failed

- ECP prevents possible unplanned pregnancy resulted from unprotected intercourse

- Do not need MR/abortion/traditional methods/ways for pregnancy termination

- Decrease maternal morbidity and mortality FRONTIERS

\section{Characteristics of Emergency Contraception}

- Safe, effective and easy to use

- Physical examination is not medically necessary

- Can be provided without prescription

- Can be provided any time during monthly cycle

- Cannot use as a regular method

- Do not prevent STI/HIVIAIDS

It prevents pregnancy and does not cause any abortion or harm to the existing pregnancy 


\section{Situations When EC Could be Used}

\section{In case of unprotected intercourse}

II Voluntary sexual intercourse where no contraceptive is used

II - When there is a contraceptive method failure or method is used incorrectly, such as:

- Condom leakage/slippage

- Failure to take OCP for 3 consecutive days

- Being late for a contraceptive injection more than 2 weeks

- Miscalculation of the infertile (safe) period

- Failed coitus interrupts, when ejaculation has occurred inside the vagina or on the external genitalia

$\| \square$ Involuntary sex such as rape/sexual assault

\section{Methods of Emergency Contraception}

Emergency contraception can be carried out by two methods: -

1. Emergency contraceptive pills (ECPS) and

2. Intra-uterine devices (IUDs) 


\section{Types of ECP}

ECPs are hormonal methods that can be used to prevent pregnancy following unprotected sexual intercourse. This includes:

- Increased doses of Combined Oral Contraceptive (COC) Pills: containing ethinyl estradiol and levonorgestrel

- High doses of Progestogen-only Oral Contraceptive (OCP) Pills: containing levonorgestrel only

\section{Who Could Use ECP?}

- Any woman can use ECPs, even those who are advised not to use OCP as a regular method.

- The sole contraindication for the use of ECP is pregnancy or suspected pregnancy. It is primarily because they will not be effective. 


\section{ECPs: Possible Mechanism of Action}

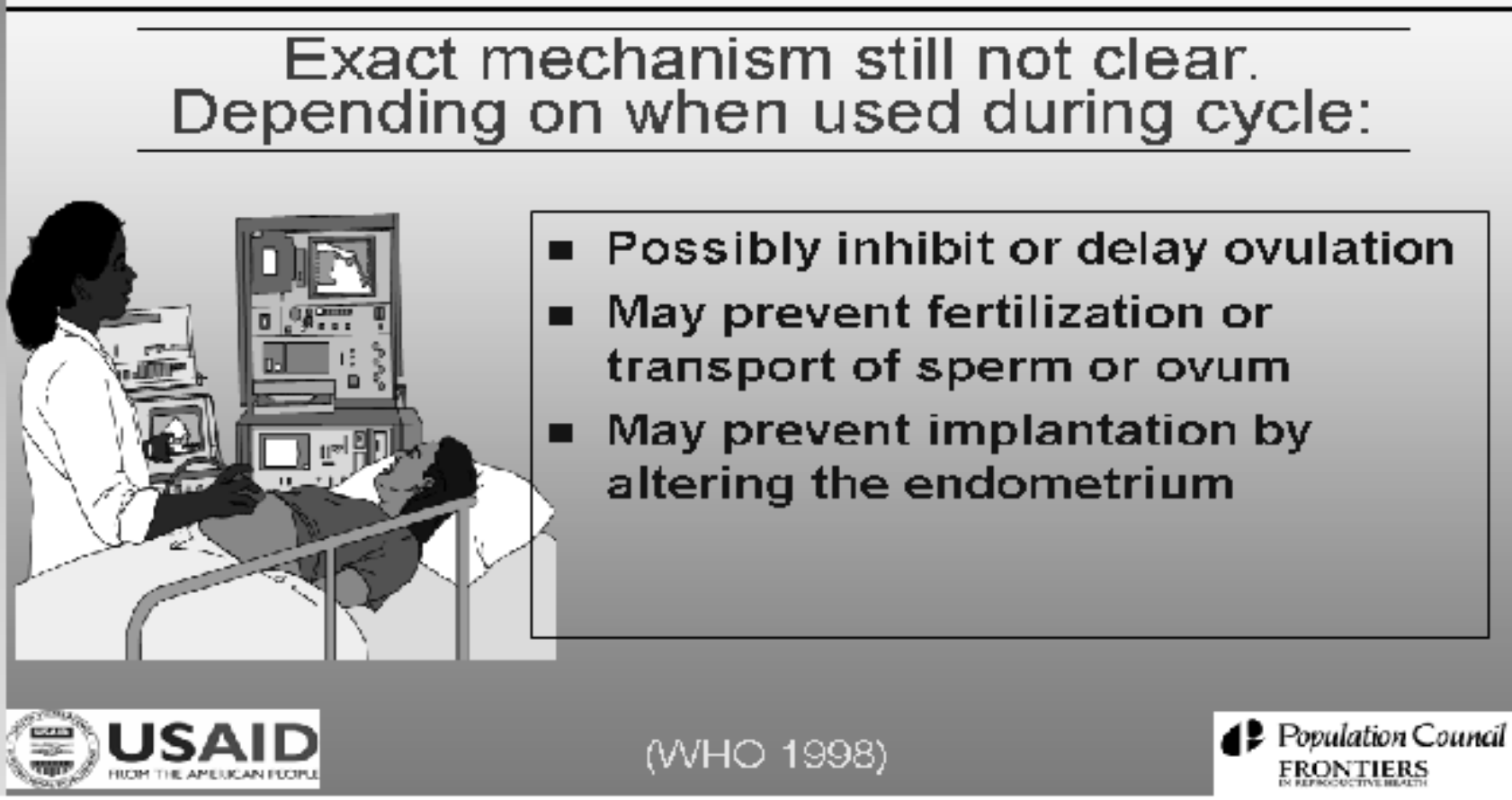

\section{What is the Regimen?}

Combined OCPs (COC) (Ethinyl estradiol +Levonorgestrel)

Low-dose or Standard-dose COC:

1. each dose should contain at least 100 microgram

(0.1mg) ethinyl estradiol and 500 microgram

(0.5mg) levonorgestrel

\section{Progestogen-only pill (Levonorgestrel)}

- each dose should contain 750 microgram $(0.75 \mathrm{mg}$ ) levonorgestrel alone 


\section{Emergency Contraceptive Pill: How Should it be Taken?}

When to take?

How many doses?

Hours between two doses?

How many pills in each dose?
Start as soon as possible. First dose must be started within 72 hours ( 3 clays) of an unprotected intercourse

2 doses

12 hours

Low dose- 4 pills

Standard dose- 2 pills

Progestogen-only- 1 pill

\section{Changed Regime}

- $1.5 \mathrm{mg}$ levonorgestrel single dose within 120 hours (5 days) of unprotected sex

Effectiveness and side-effects remain same

- Recommended to use both the tablets together if single dose $1.5 \mathrm{mg}$ levonorgestrel is unavailable 


\section{Effectiveness: Combined Oral Pill ECP}

\section{If 100 women have a single act of unprotected intercourse during the $2^{\text {nd }}-3^{\text {rd }}$ week of cycle}

\section{ECP not used: \\ 8 women would become pregnant}

ECP used:

2 women become pregnant

Prevents 6 out of 8 , or $75 \%$ of expected pregnancies

\section{Effectiveness: Progestogen-only ECP}

If 100 women have a single act of unprotected
intercourse during the $2^{\text {nd }}-3^{\text {rd }}$ week of cycle
ECP not used:
8 women would become pregnant 1 woman becomes pregnant
Prevents 7 out of 8, or 85\% of expected pregnancies
(CEO 2004; FHI 2002; WHO 1998)




\section{Effectiveness of ECPs by Timing of Initiation: Most Effective When Taken Early}

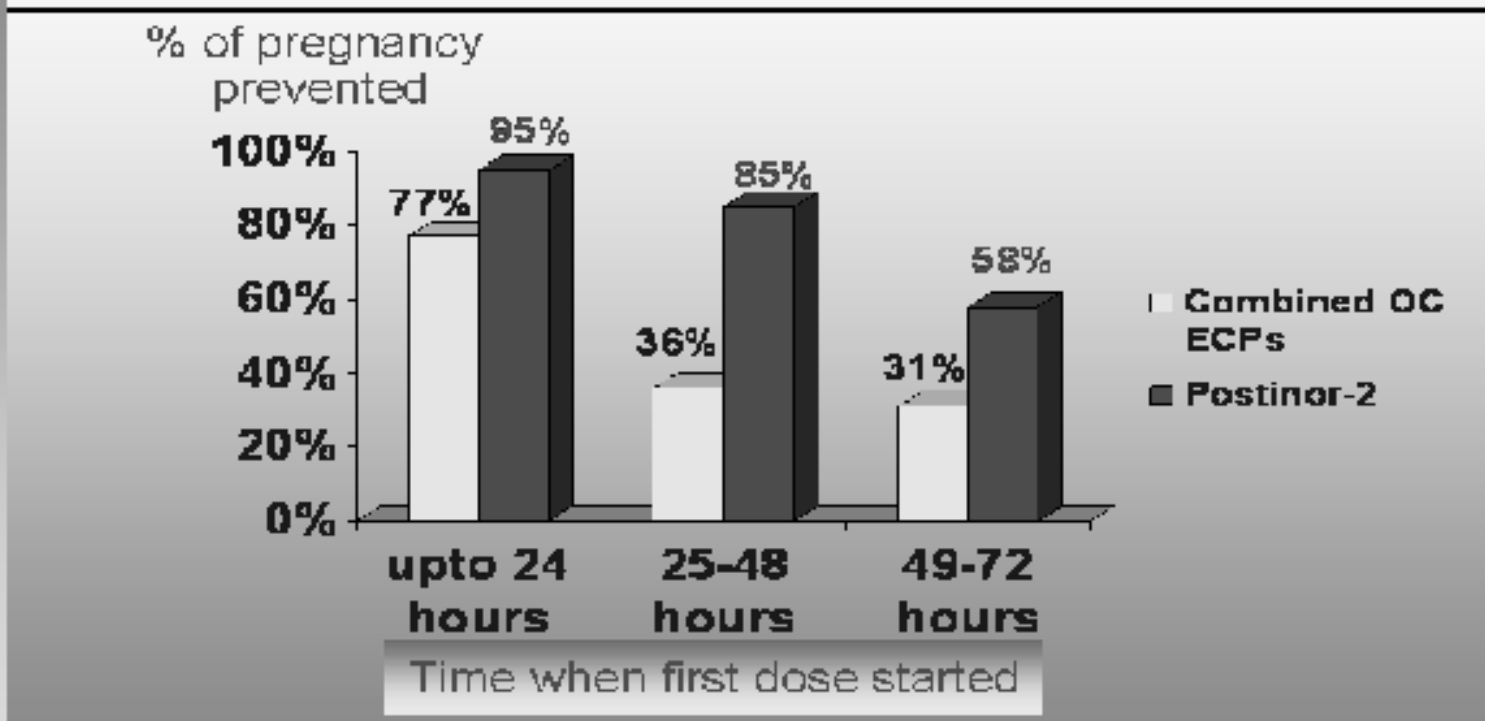

\section{Possible Side-Effects}

Common Side-effects:

Nausea

Vomiting

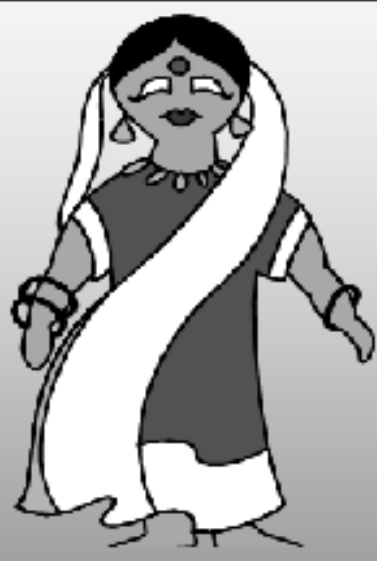

Headache

Dizziness

Fatigue

Breast

tenderness

Menstrual

disturbance

\section{Generally, less than $20 \%$ women suffer from any} side-effect and none last more than 24 hours 


\section{What FP Methods Could be Started After the Use of ECP?}

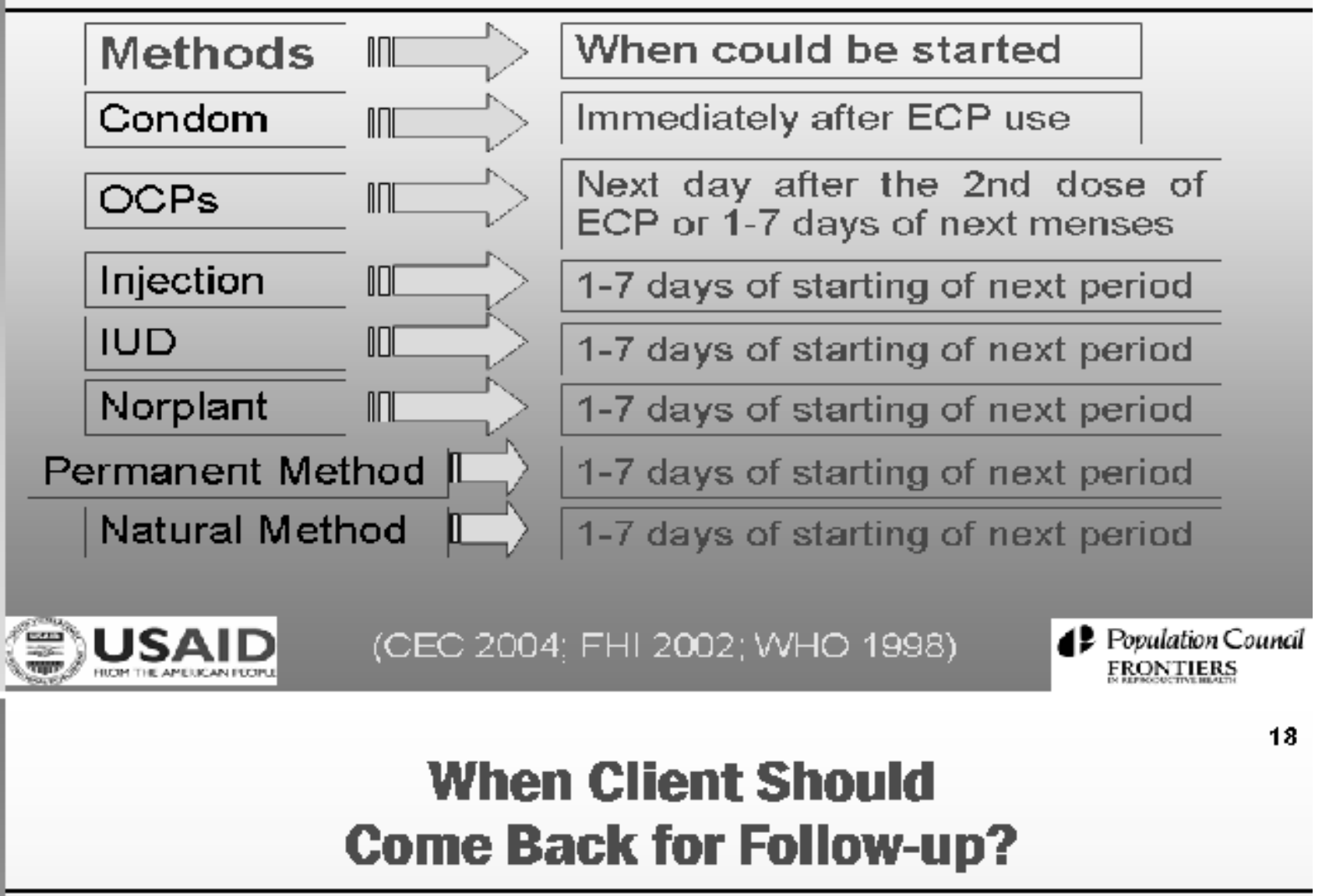

There is no need for routine follow-up in case of ECP use. However, client should come back to the clinic or service provider if:

- period is late for more than 7 days than expected

- menstrual bleeding is too light in terms of color

- wants to use regular FP method

- wants to talk more about ECP or need more counseling 


\section{Vomiting After the First Dose of ECP: What Should be Done?}

If there is vomiting within 2 hours of the first dose of ECP, the dose should be repeated. Moreover, the client should take an anti-emetic before the second dose. If there is severe vomiting, the second dose may be administered vaginally.

\section{Frequently Asked Questions about ECP}

- What will be the impact of ECP on menses?

- Would it be effective for the next days of the cycle?

- How many times can one take ECP in a month?

- Will ECP cause abortion?

- Can breastfeeding mother take ECP?

- Do women need to use ECP during safe period?

- Can women use the ECP before the intercourse?

- Does ECP work against multiple intercourse?

- Will failure of ECP cause harm to the fetus? 


\section{Sum-up: ECPs}

- Safe and effective back-up method

- Any women of reproductive age can use it

- Most effective when used as soon as possible after an unprotected intercourse

- Postinor-2 has less side-effects and more effective than combined pill ECPs

Better access to ECP can improve the life of women and their families

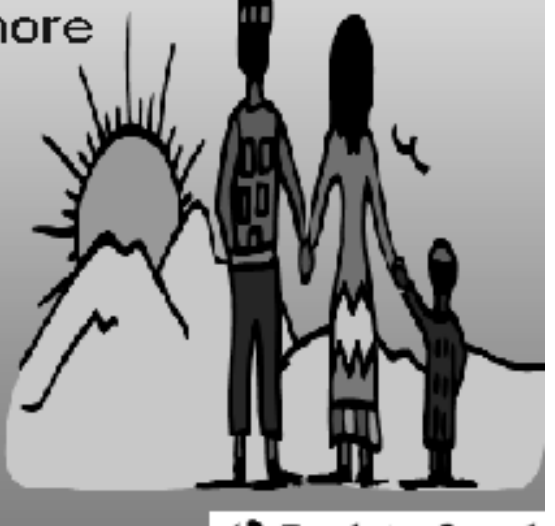

Population Council FRONTIERS 





\section{E mer gency Contraception and Emer gency Contraceptive Pills}

\section{Objectives}

By the end of Session 3, participants would know:

- Who can provide services for emergency contraceptive pills

- Who is eligible for services related to emergency contraceptive pills

- What services should providers offer

- How services should be provided to clients who have requested for emergency contraceptive pills

- Guidelines for providing emergency contraceptive pills to clients who have experienced method failure

- What should be done in case emergency contraceptive pills fail and the client becomes pregnant

\section{Methods/presenting session}

The following methods should be used:

a. An overhead projector for the transparencies

b. An informal discussion and question-answer session should follow where participants can clarify their doubts

Time needed for Session 3

Presentation: 30 minutes

Discussion and question-answer: 30 minutes 



\section{E mer gency Contraception and Emer gency Contraceptive Pills}

\section{Who Can Provide Services for Emergency Contraceptive Pills?}

Emergency contraceptive pills can be provided safely and effectively by a variety of trained personnel as well as by clinical and non-clinical service delivery systems. Doctors, nurses, midwives, pharmacists, paramedics, Family Welfare Assistants, Heath Assistants, Depot holders and other clinically trained personnel as well as community health workers can effectively provide such services.

To ensure that emergency contraceptive pills are correctly dispensed, all providers should be appropriately trained and should follow clear service delivery guidelines. Training must include information on indications for emergency contraceptive pills, as well as the regimen, mode of action, efficacy and failure, side-effects and their management, screening of women who have requested for emergency contraceptive pills, counseling and follow-up procedures. In addition, since emergency contraceptive pills are a back-up support, training should also include information on other contraceptive methods, if necessary. Refresher training on other methods would help participants understand in which contexts emergency contraceptive pills are appropriate and how to encourage clients to go back to their regular method.

\section{To Whom Should Services for Emergency Contraceptive Pills be Provided?}

Three types of clients need to be informed and educated on emergency contraceptive pills:

- Potential contraception users (those who are not yet using any method of contraception)

- Regular family planning clients, particularly those using barrier methods (condoms), oral contraceptive pills, DMPA injections or traditional methods such as withdrawal and safe period

- Clients who have requested for emergency contraceptive pills.

\section{What Services Should Providers Offer?}

Service providers should:

- Routinely inform women and their husbands about the availability of emergency contraceptive pills during regular family planning consultations

- Distribute material on emergency contraceptive pills to create awareness among potential clients

- Try and provide women with a supply of emergency contraceptive pills in advance. 
Whenever possible, clients requesting for short-term contraceptive methods (such as barrier methods, oral contraceptive pills, DMPA injections or traditional methods) should be given information and services for emergency contraceptive pills. Clients requesting for long-term and permanent methods should not be provided with such information and services. Clients who are interested in learning about other methods of contraception when they visit for emergency contraceptive pills should also be provided information and supplies.

\section{How Should Services be Provided to Clients Who Have Requested for ECP?}

Following awareness raising, women and men may seek services for emergency contraceptive pills. Service providers should address requests for emergency contraceptive services from both men and women. Service providers should remember that sexual assault is an important indication for emergency contraceptive pills. In such cases, the victim needs counseling, and legal and long-term emotional support. These women also need to be screened and treated for STIs/AIDS. These services should be provided according to the laws of the country. Service providers must follow the following guidelines when dealing with clients who have requested for emergency contraceptive pills.

\section{a) Ask and assess}

- Date of last menstrual period (LMP) (because she may be already pregnant)

- Length of the woman's normal menstrual cycle (to assess whether it is normal)

- The time of all unprotected or inadequately protected episodes of sexual intercourse in the current menstrual period (women may have several episodes of unprotected intercourse in a given menstrual cycle)

- The number of hours since the first episode of unprotected intercourse in that cycle (to know whether within 120 hours time limit or not).

When a client asks for emergency contraceptive services, the first step is to assess whether emergency contraceptive pills are appropriate for her. In some cases, the client may be seeking treatment too late or may already be pregnant.

- If intercourse has occurred within the previous 120 hours (5 days) and the client is not breastfeeding, then either combined emergency contraceptive pills or progestin pills can be prescribed and provided

- If the client is breastfeeding, then progestin pills are more appropriate as they do not affect the quantity or the quality of breast milk. However, there is no evidence that combined emergency contraceptive pills decrease the quantity and quality of breast milk as the length of exposure of hormone is very short

- If the recommended time limit of 120 hours for using emergency contraceptive pills has been crossed then she should be referred to an appropriate health center

- If the woman has crossed the 120 -hour time limit or if there is a possibility that she may be pregnant, she should be asked to wait until the next menses starts. A 
pregnancy test can be conducted to confirm her pregnancy status. Other health assessments such as a pelvic exam are not recommended. Sample screening questions are presented below.

\section{Sample screening questions}

1. Have you had unprotected intercourse during the last five days?

Yes $\square \quad$ No $\square$

Date (s):

Time (s): a.m. p.m.

2. Which was the first day of your last menstrual period?

Date:

Is this less than 4 weeks ago? $\quad$ Yes $\square \quad$ No $\square$

3. Was this period normal in terms of both length and duration?

Yes

No

If the response to all three questions is YES, emergency contraceptive pills can be prescribed. If the response to any of these questions is NO, or the provider feels that the client's sexual history is inaccurate, the client should have a pregnancy test. If the pregnancy test is negative, emergency contraceptive pills may be prescribed. However, the client should be informed that it may be too early to detect pregnancy and, if the woman is already pregnant, emergency contraceptive pills will neither prevent the pregnancy nor harm the fetus.

\section{b) Inform and explain}

Clients should be informed about various aspects of emergency contraceptive pills, such as the correct dosage, how they work to prevent a pregnancy, their failure rate, how effective they are, why they should be taken as soon as possible after unprotected intercourse, possible side-effects and their management. Clients should also be informed that the next period may be early or delayed by a few days but it must be within one week of the expected date.

\section{c) Remind the client}

Clients should be reminded about the side-effects of emergency contraceptive pills and how to manage them. They should also be told when to come back for a follow-up visit, if required. Generally, follow-up visits for emergency contraceptive pills are not necessary but a client should return to the clinic if her period is delayed by more than a week or if she has had very light (in terms of color) menstruation. Very light menstruation may be a sign of ectopic pregnancy, especially if it is accompanied by severe lower abdominal pain and fainting. However, there is no evidence that emergency contraceptive pills increase the chance of an ectopic pregnancy. 


\section{d) Use missed opportunity}

When a client asks for emergency contraceptive pills, the service provider should take the opportunity to inform her about regular methods of contraception as well. If the client is seeking treatment after method failure, she should be told how to use the method correctly and consistently. If the client has not used any contraceptive method, she should be informed about the available methods for contraception and the advantages of regular contraception. If the client visits for other family planning services, the provider should use the opportunity to talk about emergency contraceptive pills. It is not suggested that emergency contraceptive treatment is discussed with women who are seeking long-term or permanent contraceptive methods.

\section{e) Initiating or resuming regular contraception (encourage the client to resume regular contraception)}

It is crucial that clients do not rely entirely on emergency contraceptive pills for regular contraception. Clients must be encouraged to continue using regular and permanent methods so that the country's total fertility rate decreases. Service providers must try and encourage users of emergency contraceptive pills to return to a regular contraceptive method (informed) or to the method that was being used earlier, whichever is preferred.

\begin{tabular}{|c|c|}
\hline Figure 3: Contraceptive Options after Emergency Contraceptive Treatment \\
\hline Condom Users
\end{tabular}


A client can choose a method from a number of regular contraceptive options after using emergency contraceptive pills.

- Condoms or oral contraceptive pills, which can be used immediately after the second dose of emergency contraceptive pills is taken

- Injectables, IUDs, Implants (Norplant), sterilization or natural/traditional methods, which should be started after assessing the next menstruation. Some providers suggest that oral contraceptive pills should also be started after assessing the next menstruation.

Options for regular contraception after the use of emergency contraceptive pills and when and how to start them are presented in Figure 3

\section{What Should be Done in Case of Regular Contraceptive Method Failure?}

\section{If a client misses an oral contraceptive pill for three consecutive days:}

The National Family Planning Program has set guidelines on what should be done if 1,2 , or 3 oral contraceptive pills are missed consecutively. Only low-dose pills are available in the Bangladesh, India, and Nepal through the National Family Planning program. The social marketing companies are also marketing low-dose oral contraceptive pills. The current national guidelines should be followed for missing 1 and 2 pills. The national guidelines have recommended that in case three consecutive pills are not taken:

- The pills should be discontinued and discarded as the contraceptive effect of the pills would be lost. Moreover, many women may have withdrawal bleeding and

- The client should use condom during the rest of the cycle, if needed and

- The client should start a new pill packet from the first day of the beginning of the next cycle.

\section{The revised guidelines are:}

Some women who have missed three consecutive pills may start withdrawal bleeding. These women should follow the earlier guidelines. Women who have not started withdrawal bleeding are potential clients for emergency contraceptive pills. They have several options:

\section{Those who have had intercourse should:}

- Take two doses of emergency contraceptive pills and

- After taking both doses, they should continue to take the rest of the oral contraceptive pills, one tablet daily till the next menstrual cycle starts (this will help the woman maintain the length of her menstrual cycle) and

- Use a condom for any further intercourse as the contraceptive effect of the pills is lost once two or more pills of low-dose pills have been missed consecutively and

- Start a new packet of oral contraceptive pills on the first day of the next cycle. 


\section{Those who have not had intercourse should:}

- Stop using oral contraceptive pills and

- Use condoms (if any intercourse happens) till the next menstrual period begins and

- Start a new packet of oral contraceptive pills on the first day of the next cycle.

(Note: Those women who were using progesterone-only pills should be advised to take the pills continuously at the same time each day. If one or more pills are missed, she can take ECP. She should also continue to take oral contraceptive pills as usual and must use condom for subsequent intercourses).

\section{If the condom burst or leaked during intercourse}

\section{The client should:}

- Take two doses of emergency contraceptive pills and

- After taking two doses, use condoms consistently and correctly till the beginning of the next menstrual period and

- Start using a condom again from the beginning of the next menstrual cycle (if the client wants to rely on condoms) or

- Start a new packet of oral contraceptive pills after the second dose of emergency contraceptive pills or to other methods according to national guidelines (if the client wants to shift).

\section{If the client misses the due date of a contraceptive injection}

A contraceptive injection can be taken 14 days prior to or after the recommended date. If a woman crosses this 14-day period and seeks treatment within 120 hours of intercourse, she should be treated with emergency contraceptive pills. If she has not had intercourse she can be given a contraceptive injection.

Women who have missed the recommended date for the injection and seek treatment after having intercourse should:

- Take two doses of emergency contraceptive pills and

- After taking both doses, use condoms till the next menstrual cycle begins and

- Take an injection on the first day of the next menstrual cycle.

Some women who are taking contraceptive injections do not experience menstrual bleeding for many months. Service providers are often unsure about what should be done in case a woman has missed the due date for an injection and seeks treatment after intercourse. In such situations, it is advisable that after treatment with emergency contraceptive pills and before a subsequent injection is administered, the service provider should confirm that the client is not pregnant. A simple urine test can be performed to test for pregnancy. 


\section{What Should be Done if Emergency Contraceptive Pills Fail and the Client Becomes Pregnant?}

It is estimated that about 15-25 percent of the women who use emergency contraceptive pills may become pregnant even though they use the pills correctly. The possibility of "failure" must be mentioned when emergency contraceptive pills are dispensed otherwise the service provider may be blamed if the pills are ineffective. This may have an adverse impact on the ongoing National Family Planning Program.

If the client has used emergency contraceptive pills and has not menstruated for a week or more after the expected date, she may be pregnant. A pregnancy test should be conducted to confirm the pregnancy. If the client is pregnant, she should be told about the available options, and asked to choose the most appropriate option for her situation. If the client would like to continue with the pregnancy, she should be reassured that emergency contraceptive pills do not harm the fetus. 



\section{ECP Service Delivery Guidelines}

\section{Session Objectives}

After the session the participants will have knowledge and able to understand:

- Who should be provided with ECP services

- How the clients are informed and provided ECP services

- Counsel clients what, when and how to return to regular FP methods

- Guidelines in providing ECP particularly in case of method failure cases

- Guideline in managing side-effects

- What could be done in case of ECP failure 


\section{Who Should be Provided with ECP Service?}

Three types of clients:

- Potential contraception users

- Regular FP clients particularly those who are using OCP, DMPA injection, barrier method and traditional method

- Any client requesting for ECP service

\section{How Will Clients be Informed and Provided ECP Service?}

\section{New and Regular clients:}

- Routinely inform all clients about ECP

- Distribute BCC materials

- Explain and remove any misconception about ECP 
Cont.

\section{How Will Clients be Informed and Provided ECP Services?}

\section{Clients Who have Requested:}

a) Ask and assess

- Date of last menstrual period

- Length of woman's normal menstrual cycle

- Number of hours since the first unprotected intercourse

b) Inform and explain ECP use

c) Remind client about salient points on ECP

d) Utilize missed opportunity for counseling other methods

e) Counsel clients on how to resume regular contraception after use of ECP

\section{What FP Methods Could be Started After the Use of ECP?}

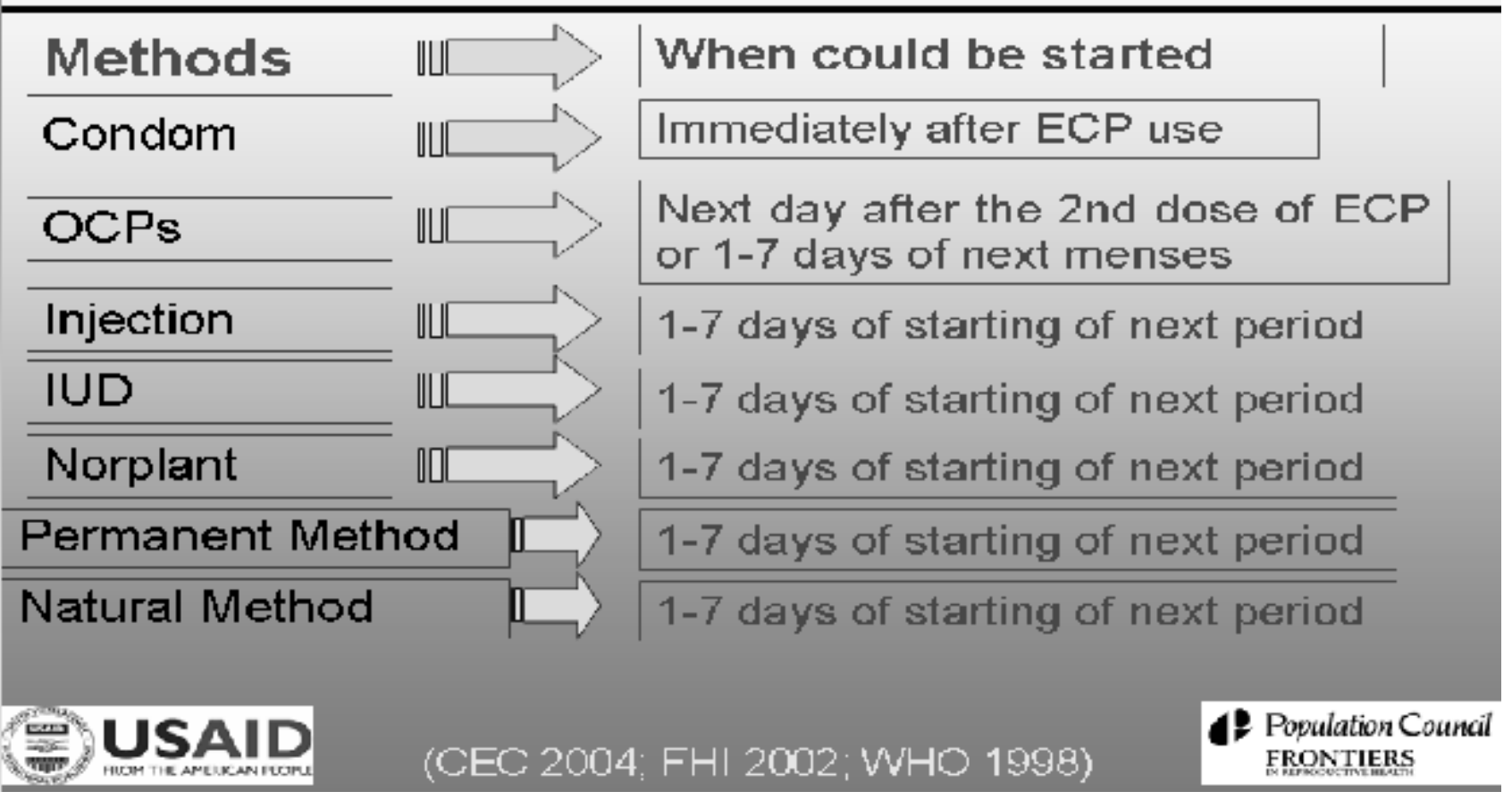




\section{Forgot to Take 0CP for 3 Consecutive Days: What Should be Done}

- Those who have started menstrual bleeding should be advised to continue the national guidelines as follows:

- stop taking OCP and discard rest of the pills and

. start a new packet of OCP at the $1^{\text {st }}$ day of the next menses

- Those who have not started menses and had intercourse they should be advised to:

- take two doses of ECP 12 hours apart and

continue to take rest of the OCPs-one tablets daily and

. use condom for any further intercourse and

- start a new packet of OCP at the first day of the next menstrual cycle

\section{Missed Injection Due Date: What Should be Done}

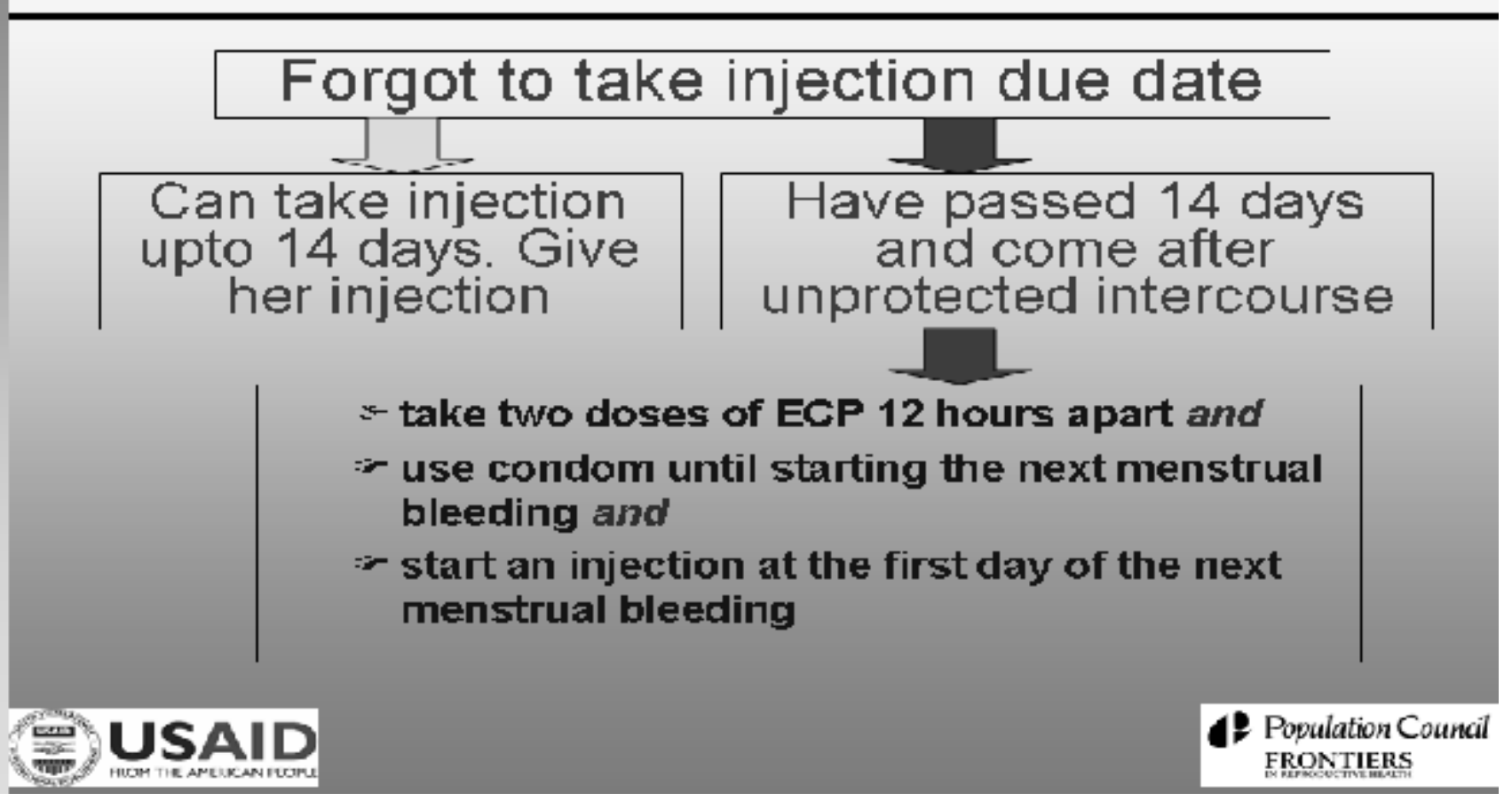




\section{Condom Burst or Leaking: What Should be Done}

The client should be advised that:

- take two doses of ECP 12 hours apart and

use condom again till beginning of the next menstrual bleeding and

- start condom again from the beginning of the next menstruation if wants or

If the client wants to change the method

a start a new packet of OCP after the second dose of ECP if want to shift or

- start any other method on the 1st day of the next menstruation such as injection

\section{Management of Side-Effects}

- Nausea may reduce if ECP is taken just after food

- Some women (30\%) may be benefited by taking anti-emetic tablet before taking ECPs. Anti-emetic has to be taken $1 / 2$ half to 1 hour before taking ECP. Most effective anti-emetic is meclizine hydrochloride (Antivert $50 \mathrm{mg}$ tablet once daily/Acliz $50 \mathrm{mg}$ ). Other anti-emetics also work

- Paracetamol/aspirin is effective against headache and breast tenderness. Even ibuprofen can be used

- No treatment is necessary for menstrual problems 


\section{Vomiting After the First Dose of ECP: What Should be Done?}

Has taken ECF $\square$ within 2 hours $\square \begin{aligned} & \text { What } \\ & \text { should be } \\ & \text { done? }\end{aligned}$

If there is vomiting within 2 hours of the first dose of ECP, the dose should be repeated. Moreover, the client should take an anti-emetic before the second dose.

These practices should be performed only by the service provider at the clinic level and not by the worker.

\section{What Could be Done in Case of ECP Fallure?}

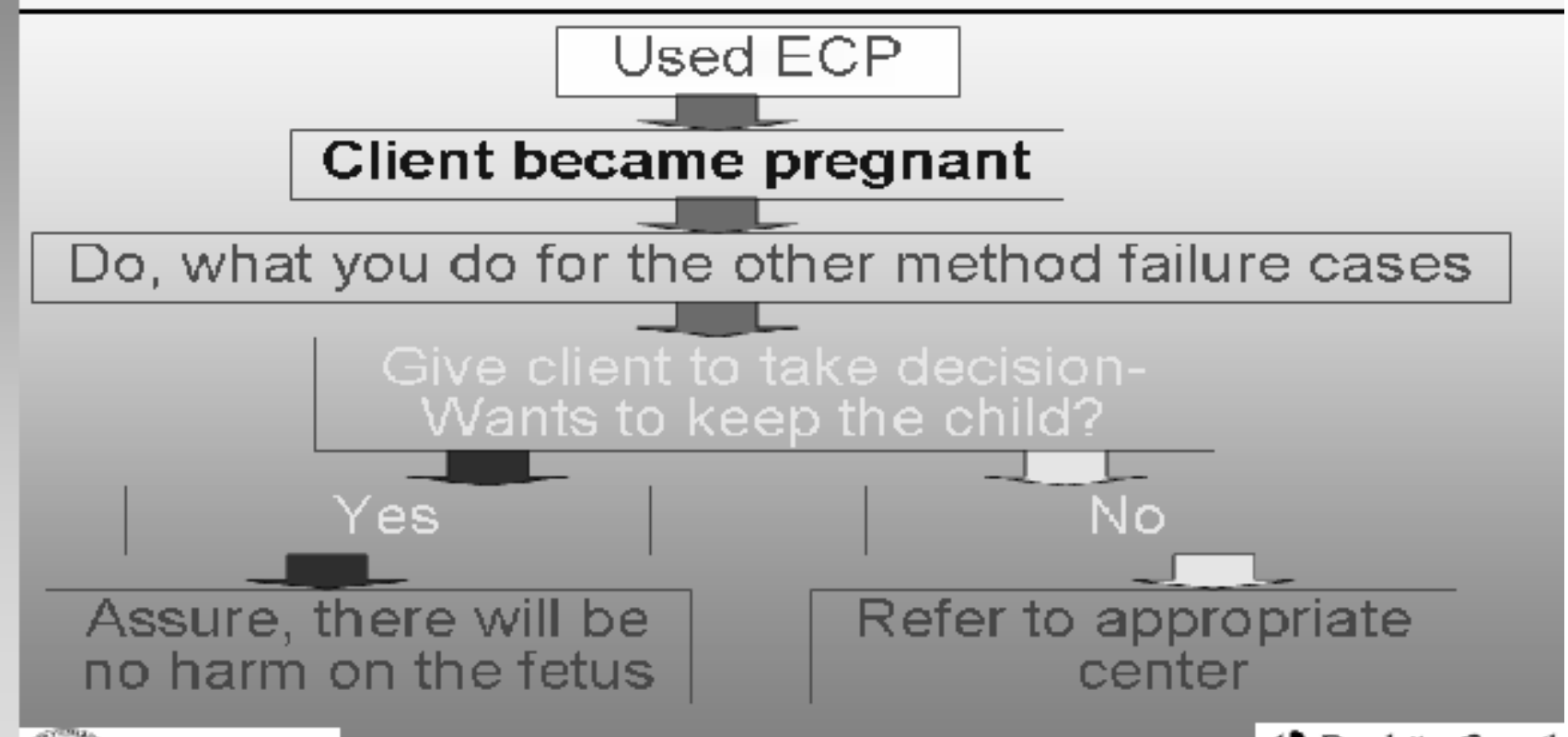






\section{Counseling on E mer gency Contraceptive Pills}

\section{Objectives}

By the end of Session 4, participants will know:

- What and how to counsel on emergency contraceptive pills

- The answers to frequently asked questions on emergency contraceptive pills.

\section{Methods/presenting the session}

The following methods should be used:

a. Presentation of the transparencies with an overhead projector

b. An informal discussion and question-answer session

Time needed for Session 4

Presentation: 30 minutes

Discussion and question-answer: 30 minutes 



\section{Counseling on E mer gency Contraceptive Pills}

\section{Whom to Counsel and About What?}

Counseling is an integral and essential part of family planning service delivery. Family planning counseling is a face-to-face communication in which one person helps another to make decisions and act upon them by providing relevant information. Any family planning provider, at any level and at any time, can help a client to make these decisions.

Counseling on emergency contraceptive pills is no different from counseling on other family planning methods. As it is a relatively new back-up method, and most clients do not know much about it, it is important that potential clients are properly informed.

All clients do not need counseling on every method at the time of a contraceptive consultation. Information must be tailored to suit the client's needs. As emergency contraceptive pills are a relatively new back-up support, it is essential that clients are provided information and services (i.e., the supply of pills) on this method during counseling on other contraceptive methods. Clients who are interested in learning about other methods when they visit for counseling on emergency contraceptive pills should be given information on these methods as well.

Three types of clients need to be educated on emergency contraceptive pills:

- Potential contraceptive users (those who are not yet using any method of family planning)

- Regular family planning clients, particularly those who use barrier methods, oral contraceptive pills, DMPA injections and traditional methods

- Clients who ask for emergency contraceptive pills.

\section{Potential Contraceptive Users}

It is essential that all potential clients for contraception are informed about the benefits of family planning and provided option for contraceptive methods. While talking about all other contraceptive methods, there is a great opportunity for providers to inform clients about emergency contraceptive pills. Non-users of family planning methods should be informed about:

- The methods available for contraception

- Details about the family planning methods

- The scope of emergency contraceptive pills as a back-up support 


\section{Regular Family Planning Clients}

Users of barrier methods, DMPA injections and traditional methods must be told:

- How to use barrier methods, DMPA injections and traditional methods correctly

- When and how to use emergency contraceptive pills

- What the side-effects of emergency contraceptive pills are and how these should be managed

- What contraceptive options are available after using emergency contraceptive pills

- What should be done if a woman misses her expected menses more than 7 days after having used emergency contraceptive pills

Users of oral contraceptive pills must be told in particular:

- What to do if they miss three consecutive pills

- When and how emergency contraceptive pills should be used

- What should be done with the rest of the pills in the packet

- Why condoms should be used for any further intercourse

- What should be done if the menstrual cycle is delayed by more than 7 days and

- How to come back to using oral contraceptive pills regularly once the next menstrual cycle starts.

\section{Clients Who Have Asked for Emergency Contraceptive Pills}

Counseling clients who have requested for emergency contraceptive pills after unprotected intercourse is simple. Five steps should be followed:

1. Ask and assess (screening questions)

2. Inform

3. Explain

4. Remind

5. Return

Ask screening questions to assess whether the woman is in the 72 hours time frame. If the client visits within the 72 hours time period, she should be informed about the correct use of emergency contraceptive pills, how emergency contraceptive pills work, efficacy and failure, and when emergency contraceptive pills are most effective. Clients should be told NOT to take any extra pill(s) as this will NOT make them work better, and may result in more sideeffects. Many clients mistakenly believe that emergency contraceptive pills result in immediate menstruation. Clients should be told that emergency contraceptive pills do not result in immediate menses but will come at the expected time or few days earlier or later.

The next step is to remind the client about the side-effects of emergency contraceptive pills and how these should be managed. If the client is counseled before she takes the pills, she will find it easier to cope with the side-effects. Moreover, the client needs to be told that emergency 
contraceptive pills are not 100 percent effective and can result in failure. The client should be reminded that emergency contraceptive pills should be used only in emergencies and not as a regular method of contraception as they are not as effective as regular contraceptives. Moreover, emergency contraceptive pills have a higher failure rate and more side-effects than regular contraceptives.

Although users of emergency contraceptive pills do not require routine follow-up, clients should be asked to come back to the clinic if their menses is delayed by more than a week, or if the menses is too light in terms of color. Clients who would like to discuss emergency contraceptive pills in detail, or would like to talk about future contraception, or has any other concern, should also be asked to come back.

It is crucial that the client should not rely totally on emergency contraceptive pills for her contraceptive needs. Service providers should try and encourage the client to return to a regular method or to her previous method rather than continue to use emergency contraceptive pills. There are many regular contraceptive options that a client can use after emergency contraceptive treatment, which have been listed in the service delivery guidelines. 


\section{Frequently Asked $Q$ uestions about E mergency Contraceptive Pills and Women's Concerns}

\section{Are emergency contraceptive pills safe?}

YES, emergency contraceptive pills can be given even to women who cannot use oral contraceptive pills regularly, such as those with a history of hypertension or severe migraine. This is because emergency contraceptive pills are taken for a short span of time and, consequently, will have fewer side-effects than oral contraceptive pills. It will not have sideeffects that may have developed due to use of oral contraceptive for long periods.

\section{How will emergency contraceptive pills affect a woman's menses?}

Emergency contraceptive pills have no significant impact on a woman's menses. Only 10-15 percent of the women who use emergency contraceptive pills will have menstrual problems. A woman's menses will be at about the expected time, or at most a week early or late (usually 2-3 days). In a few cases, menstrual flow might be heavier, lighter or more spotty than usual.

Will emergency contraceptive pills protect a woman from future unprotected intercourse?

NO. Emergency contraceptive pills do not protect a woman from any future unprotected intercourse.

Will emergency contraceptive pills harm an existing pregnancy or a pregnancy caused by the failure of emergency contraceptive pills?

NO. Available studies show that emergency contraceptive pills do not have an adverse effect on pregnancy.

Can emergency contraceptive pills be taken if there is problem in the leg (such as varicose veins)?

YES. As the dose of hormones in emergency contraceptive pills is relatively low, the short exposure to estrogen and/or progestin does not appear to alter blood-clotting mechanisms, as in the case of combined oral contraceptives, which are used over a longer period.

\section{How many times can one take emergency contraceptive pills in a month?}

Emergency contraceptive pills are not intended for repeated use. These pills should be used only as an emergency method for back-up support. Women who have sex only three or four 
times in a month should not use emergency contraceptive pills as a regular family planning method. However, given that there is little likelihood that limited repeated use will cause harm, emergency contraceptive pills should not be denied only because a woman has used them before, even within the same menstrual period. All women who use emergency contraceptive pills, particularly those who use them repeatedly, should be informed that emergency contraceptive pills are less effective and have more side-effects than regular contraceptives. They should also be briefed on how to avoid contraceptive failure in future.

How soon after emergency contraception should a regular contraceptive be started?

Regular contraceptive methods (such as condoms and pills) can be resumed immediately after emergency contraceptive treatment. Alternatively, clients could switch over to condoms till the start of the next menstrual cycle. Other regular contraceptives such as IUD, Norplant, among others, can be started within 7 days of the next menstrual period.

What should be done if menses is delayed by more than 7 days after using emergency contraceptive pills?

The woman should undergo a pregnancy test.

\section{Do emergency contraceptive pills increase the risk of an ectopic pregnancy?}

NO. Emergency contraceptive pills neither prevent nor increase the chance of an ectopic pregnancy (a pregnancy that develops outside the uterus but inside the fallopian tube/abdomen).

\section{Is emergency contraception the same as abortion?}

NO. Emergency contraception and abortion are entirely different. Emergency contraceptives only prevent pregnancy from unprotected sex by preventing or delaying ovulation. In an abortion, a fertilized fetus is removed.

\section{Are emergency contraceptive pills and RU-486 same?}

NO. Emergency contraceptive pills are used to prevent pregnancy. Mifepristone or RU-486 is abortive and is used to abort an established early pregnancy. However, RU-486 can also be used as emergency contraceptive.

What are the types and brands of pills one can use as an emergency contraceptive pills? 
The types of pills that can be used as an emergency contraceptive are given in Table 6 in Section 2. See Table for answers specific to your country.

Should combined emergency contraceptive pills be given to a woman who does not take regular oral contraceptive pills for any of the following reasons:

\begin{tabular}{|l|c|}
\hline Conditions & Can be given emergency contraceptive pills \\
\hline Smoker and over 35 years & Yes \\
\hline Diabetic with vascular disease & Yes \\
\hline History of severe migraine (headache) & Yes \\
\hline History of venous thromboembolism & Yes \\
\hline Benign/malignant tumor & Yes \\
\hline
\end{tabular}

If a woman vomits within two hours of taking a dose of emergency contraceptive pills, what should she do?

She should repeat the first dose of emergency contraceptive pills. An anti-emetic can be taken one hour before the second dose to reduce nausea.

\section{Do women need to use emergency contraceptive pills during the "infertile period"?}

Studies have shown that intercourse can result in fertilization only during a five to seven day period around the time of ovulation (Wilcox et al. 1995). Theoretically, emergency contraceptive pills are not needed if unprotected intercourse occurs at other times of the cycle because the possibility of becoming pregnant even without emergency contraceptive pills would be negligible. However, in practice, and for the family planning program, it is often difficult to determine with certainty whether a specific act of intercourse occurred on a fertile or infertile day of the cycle. This is particularly true for illiterate women. Therefore, emergency contraceptive pills should be provided if unprotected intercourse has taken place on any day of the cycle (within 72 hours) and the client feels that she is at risk of becoming pregnant. In situations where unprotected intercourse is unlikely to result in pregnancy, the client's anxiety level, the availability of the program and the resources of the client should be taken into account when taking a decision.

\section{Can women use emergency contraceptive pills before intercourse?}

NO. Clients should be discouraged from using emergency contraceptive pills before intercourse. No data are available on how long the contraceptive effect of emergency contraceptive pills persists after the pills have been taken. Presumably emergency contraceptive pills taken immediately before intercourse are as effective as pills taken immediately afterwards. However, if a woman has the opportunity to plan to use a contraceptive method before intercourse, a regular method other than emergency contraceptive pills, such as condoms, is recommended. 
Can emergency contraceptive pills be used after more than one unprotected act of intercourse within 72 hours?

Emergency contraceptive pills should not be withheld if the client has had more than one unprotected act of intercourse within 72 hours, unless she is known to be already pregnant. However, clients should be informed that, as the interval between the earliest unprotected sexual act(s) and the use of emergency contraceptive pills lengthen the efficacy of emergency contraceptive pills will be lower. Clients should be encouraged to use emergency contraceptive pills as soon as possible after unprotected intercourse rather than wait until they have had a series of episodes of unprotected intercourse. Only one regimen for emergency contraceptive pills should be given at a time, regardless of the number of prior episodes of unprotected intercourse.

\section{Can emergency contraceptive pills be used more than $\mathbf{7 2}$ hours after unprotected intercourse(s)?}

Studies show that the efficacy of treatment declines with time, so that there is declining effectiveness as the 72 hours progress. However, experts suggest that emergency contraceptive pills probably retain some limited efficacy even after that period (Ellertson et al. 2000; Piaggio et al. 1999). Since emergency contraceptive pills pose no danger either to the woman or to the embryo, it is reasonable to provide women emergency contraceptive pills even after 72 hours even if emergency contraceptive pills fail. However, the client should be informed about the possibility of pregnancy, if the method fails or if she is already pregnant.

\section{Can emergency contraceptive pills be taken when a woman is breastfeeding?}

A woman who is less than six months postpartum, exclusively breastfeeding and who has not had a menstrual period since delivery is unlikely to be ovulate and, therefore, may not need emergency contraceptive pills. However, a woman who is providing supplementary feeding to her infant or who has had menses since delivery, even a single time, may be at risk of pregnancy. A single treatment with combined emergency contraceptive pills is unlikely to have a serious effect on the quantity and quality of milk she produces. Some hormones may get absorbed into the breast milk but they are unlikely to affect the infant adversely. The amount of hormone that goes into the infant's body is almost same as the infant would normally take from the mother's body through breast milk. However, for women who are breastfeeding, progestin-only emergency contraceptive pills are more suitable and they do not change the quantity and quality of breast milk.

Can emergency contraceptive pills be given while the status of pregnancy is unclear?

Emergency contraceptive pills may be given when a woman's pregnancy status is unclear and a pregnancy test is not available, as there is no evidence suggesting that emergency 
contraceptive pills harm the woman or an existing pregnancy. However, a client should be informed that she might already be pregnant and, in such cases, emergency contraceptive pills will not be effective.

If knowledge of emergency contraceptive pills become widespread, could incorrect use or overuse of these pills become a problem?

Misuse is not likely. Even in countries where emergency contraceptive pills are easily available, they have not been misused. The World Health Organization suggests that making emergency contraceptive pills readily available with accurate instructions through established family planning services, whether clinic, pharmacy or community-based, will help to reduce any risk of incorrect use or overuse and will ensure appropriate follow-up counseling and contraceptive services.

\section{Do emergency contraceptive pills interact with other drugs?}

There is no specific data available about the interaction of emergency contraceptive pills with other drugs that the client may be taking. However, it seems reasonable that drug interactions would be similar to those with regular oral contraceptive pills. Women taking drugs that may reduce the effectiveness of oral contraceptives including but not limited to Rifampicin and certain anticonvulsant drugs should be advised that the effectiveness of emergency contraceptive pills may be reduced. In this case, she may increase the amount of hormone in each dose. 


\section{Counseling on ECP and Its Loglstlc Management}

\section{Session Objectives}

After the session the participants will have knowledge and able to:

- Describe whom and what to be counseled about ECP

- Understand what, when and how to start regular contraception after the use of ECP (contraception options)

- Answer common questions related to ECP 


\section{Whom and What to be \\ Counseled about ECP?}

- Potential Contraception Users:

$;-$ - methods available for contraception

$\therefore$ - details about the FP methods

- scope of ECP as a back-up method

- Regular Family Planning Clients

(Barrier method, DMPA injection and traditional method users must be explained):

ir how to use these methods correctly

; when and how to use ECP

- Side-effects of ECP and their management

* methods of contraception after the use of ECP

f what to do when they miss cycle for more than 7 days

Contd....

\section{Whom and What to be Counseled about ECP?}

Special attention must be given to OCP users to check that:

in users are properly explained what to do if they miss three pills

1.s. When and how to use ECP

's what client should do with the rest of the pills in the packet

1. Why they need to use condom for any further intercourse

what to do when they miss cycle for more than 7 days

1.s. how to come back to regular use of OCP in the next menstrual cycle

's why ECP cannot be used as a regular method 
Contd....

\section{Whom and What to be Counseled about ECP?}

Client who has requested for ECP the following four steps could be followed:

- Before providing ECP, assess whether ECP is appropriate for the client then-

1) (correct use of ECP, how it works, can not use as regular purpose and efficacy and failure)

2) explein (when it is more effective)

3) remind (side-effects and their management and when she should come back for followup)

4) return (how to come back to the regular methods)

\section{When Client should Come Back for Follow up?}

There is no need for routine follow-up in case of ECP use. However, client should come back to the clinic or service provider if:

- period is late for more than 7 days than expected

- menstrual bleeding is too light in terms of color

- wants to use regular FP method

- wants to talk more about ECP or need more counseling 


\section{Frequently Asked Questions about ECP}

- How many times one can take ECP in a month?

- Will ECP cause abortion?

- Would it be effective for the next days of the cycle?

- Do women need to use ECP during safe period?

- Can women use ECP before intercourse?

- Does ECP work against multiple intercourse?

- If ECP failed to protect pregnancy, will it cause harm to the fetus?

- Can ECP be used after 72 hours of unprotected intercourse?

\section{Logistics Management of ECP: Supply, Recording and Reporting}

-The existing guidelines for logistic management (Storing, Supplying, Recording, Reporting and Money deposition, etc.) will be equally applicable for ECP

-All service providers/NGO should submit ECP information/report to the appropriate authority as done for other contraceptives 



\section{PRE- AND POST-TEST ASSESSMENTS TOOLS}

\section{Training of Master Trainers \\ On Emergency Contraceptive Pill (ECP) \\ 1 Pre-test Questionnaire}

Designation:

Specialty (if any):

1. Which of the following statements describe the purpose of emergency contraceptive pills (ECP) as a contraceptive method? (check one that apply)

$\square$ ECP is used before unprotected intercourse* to avoid unwanted pregnancy

$\square$ ECP is used after unprotected intercourse* to avoid unwanted pregnancy

2. When you will say unprotected intercourses that have happened require ECP? (check all that apply)

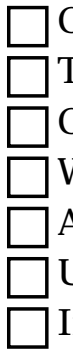

One combined oral contraceptive pills were missed in a given cycle

Three combined oral contraceptive pills were missed in a given cycle

$\square$ One progestin-only oral contraceptive pills were missed in a given cycle

$\square$ When missed injection due date (also extended 14 days) and had unprotected intercourse

A contraceptive method failed during use (e.g. the condom leak or slipped)

$\square$ Unprotected intercourse occurred as the result of rape

Intercourse without any method

3. What amount of hormone the combined oral contraceptive pill must contain (Yuzpe regimen) to be effective as emergency contraceptive pill: (check all that apply)

$\square$ At least $0.1 \mathrm{mg}$ of ethinyl estradiol and $0.5 \mathrm{mg}$ of levonorgestrel
$\square$ At least $0.2 \mathrm{mg}$ of ethinyl estradiol and $0.5 \mathrm{mg}$ of levonorgestrel
$\square$ At least 100 microgram of ethinyl estradiol and 500 microgram of levonorgestrel
$\square$ At least 200 microgram of ethinyl estradiol and 1000 microgram of levonorgestrel
$\square$ Do not know

4. What amount of hormone the progestin-only pill regimen must contain to be effective as emergency contraceptive pill: (check all that apply)

$\square$ At least $0.5 \mathrm{mg}$ of levonorgestrel

$\square$ At least $0.75 \mathrm{mg}$ of levonorgestrel

$\square$ Do not know

$\square$ At least $1.5 \mathrm{mg}$ of levonorgestrel

At least $1 \mathrm{mg}$ of levonorgestrel

5. In what way emergency contraceptive pills work: (check all that apply)

$\square$ It prevents ovulation
$\square$ It kills spermatozoa
$\square$ It delays ovulation
$\square$ It prevents implantation

$\square$ It prevents fertilization

$\square$ It aborts fertilized ovum

$\square$ It makes uterine cavity unsuitable for ovum

$\square$ Do not know

*Unprotected intercourse means intercourse without any contraceptive methods or methods used incorrectly or thought that method used may not work perfectly. 
6. ECP must be initiated within hours: (check one that apply)

$\square$ Within 24 hours after unprotected sex
$\square$ Within 48 hours after unprotected sex

$\square$ Within 72 hours after unprotected sex

$\square$ Within 120 hours after unprotected sex

7. How many doses ECP should be taken: (check one that apply)
$\square$ One
$\square$ Two
$\square$ Four
Do not know

8. What is the interval between doses of ECP (if used divided dose): (check one that apply)
$\square 6$ hours
$\square 24$ hours
48 hours
$\square$ Do not know

9. Below is a list of statements regarding emergency contraceptive pills. Please indicate whether each statement is true $(\mathrm{T})$ or false $(\mathrm{F})$ by circling the correct answer.

$\mathrm{T} \quad \mathrm{F} \quad$ ECP can be used at any time during the menstrual cycle

T F ECP is an abortifacient

T F ECP can be used as a regular method

T F ECP cannot be used by breast feeding mother

10. Emergency contraceptive pills have varying effectiveness in preventing unwanted pregnancy from 75 to 85 percent depending on the hormonal preparation used. Please indicate which are true.
$\square$ Combined pill ECP is $75 \%$ effective
$\square$ Progestin-only ECP is $75 \%$ effective
$\square$ Combined pill ECP is $85 \%$ effective
$\square$ Progestin-only ECP is $85 \%$ effective

11. Which ECP has less side-effects? (check one that apply)
$\square$ Progestin-only ECP
$\square$ Do not know
$\square$ Combined pills ECP

12. Which of the following side effects are associated with ECP: (check all that apply)

$\begin{array}{lll}\square \text { Breast tenderness } & \square \text { Headache } & \square \text { Weakness } \\ \square \text { Nausea and vomiting } & \square \text { Spotting } & \square \text { Heavy bleeding } \\ \square \text { Insomnia } & \square \text { Fatigue } & \square \text { Dizziness } \\ \square \text { Cramping and bleeding } & \square \text { Do not know } & \end{array}$

13. Most of these side-effects last for? (check one that apply)

$\square$ One day
$\square$ More than three days

$\square$ Two days
$\square$ Do not know

Three days 


\section{Training of Master Trainers \\ On Emergency Contraceptive Pill (ECP) \\ 2 Post-test Questionnaire}

Designation:

Specialty (if any):

1. Which of the following statements describe the purpose of emergency contraceptive pills (ECP) as a contraceptive method? (check one that apply)

$\square$ ECP is used before unprotected intercourse* to avoid unwanted pregnancy

$\square$ ECP is used after unprotected intercourse* to avoid unwanted pregnancy

2. When you will say unprotected intercourses that have happened require ECP? (check all that apply)

$\square$ One combined oral contraceptive pills were missed in a given cycle

$\square$ Three combined oral contraceptive pills were missed in a given cycle

$\square$ One progestin-only oral contraceptive pills were missed in a given cycle

$\square$ When missed injection due date (also extended 14 days) and had unprotected intercourse

$\square$ A contraceptive method failed during use (e.g. the condom leak or slipped)

$\square$ Unprotected intercourse occurred as the result of rape

$\square$ Intercourse without any method

3. What amount of hormone the combined oral contraceptive pill must contain (Yuzpe regimen) to be effective as emergency contraceptive pill: (check all that apply)

$\square$ At least $0.1 \mathrm{mg}$ of ethinyl estradiol and $0.5 \mathrm{mg}$ of levonorgestrel

$\square$ At least $0.2 \mathrm{mg}$ of ethinyl estradiol and $0.5 \mathrm{mg}$ of levonorgestrel

$\square$ At least 100 microgram of ethinyl estradiol and 500 microgram of levonorgestrel

$\square$ At least 200 microgram of ethinyl estradiol and 1000 microgram of levonorgestrel

$\square$ Do not know

4. What amount of hormone the progestin-only pill regimen must contain to be effective as emergency contraceptive pill: (check all that apply)

$\square$ At least $0.5 \mathrm{mg}$ of levonorgestrel

$\square$ At least $0.75 \mathrm{mg}$ of levonorgestrel

$\square$ Do not know

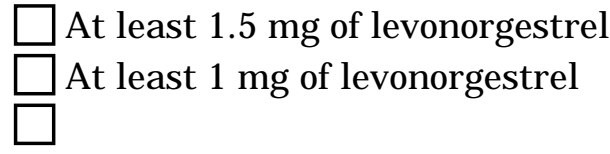

5. In what way emergency contraceptive pills work: (check all that apply)

$\square$ It prevents ovulation
$\square$ It kills spermatozoa
$\square$ It delays ovulation
$\square$ It prevents implantation

$\square$ It prevents fertilization
$\square$ It aborts fertilized ovum
$\square$ It makes uterine cavity unsuitable for ovum
$\square$ Do not know

6. ECP must be initiated within hours: (check one that apply)

$\square$ Within 24 hours after unprotected sex

$\square$ Within 48 hours after unprotected sex

$\square$ Within 72 hours after unprotected sex
$\square$ Within 120 hours after unprotected sex

*Unprotected intercourse means intercourse without any contraceptive methods or methods used incorrectly or thought that method used may not work perfectly. 
7. How many doses ECP should be taken: (check one that apply)
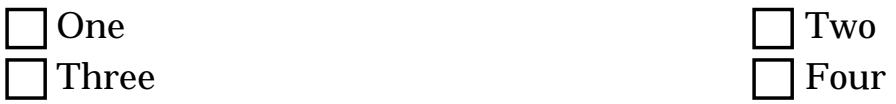

Do not know

8. What is the interval between doses of ECP (if used divided doses): (check one that apply)
$\square 6$ hours
$\square 12$ hours
$\square 24$ hours
Do not know

9. Below is a list of statements regarding emergency contraceptive pills. Please indicate whether each statement is true $(\mathrm{T})$ or false $(\mathrm{F})$ by circling the correct answer.

$\mathrm{T} \quad \mathrm{F}$ ECP can be used at any time during the menstrual cycle

T $\quad \mathrm{F} \quad$ ECP is an abortifacient

T F ECP can be used as regular a method

T F ECP cannot be used by breast feeding mother

10. Emergency contraceptive pills have varying effectiveness in preventing unwanted pregnancy from 75 to 85 percent depending on the hormonal preparation used. Please indicate which are true.
$\square$ Combined pill ECP is $75 \%$ effective
$\square$ Combined pill ECP is $85 \%$ effective
$\square$ Progestin-only ECP is $75 \%$ effective
Progestin-only ECP is $85 \%$ effective

11. Which ECP has less side effects? (check one that apply)
$\square$ Progestin-only ECP
$\square$ Do not know
Combined pills ECP

12. Which of the following side effects are associated with ECP: (check all that apply)

$\begin{array}{lll}\square \text { Breast tenderness } & \square \text { Headache } & \square \text { Weakness } \\ \square \text { Nausea and vomiting } & \square \text { Spotting } & \square \text { Heavy bleeding } \\ \square \text { Insomnia } & \square \text { Fatigue } & \square \text { Dizziness } \\ \square \text { Cramping and bleeding } & \square \text { Do not know } & \end{array}$

13. Most of these side effects last for? (check one that apply)

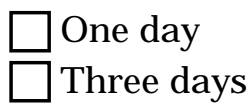

$\square$ Two days
$\square$ More than three days

$\square$ Do not know

We will appreciate if you could give your views and opinions on the clarity and understanding of the three sessions conducted during the course. Your frank comments will help in improving the quality of training. Please rank accordingly, 5 for excellent, 4 for very good, 3 for good, 2 for bad and 1 for extremely bad.

Understanding and clarity of the presentation?
a. ECP technical part
\begin{tabular}{lllllll}
5 & 4 & 3 & 2 & 1 \\
\hline
\end{tabular}
b. Service delivery guidelines
\begin{tabular}{|l|l|l|l|l|}
5 & 4 & 3 & 2 & 1 \\
\hline
\end{tabular}
c. Counseling on ECP
$\begin{array}{lllllll}5 & 4 & 3 & 2 & 1\end{array}$ 


\section{Any further comments:}

\section{Answer Key to the pre- and post-test questionnaire}

Below are the correct answers

Question 1: 2,

Question 2: 2, 3, 4, 5, 6, 7

Question 3: 1, 3

Question 4: 2, 3

Question 5: 1, 2, 5

Question 6: 4,

Question 7: 1, 2

Question 8: 3,

Question 9: 1=T, 2=F, 3=F, 4=F

Question 10: 1=T, 2-F, 3=F, 4=T

Question 11: 1

Question 12: 1, 2, 4, 5, 8, 9, 10

Question 13: 1 



\section{Developing Counseling Skills on E mer gency Contr aceptive Pills}

Role play has been found to be an useful tool for training, as it stimulates the participants and makes the training participatory. In this, one participant acts as 'provider' while another one as the "client" and the interaction between the "client" and "provider" is observed by rest of the trainees. The trainees are asked to note whether the "provider" gave the correct information and answers; counseling (client-provider interaction) was good or if anything was lacking, if yes, what?

After the role play the observations of the trainees are discussed with all trainees. At the end, the moderator/trainer summarizes his/her observations from the client-provider interaction.

Our experience during training showed that the providers like role plays, took active part and enjoyed the process both as a player or as an audience member to watch how the provider imparted information to its "client". The exercise helped in assimilating the relevant points on ECP.

\section{Role Play A}

Ms. "M" is 35 years old. She has four children- two daughters and two sons. Her husband is a businessman. He used to travel frequently for business purposes. Both husband and wife do not want any more children. He used to use condom. But, now a days, he does not get enough pleasure with condom. Both husband and wife have fear about sterilization. From the last 5-6 months, Ms. M is taking DMPA injection. There is no problem with the injection. This month she forgot to take the injection. Her husband came back home yesterday as well. She had sex last night. She is very worried about the sexual acts. In the morning, she goes to the Dr. Apa in her village. What did Dr. Apa do?

\section{INSTRUCTIONS:}

From the participants, one will be the client and one will be the Dr. Apa. The client will ask Dr. Apa for help or for injection. The doctor should respond to the clients need and counsel her. For staging the drama they will get 15 minutes. The other participants should observe and jot down the interaction between doctor and the client, what they missed and what should have been ideally done.

\section{Role Play B}

Ms. "S" is a mother of one child. The age of her child is only one year. She is 20 years old. She has a two year age difference with her husband. She works in a garment factory. Her husband also works at the same factory. She does not want any more children at this stage because she is already troubled with her present child. Every day she has to keep the child at her mother's 
house before going to the factory. She is using "SHUKHI" oral pill. She suffers from headache after having SHUKHI. Due to work pressure and tiredness, she frequently misses pills and she forgot to take pills for the last three days. Moreover, she had sex day before yesterday. She forgot what she was supposed to do in this case. She went to a FWV nearby. What did FWV suggest to her?

\section{INSTRUCTIONS:}

From the participants, one will be the client and one will be the Family Welfare Assistant (FWA). The client will ask the FWV for her suggestions in this situation. The FWV should counsel the client.For staging the drama they will get 15 minutes. The other participants should observe and jot down the interaction between the client \& FWV, what they missed and what should have been ideally done.

\section{Role Play C}

Mr. " $\mathrm{K}$ " is a bank officer. He has good understanding with his wife. They have two daughters. His wife always thinks of having a male child. But he feels that this is not the appropriate time to have another child. Maybe two years later. He uses condom as a contraceptive method. Three days back he experienced a condom burst. He has heard about ECP. While going to the office he met with health worker/community mobilizer who always came to Mr. K's house. Mr. K explained to him the situation and asked for ECP. What did the health worker/community mobilizer suggest?

\section{INSTRUCTIONS:}

From the participants, one will be Mr. $\mathrm{K}$ and one will be the health worker/community mobilizer. Mr. K will explain the situation and ask for suggestions. The health worker/community mobilizer will counsel the client. For staging the drama they will get 15 minutes. The other participants should observe and jot down the interaction between the health worker/community mobilizer and the client, what they missed and what should have been ideally done.

After the small groups have completed all three role plays, discuss the exercise in a plenary session. Discuss the content of each role pay separately following the outline below.

a) Ask someone who has played the part of the "provider" to describe the client's visit, including what information and/or services he/she provided to the client.

b) Ask others if they discovered any additional information about the client that led them to provide different treatment or services or advice. Discuss any difference or deficiencies in the treatment provided.

c) Using the Emergency Contraceptive Pills Counseling Checklist as a guide, ask participants if the "providers" they observed demonstrated any areas of particular strength or weakness. Ask participants to suggest ways "providers" could improve counseling and service delivery skills. 
Key points to discuss in the Role Play A:

- Husband is a frequent traveler. Husband wife do not want any more children (need long-term or permanent method). They already have four children.

- Husband does not get enough pleasure when using a condom

- They have fear of sterilization. She is using DMPA injection and she forgot to take it within the due date.

- She had sex last night.

- Is the client fit for ECPs (within 120 hours of unprotected intercourse, normal last menstrual period)?

- Is she ammenorrhic?

- Does the client know about ECP?

- Will she be given special counseling on condom use, as husband is a frequent traveler?

Key points to discuss in the Role Play B:

- She does not want any more children at this time. She is a working woman.

- She is a low-dose oral pills user.

- She misses pills frequently. Long-term method may be suitable for her.

- She also misses pills in the last three days.

- She forgets what to do in this case.

- She suffers from headache.

- ECP is not contraindicated in migraine.

- She had sex last night.

- Is the client fit for ECP?

Key points to discuss in the Role Play C:

- He has two daughters. Wife wants a male child but he does not want anther child now. Maybe a client for a long-term method.

- Wife does not want to use any method. He experienced condom burst three days back.

- Are they fit for ECP or within 72 hours time limit?

- What has he heard about ECP?

- Does the client know the right things about ECP?

- Do they need couple counseling? 



\section{Trainer's Tool: \\ E mergency Contraceptive Pills: Side effects case studies}

\section{Case 1:}

Ms. F is a 18-year-old woman who took her first dose of emergency contraceptive pills seven hours ago. She has returned to you because she is nauseous and afraid that she will vomit with the second dose. How would you handle the client's complaint?

\section{Case 2:}

Ms. W is a 39-year-old woman who completed the second dose of emergency contraceptive pills 10 hours ago. Now she is having cramps in the lower abdomen and spotting. She has returned to you for suggestions. What suggestions will you give her?

\section{Case 3:}

Ms. $\mathrm{K}$ is a 24-year-old woman who vomited six hours after her first dose of emergency contraceptive pills. She is afraid of taking the second dose and has come to you for advice. How will you handle the client's situation?

\section{Answer Key}

\section{Case 1:}

Remind "Ms. F" that nausea is a common problem. Tell her that anti-nausea medication is not likely to relive her nausea. Encourage Ms. F to take her second dose with food. Alternatively, tell her that she can place the tablet in her vagina; it may not reduce the nausea but it will ensure the medicine gets into her blood to prevent pregnancy.

\section{Case 2:}

Assure "Ms. W" that after having emergency contraceptive pills cramps and spotting may occur. But there is no harm in it. This will not last more than 1-2 days. She would have her menstrual bleeding on time or few days earlier or 2-3 days later than the expected date.

\section{Case 3:}

Assure "Ms. K" that vomiting can occur with emergency contraceptive pills use. Since she vomited long after taking the pills, the hormone is in her blood to prevent pregnancy. Tell her to take the second dose with food. Remind her that if she vomits within two hours, second dose can be repeated. Alternatively, tell her that she can place the tablet in her vagina; it may not reduce the nausea but it will ensure the medicine gets into her blood to prevent pregnancy. She may need an extra packet of emergency contraceptive pills. 
SAMPLE TRAINING AGENDA

Emergency Contraception

Two-day Training of Trainers (TOT)

Dates: March 4-5, 2003

Venue: Center Point Hotel, Gulshan, Dhaka

\begin{tabular}{|c|c|c|}
\hline \multicolumn{3}{|c|}{ First Day } \\
\hline Time & Topics & Resource Persons \\
\hline 8:30-9:00 & Registration & \\
\hline 9:00-9:15 & $\begin{array}{l}\text { Welcome address: Introduction and } \\
\text { objective of the training }\end{array}$ & $\begin{array}{l}\text { Mr. Jestyn Portugill, COP, NSDP/ Dr. Shalini } \\
\text { Shah, Clinical Services Advisor, NSDP }\end{array}$ \\
\hline 9:15-9:30 & Pre-training test & All participants \\
\hline 9:30-9:45 & Expectation of the participants & $\begin{array}{l}\text { Dr.Zeenat Sultana, Training Coordinator, } \\
\text { NSDP and Mr. Moshiur Rahman, Research } \\
\text { Officer, Population Council }\end{array}$ \\
\hline 9:45-10:15 & $\begin{array}{l}\text { Presentation: Role of ECP as a } \\
\text { reproductive health intervention }\end{array}$ & $\begin{array}{l}\text { Dr. Sharif Mohammed Ismail Hossain, Project } \\
\text { Director, Population Council }\end{array}$ \\
\hline \multicolumn{3}{|c|}{\begin{tabular}{|l|l|} 
10:15-10:30 & Open discussion \\
\end{tabular}} \\
\hline \multicolumn{3}{|c|}{\begin{tabular}{|l|l|} 
10:30-10:45 & Tea \\
\end{tabular}} \\
\hline 10:45-11:15 & $\begin{array}{l}\text { Presentation: Emergency contraceptive } \\
\text { pills: History- Worldwide and Bangladesh } \\
\text { scenarios }\end{array}$ & $\begin{array}{l}\text { Dr. Sharif Mohammed Ismail Hossain, Project } \\
\text { Director, Population Council }\end{array}$ \\
\hline \multicolumn{3}{|c|}{ 11:15-11:30 Open discussion } \\
\hline 11:30-12:15 & $\begin{array}{l}\text { Presentation: } \\
\text { - What is Emergency Contraception } \\
\text { - Situations when EC can be used } \\
\text { - Methods of Emergency Contraception } \\
\text { - What is Emergency Contraceptive Pill } \\
\text { (ECP), types and mode of action } \\
\text { - Characteristics of ECP } \\
\text { - How ECP should be used, dose, } \\
\text { interval between doses and time limit } \\
\text { - when ECP can be used } \\
\text { - Effectiveness of ECP } \\
\text { - ECP } \\
\text { - Side-effects of ECP }\end{array}$ & $\begin{array}{l}\text { Dr. Sharif Mohammed Ismail Hossain, } \\
\text { Project Director, Population Council }\end{array}$ \\
\hline \multicolumn{3}{|c|}{\begin{tabular}{|l|l|} 
12:15-12:45 & Open discussion \\
\end{tabular}} \\
\hline 12:45-1:45 & Lunch & \\
\hline 1:45-2:15 & $\begin{array}{l}\text { Presentation: Service delivery } \\
\text { guidelines }\end{array}$ & $\begin{array}{l}\text { Dr. Sharif Mohammed Ismail Hossain, Project } \\
\text { Director, Population Council }\end{array}$ \\
\hline 2:15-2:45 & Open discussion & \\
\hline 2:45-3:15 & Presentation: Counseling on ECP & $\begin{array}{l}\text { Dr. Sharif Mohammed Ismail Hossain, Project } \\
\text { Director, Population Council/ Dr. Zeenat } \\
\text { Sultana, Training Coordinator (FP), NSDP }\end{array}$ \\
\hline 3:15-3:30 & Open discussion & \\
\hline
\end{tabular}




\begin{tabular}{|c|c|c|}
\hline $3.30-3.45$ & Tea & \\
\hline $3: 45-4: 45$ & $\begin{array}{l}\text { Demonstration: Role play by the } \\
\text { participants and open Discussion (5 } \\
\text { minutes after each role play) }\end{array}$ & \\
\hline \multicolumn{3}{|l|}{ Second Day } \\
\hline $9: 00-9: 30$ & $\begin{array}{l}\text { Recapitulation: Questions and } \\
\text { Answers Session }\end{array}$ & $\begin{array}{l}\text { Dr. Zeenat Sultana, Training } \\
\text { Coordinator, NSDP }\end{array}$ \\
\hline 9:30-10:00 & $\begin{array}{l}\text { Interactive discussion: Emergency Contra- } \\
\text { ceptive Pills in relation with Contraceptive } \\
\text { Technology Updates- OCP, injectables and } \\
\text { condom, traditional methods }\end{array}$ & $\begin{array}{l}\text { Dr. Sharif Mohammed Ismail Hossain, } \\
\text { Project Director, Population Council }\end{array}$ \\
\hline \multicolumn{3}{|c|}{\begin{tabular}{l|l|l|}
$10: 00-10: 15$ & Tea \\
\end{tabular}} \\
\hline $10: 15-10: 45$ & $\begin{array}{l}\text { Presentation: Selected findings from } \\
\text { the ECP OR study }\end{array}$ & $\begin{array}{l}\text { Dr. Sharif Mohammed Ismail Hossain, } \\
\text { Project Director, Population Council }\end{array}$ \\
\hline \multicolumn{3}{|c|}{\begin{tabular}{l|l}
$10: 45-11: 00$ & Open discussion \\
\end{tabular}} \\
\hline $11: 00-11: 15$ & $\begin{array}{l}\text { Presentation and discussion: } \\
\text { Monitoring and supervision }\end{array}$ & $\begin{array}{l}\text { Dr. Sharif Mohammed Ismail Hossain, } \\
\text { Project Director, Population Council }\end{array}$ \\
\hline $11: 15-11: 30$ & Presentation and discussion: Reporting & Dr. Salauddin, QI Coordinator, NSDP \\
\hline $11: 30-11: 45$ & Presentation and discussion: Management & M. Kamrul Ahsan, MIS Specialist, NSDP \\
\hline $11: 45-12: 00$ & $\begin{array}{l}\text { Presentation and discussion: Materials } \\
\text { used for training and field }\end{array}$ & $\begin{array}{l}\text { Dr. Sharif Mohammed Ismail Hossain, Project } \\
\text { Director, Population Council }\end{array}$ \\
\hline 12:00-12:15 & $\begin{array}{l}\text { Presentation: Steps toward expanding } \\
\text { ECP availability }\end{array}$ & $\begin{array}{l}\text { Dr. Sharif Mohammed Ismail Hossain, Project } \\
\text { Director, Population Council }\end{array}$ \\
\hline \multicolumn{3}{|c|}{\begin{tabular}{|l|l|}
$12: 15-12: 30$ & Open discussion \\
\end{tabular}} \\
\hline $12: 30-1: 30$ & Lunch & \\
\hline 1:30-3:00 & $\begin{array}{l}\text { Group work: } \\
\text { - Roles \& responsibilities of the Master } \\
\text { trainer } \\
\text { - Service providers' responsibilities for } \\
\text { implementing ECP service } \\
\text { - Training implementation plan } \\
\text { - Organizing the next training } \\
\text { - Why and what are required } \\
\text { - Schedule for the next training } \\
\end{array}$ & $\begin{array}{l}\text { Mr. Kamru Ahsan, Training Cordnator, } \\
\text { NSDP, Dr. Zeenat Sultana, Training } \\
\text { Coordinator (FP), NSDP/ Dr. Sharif } \\
\text { Mohammed Ismail Hossain, Project Director, } \\
\text { Population Council }\end{array}$ \\
\hline $3: 00-3: 30$ & $\begin{array}{l}\text { Group presentations: Presentation by all } \\
\text { groups }\end{array}$ & $\begin{array}{l}\text { Dr. Zeenat Sultana, Training Coordinator, NSDP } \\
\text { and Dr. Sharif Mohammed Ismail Hossain }\end{array}$ \\
\hline $3: 30-3: 45$ & $\begin{array}{l}\text { Open discussion ( } 5 \text { minutes after each } \\
\text { presentation) }\end{array}$ & \\
\hline $3: 45-4: 00$ & Tea & \\
\hline $4: 00-4: 15$ & Post-training test & All participants \\
\hline $4: 15-4: 30$ & Sum up & $\begin{array}{l}\text { Dr. Zeenat Sultana, Training Coordinator, } \\
\text { NSDP and Dr. Sharif Mohammed Ismail } \\
\text { Hossain }\end{array}$ \\
\hline $4: 30-4: 45$ & Closing & $\begin{array}{l}\text { Dr. Shalini Shah, Clinical Services } \\
\text { Advisor/ Dr. Ahamed Niaz, Training } \\
\text { Director, NSDP }\end{array}$ \\
\hline
\end{tabular}




\section{SAMPLE TRAINING AGENDA \\ Emergency Contraception \\ One-day Training of Service Providers \\ Participants: Service Providers of 2nd Urban Primary Health Care Project \\ Dhaka City Corporation \\ VENUE: MF\&TC, Mohammadpur, Dhaka \\ DATE: September 16/17/18/19/20, 2007}

\begin{tabular}{|c|c|c|}
\hline Time & Topics & Resource Persons \\
\hline 08:30am-09:00am & Registration & \\
\hline 09:00am-09:30am & Inauguration and objectives of training & $\begin{array}{l}\text { Dr. A. T. M. Mostafa Kamal, Director } \\
\text { (MCH-Services) and Line Director (MC- } \\
\text { RH), DGFP/Dr. Parveen Haque } \\
\text { Chowdhury } \\
\text { PM (MCH-RH), DGFP; Dr. Rafiqus } \\
\text { Sultan, NPPP, UNFPA }\end{array}$ \\
\hline 09:30am-09:45am & Pre-training test & $\begin{array}{l}\text { Dr. Tapash Ranjan Das, DPM (MHS), } \\
\text { DGFP }\end{array}$ \\
\hline 09.45am-10:00am & $\begin{array}{l}\text { Demographic scenario of Bangladesh } \\
\text { and role of EC as a reproductive health } \\
\text { intervention }\end{array}$ & $\begin{array}{l}\text { Dr. Jebun Nessa Rahman, NPPP, } \\
\text { UNFPA }\end{array}$ \\
\hline 10:00am-10:10am & Discussion & All participants \\
\hline 10:10am-10:40am & $\begin{array}{l}\text { Emergency contraception and } \\
\text { emergency contraceptive pills }\end{array}$ & $\begin{array}{l}\text { Dr. Parveen Haque Chowdhury } \\
\text { PM (MCH-RH), DGFP }\end{array}$ \\
\hline 10:40am-10:55am & Tea & \\
\hline 10:40am-10:55am & Discussion & All participants \\
\hline 10:55am-11:25am & ECP service delivery guidelines & $\begin{array}{l}\text { Dr. Sharif Mohammed Ismail Hossain, } \\
\text { Sr. Programme Officer, Population } \\
\text { Council }\end{array}$ \\
\hline 11:25pm-11:40pm & Discussion & All participants \\
\hline $11: 40 \mathrm{pm}-12: 00 \mathrm{pm}$ & $\begin{array}{l}\text { ECP counseling \& } \\
\text { ECP logistic management }\end{array}$ & $\begin{array}{l}\text { Dr. Tapash Ranjan Das, DPM (MHS), } \\
\text { DGFP }\end{array}$ \\
\hline $12.00 \mathrm{pm}-12.15 \mathrm{pm}$ & Discussion & All participants \\
\hline $12: 15 \mathrm{pm}-12: 30 \mathrm{pm}$ & $\begin{array}{l}\text { Scenario of present ECP service delivery } \\
\text { in Bangladesh }\end{array}$ & $\begin{array}{l}\text { Dr. Parveen Haque Chowdhury } \\
\text { PM (MCH-RH), DGFP }\end{array}$ \\
\hline $12.30 \mathrm{pm}-12.45 \mathrm{pm}$ & $\begin{array}{l}\text { Post-training test and discussion on pre- } \\
\text { post-training tests }\end{array}$ & $\begin{array}{l}\text { Dr. Fahmida Sultana, DPM (MHS), } \\
\text { DGFP }\end{array}$ \\
\hline 12:45am-01:15am & Lunch & \\
\hline 01:15pm-03:00pm & Role plays and discussions & $\begin{array}{l}\text { Dr. Fahmida Sultana, DPM (MHS), } \\
\text { DGFP }\end{array}$ \\
\hline 03:00pm & Closing and vote of thanks & Dr. Rafiqus Sultan, NPPP, UNFPA \\
\hline
\end{tabular}




\section{MONITORING CHECKLIST FOR TRAINING OF TRAINERS / SERVICE PROVIDERS (Observation Checklist)}

Place of visit (district): Date of visit:

Number of participants present at the beginning of the first session?

Was the inaugural session delayed?

Yes 1

No 2

First working session started at:

Have taken pre-test?

$\begin{array}{ll}\text { Yes } 1 & \text { No } 2 \\ \text { Yes } 1 & \text { No } 2 \\ \text { Yes } 1 & \text { No } 2\end{array}$

Was the overhead projector available?

Have they used supplied transparencies?

No supply 1 Interrupted 2 Uninterrupted 3 How was the power supply/electricity?

Good 1 Congested 2

How was the venue for invited number of trainees?

How many resource person conducted the sessions?

All resource persons came in time?

Yes 1

No 2

Any participants left during the session?

Yes 1

No 2

If yes, how many

Please checkout the following quality questions of each session:

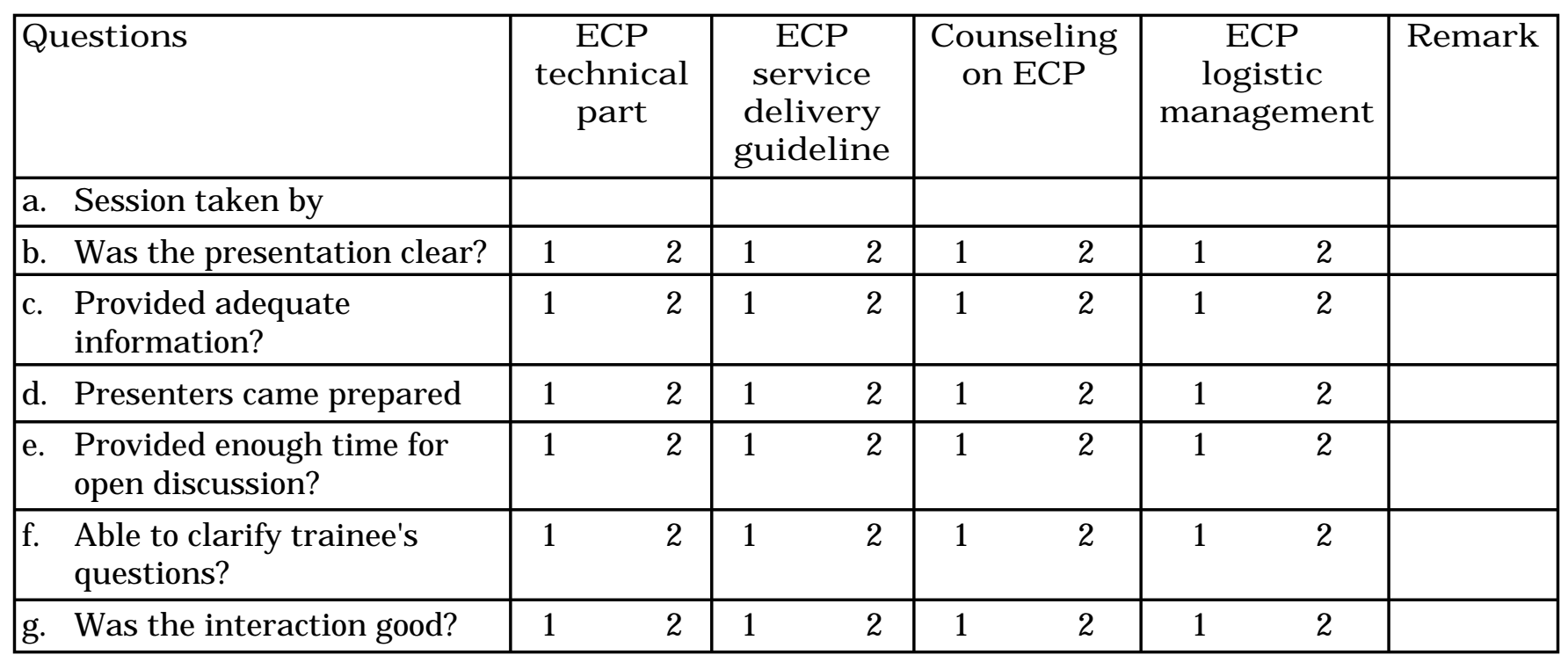

YES=1, NO=2

Have taken post-test?

Yes 1

No 2

Number of participants present at the end of the last session?

Were any sessions delayed for a particular individual? Yes 1

Impression on overall quality of training? Very good $10 \quad$ Good $2 \quad$ Need improvement 3

Session closed at?

Please write your descriptive field notes on the training in this page (Bengali or English):

Name and designation of the monitoring officer: 


\section{Monitoring and Supervision of ECP Program \\ (Questions that Supervisors Should Ask the Service Providers)}

(INSTRUCTION:During regular field visits check and complete the form. Check the answers given along with the questions. All correct answers are given in bold letter. All incorrect answers should be identified and correct answers should be explained to the providers)

Supervisor/Monitor Name

Provider Name:

Clinic Name:

Date:

\section{Knowledge Questions on ECP}

1a. If a woman has unprotected intercourse, what is the chance of her getting pregnant?

Everybody has equal chance of getting pregnant after an unprotected intercourse $=1$

Do not know $=2$

Give an incorrect answer $=3$

1b. Are you communicating it to your every family planning client? $\quad$ Yes=1 No=2

2. You have been trained and provided ECP. Could you please tell me that when you give ECP to a woman what do you say/advise?

a. When (in which situation) ECP could be used?

1 Intercourse without using any FP method

2 Failure to take OCPs for more than 3 days

3 Being late for a contraceptive injection

4 Failed coitus interruptus

5 Miscalculation of the infertile period

6 Condom burst or slip

7 Gave an incorrect answer

8 Do not know

\begin{tabular}{|c|c|c|c|}
\hline $\begin{array}{ll}\text { b. } & \text { Time limit within } \\
\text { which } 1 \text { st dose } \\
\text { must be taken? }\end{array}$ & $\begin{array}{l}\text { c. Number } \\
\text { of dose? }\end{array}$ & $\begin{array}{l}\text { d. Number of } \\
\text { pills in each } \\
\text { dose? }\end{array}$ & $\begin{array}{l}\text { e. Interval } \\
\text { between } \\
\text { doses? }\end{array}$ \\
\hline $\begin{array}{l}\text { 1=Within } 72 \text { hours } \\
\text { of unprotected } \\
\text { intercourse } \\
8=\text { Do not know } \\
3=\text { Gave an incorrect } \\
\text { answer }\end{array}$ & $\begin{array}{l}1=1 \text { dose* } \\
\text { 1= 2 doses } \\
8=\text { Do not } \\
\text { know } \\
3=\text { Gave an } \\
\text { incorrect } \\
\text { answer }\end{array}$ & $\begin{array}{l}1=1 \text { tablet } \\
8=\text { Do not } \\
\text { know } \\
3=\text { Gave an } \\
\text { incorrect } \\
\text { answer }\end{array}$ & $\begin{array}{l}\text { 1=not- } \\
\text { applicable* } \\
2=12 \text { hours } \\
8=\text { Do not } \\
\text { know } \\
3=\text { Gave an } \\
\text { incorrect } \\
\text { answer }\end{array}$ \\
\hline
\end{tabular}

3. A woman who is using pill misses 2 consecutive days, what should she do?

Take 2 pills when remember, 2 pills on the next day, then rest pills 1 pill everyday and use condom 1 Do not know $8 \quad$ Gave an incorrect answer 3

4. A woman who is using pill misses 3 consecutive days, what should she do?

Leave pills as menses could start and use condom until next menses 1

If period does not come, use ECP, continue 1 pill daily after ECP treatment and use condom until next menses $=2$

5. Whose condom has burst or slipped?

Use ECP, continue condom again and use condom from the next cycle 1

Do not know 8

Gave an incorrect answer 3

6. Who has forgotten to take injection that is due?

Use ECP, use condom until next menses and get injection from the next cycle 1

Do not know $8 \quad$ Gave an incorrect answer 3

7. A woman who has requested for ECP, what should she be asked?

Date of last menstrual period 1 Length of woman's normal menstrual cycle

Timing of all unprotected intercourse during current cycle 3 Number of hours since the 1st unprotected sex 4 Do not know 8 Gave an incorrect answer 6

* If the pills used are of $1.5 \mathrm{mg}$ of levonogestrel 


\section{M ystery Client Approach $G$ uidelines For Conduction And Write-up}

\section{What is mystery client approach?}

Mystery client approach is a methodology of data collection where data collector poses herself/himself as a client to the service provider (although she/he is a not an actual client) with the intention to assess how the provider deals with an actual client and what services in being provided from the centre. Provider does not know that she is not an actual client. This is a good approach to assess actual quality of services provided by service provider instead of conducting observation and/or face-to-face interview.

\section{Objectives for the present study:}

- Are the service providers giving the message on ECP to the family planning clients? If yes, how correctly providers are communicating it to the clients?

- To understand how much ECP counseling is being integrated into the overall family planning counseling (with other methods) of the present service delivery system

- To understand provider suggestions to manage risk of unwanted pregnancy due to mistake of the family planning methods

- To assess quality of family planning including ECP services provided by service providers.

\section{Scenario 1: (to understand integration of ECP counseling into the overall FP counseling)}

You need to go to a family welfare center (FWC) early in the morning. You need to pose as Sabriana, a 22 years old girl. Yo do not need to mention your educational status. However, keep in mind that she might ask you. Your menstrual cycle is normal (28 days), bleeding stays for $4 / 5$ days and you had your last menstrual period 10 days back. Tell the service provider that you are going to get married very soon. You do not want to a child immediately. What methods can you use for planning your fertility?

\section{INSTRUCTIONS:}

- Remember all of the details she gives you for each FP method. Did she explain some of the things like how to use the method or what to do if you miss the FP methods? Probe for all the temporary methods failure; what to do if you miss 1 pill, 2 pills, or 3 pills, condom injection due date, miscalculate safe period, or unable to practice withdrawal properly, etc.

- Remember whether she has discussed side-effects of the methods she mentioned. If not, ask in general, are there any side-effects?

- Has she mentioned anything about ECP? If no, ask her what to do if condom bursts/leaks, missed injection due date, have sex during danger period, unable to perform withdrawal or husband did not use any method during a particular sexual act.

- Ask the following questions if she has not mentioned about ECP. 'I have heard that a 
method is available to protect from unprotected intercourse. What is your opinion about ECP?' Remember what she mentions. From where could ECP could be obtained? How is ECP used? How effective is ECP? How many times in a month could ECP be used? Are there any side-effects? How could side-effects be managed? How to return to the regular family planning method after using ECP? When provider offers ECP (purchase it) and asks if she has any printed materials on ECP.

\section{PROCEDURES FOR WRITE-UP}

Immediately after you have completed the ROLE as mystery client, come out from the area and start writing. For better recall, write points in code words that can be expanded later. Write in detail of what you have seen in the FWCs (the time when the provider entered the facility, description of provider's room, methods and IEC materials present in front of the providers, posters pasted, brochure on ECP on the table, waiting time, behavior of the providers, etc.) after completing role-playing. This description part needs to be written in your language not in active language. From when you started interacting with the provider write that part in as much details as possible in the active voice according to the sequence followed in the interaction/service provision between you and provider. At the end of your write-up, you need to give your overall assessment of the provider's knowledge, details of information provided to you, counseling quality, behavior of the provider, and attitudes of the provider about ECP.

\section{CAUTIONS}

You need to be aware and prepared that the provider may ask several questions to you, measure blood pressure, ask children's age, ask husband's details and may conduct a physical examination. In the physical examination, the provider might go for per vaginal or breast examination. To avoid this, say you had unprotected intercourse last night, previous monthly period was normal and that you do not have any vaginal or breast problems. She may become suspicious but try to be as normal as any other client would be. As the provider is mostly local woman she may suspect you, therefore if possible, avoid providing an address or tell her that your are a stranger or a recent tenant in this area. If the provider offers ECP, purchase it.

\section{Scenario 2 (To understand management of condom failure by the provider)}

You need to be pose as Sabriana, a 30 years old girl. Menstrual cycle is normal (28 days), bleeding stays for $4 / 5$ days and you had the last menstrual period 10 days back. Tell the service provider that you have been married for three years. You have a child of one year. You do not want to have another child in the next 3-4 years. Your husband has been using condom. Last night it was burst/leaked. You are afraid of an unwanted pregnancy. What can be done to avoid possible unwanted pregnancy?

\section{Scenario 3 (To understand management of OCP failure by the provider)}

You need to be pose as Sabriana, a 30 years old girl. Menstrual cycle is normal (28 days), bleeding stay for $4 / 5$ days and you had last menstrual period 10 days back. Tell the service 
provider that you are married for five years. You have two children. You are using oral contraceptive pills. You do not want any more children. You have missed three pills and had sex last night. You are afraid of an unwanted pregnancy. What can be done to avoid possible unwanted pregnancy?

Scenario 4 (To understand management of unprotected intercourse due to missed injection due date)

You need to be pose as Sabriana, a 30 years old girl. You have two children. Tell to the service provider that you are married for five years. You do not want any more children. You are using injection for the last three years. You have not had any menstruation for the last three years as well. You have forgotten to take injection for the last 17 days. However, only yesterday night you had intercourse with your husband. You did not use any method. You are afraid of an unwanted pregnancy. You want suggestions from her whether injection can be taken now or is there any method to prevent possible pregnancy?

Scenario 5 (To understand management of unprotected sex due to non-use of FP method by the provider)

You need to be pose as Sabriana, a 25 years old girl. Menstrual cycle is normal (28 days), bleeding stays for $4 / 5$ days and you had the last menstrual period 10 days back. Tell the service provider that you are married for five years. You have two children. You do not want any more children. Your husband works outside and comes home every fortnight. He carries condom when he comes. This time he forgot to bring condoms and you had sex. You are afraid of an unwanted pregnancy. Is there any method to avoid possible unwanted pregnancy?

\section{INSTRUCTIONS FOR ALL METHOD FAILURES OR USER FAILURE CASES:}

- Remember what suggestions the provider has given. Has she mentioned anything about ECP? If yes, what has she mentioned. Remember all the details she has mentioned about ECP including dose, numbers of pill in each dose, interval, efficacy, and time limit for ingestion.

- Did she caution you on side-effects? What did she say? Did she mention how to manage the side-effects? Did she mention what should be done if vomiting occurs within two hours. If no, ask what is to be done?

- Did she mention how frequently ECP could be taken? If no, ask how frequently ECP can be taken?

- Did she offer ECP? Purchase it.

- Did she offer a brochure? If no, ask if there is any printed material on ECP.

- Did she mention that ECP is back-up method and cannot be used regularly?

- Did she mention how to return to the regular family planning method after using ECP?

- Did she mention anything on OCP that OCP can be used as ECP? Remember the details of what she mentioned.

- Ask whether ECP can be used to regulate menstruation? 


\section{Program Evaluation Guidelines Sample questionnaire for ECP user S}

\section{Informed Consent Form for Client}

All of the clients who would be interviewed must be requested to provide informed consent to interview. All participants have the right to refuse to give any interview and could change their mind. The following statement will be read to all clients prior to conducting an interview.

Good morning / afternoon. My name is

I am working with the Population

Council. The Directorate of Family Planning, Government of Bangladesh, Population Council, UNFPA are implementing Emergency Contraception in Bangladesh. The overall goal of the program is to decrease unwanted pregnancy by introducing emergency contraception. You can remember that few weeks/or months before the FWV or FWAs have taken your permission to take an interview on emergency contraceptive pills at your home. I would like to ask your permission to have a discussion on the family planning services you have received from the FWC or FWAs. The findings of the discussion will be used for research purposes only. All of the information collected from you will be kept strictly confidential. Your name will not appear in the data analysis or in any of the reports and nor I will share any of the information with any body. The interview will take approximately half an hour. You may decline to provide the interview if you do not want to give it anymore. Your participation is completely voluntary. You may ask me to stop the interview at any time if you decide not to answer my questions, or you may refuse to answer any single question if it makes you uncomfortable. No one will pay you any money if you agree to give the interview.

Do you agree to give this interview?

Yes No

If you have any questions or doubts, please contact me at:

\section{Population Council}

House \# 21, Road \# 118, Gulshan, Dhaka.

Telephone Number: 8821227, 8826657

(Give the participant your name, address and telephone number)

or

Directorate of Family Planning

2/3 Asad Avenue, Dhaka,

Ministry of Health and Family Welfare

Government of Bangladesh

Thank you.

Signature of the Interviewer

Date 


\section{Characteristics of Informant}

Name of the respondent:

Respondent residence:

Village/para/mohalla:

Rural

1Urban 2

Upazila:

District:

\begin{tabular}{|l|l|l|}
\hline Characteristic & \multicolumn{1}{|c|}{ ECP Users } & Husband \\
\hline Current age & & \\
\hline Age at marriage & & \\
\hline Educationa & & \\
\hline Occupationb & & \\
\hline Number of children & & \\
\hline Age of youngest child & & \\
\hline
\end{tabular}

a 1. Illiterate, 2. Literate but no formal education, 3. Up to primary, 4. 5-8 classes, 5. 9-10 Classes, 6. 11-12 classes, 7. Graduate, 8. MA or more

b 1. House wife, 2. Self employed business, 3. Paid labour, 4. Handicraft

5. Cultivator,

6. Service, 7. Others.

A1 (a) Often couples because of various reasons have unprotected sex, i.e. sexual intercourse without using any family planning method to prevent unwanted pregnancy. Do you have such occasions in the past three months? If yes, how many times?

A1 (b) When such unprotected sex occurs, does it create any tension in mind? If yes, what sort of tension? Why such tension? What will happen if you become pregnant once more?

A1 (c) Who faces these tensions, you or your husband or both?

A1 (d) If husband is not mention ask how about husband? How does he feel after having unprotected sex?

B1 (a) Recently to manage such problem, in your area EC pills have been introduced and women have been informed by the family planning workers what to do in such situation to avoid unwanted pregnancy from unprotected sex. Has anybody told you about EC pills?

B1 (b) If yes, who informed you about this method?
1. Health workers
2. Friends/relatives
3. Paramedic/FWV/doctors

If health worker, Paramedic, FWV, doctors mentioned, ASK is anybody else informed her about this other than them?

Who are they? [MULTIPLE RESPONSE POSSIBLE: PROBE FOR EACH PERSON MENTIONED. Ask question as given in Table 1]

Table 1: Obtained characteristics of each person who have given information about ECP to the informant?

\begin{tabular}{|c|c|c|c|c|}
\hline Sl No. & Relationship $^{\mathbf{a}}$ & $\begin{array}{c}\text { Place of } \\
\text { residence }\end{array}$ & $\begin{array}{c}\text { From where they came } \\
\text { to know about ECP? }\end{array}$ & $\begin{array}{c}\text { Aware whether they } \\
\text { had used it anytime? } \\
\text { 1. Yes 2. No }\end{array}$ \\
\hline 1 & & & & \\
\hline 2 & & & & \\
\hline 3 & & & & \\
\hline 4 & & & & \\
\hline 5 & & & & \\
\hline
\end{tabular}


a 1. Neighbors, 2. Friends, 3. Sisters-in-law, 4. Sister, 5. Husband, 6. Senior relatives and other close relatives,

7. Other specify ...............................

b 1. Same house hold, 2. Neighbour, 3. Same village, 4. Other village (ask distance).

B2 When did you hear about ECP for the first time?

Weeks before

B3 Could you please tell me what all were told about the method? For example tell me:

Month before

[INSTRUCTION: Check first one by one whether the concerned person has mentioned it. If yes, whether or not correctly code according to the information gives below the Table 2]

Table 2: Information provided about ECP

\begin{tabular}{|c|c|c|c|c|c|}
\hline & \multicolumn{5}{|c|}{ What all information about ECP provided to you* } \\
\hline & $\begin{array}{l}\text { Health } \\
\text { worker }\end{array}$ & $\begin{array}{l}\text { Relatives living } \\
\text { in same household }\end{array}$ & $\begin{array}{l}\text { Neighbor/ } \\
\text { Friends }\end{array}$ & Husband & Other \\
\hline \multicolumn{6}{|l|}{$\begin{array}{l}\text { 01. How this method works - prevents } \\
\text { pregnancy or induces abortion? }\end{array}$} \\
\hline \multicolumn{6}{|l|}{ 02. Number of doses? } \\
\hline \multicolumn{6}{|l|}{ 03. Number of pill per dose? } \\
\hline \multicolumn{6}{|l|}{ 04. Interval between dose? } \\
\hline \multicolumn{6}{|l|}{ 05. When to take first dose? } \\
\hline \multicolumn{6}{|l|}{ 06. How often ECP can be used? } \\
\hline \multicolumn{6}{|l|}{ 07. How effective is ECP? } \\
\hline \multicolumn{6}{|l|}{ 08. Possible side-effects? } \\
\hline \multicolumn{6}{|l|}{$\begin{array}{l}\text { 09. What is to be done in case of vomiting } \\
1 \text { st dose within } 2 \text { hours of ingestion? }\end{array}$} \\
\hline \multicolumn{6}{|l|}{$\begin{array}{l}\text { 10. What method needs to be used } \\
\text { immediately after use of ECP? }\end{array}$} \\
\hline \multicolumn{6}{|l|}{ 11. Where is ECP available? } \\
\hline \multicolumn{6}{|l|}{$\begin{array}{l}\text { 12. When to come back to the regular } \\
\text { FP method? }\end{array}$} \\
\hline \multicolumn{6}{|l|}{ 13. When to come back for follow-up? } \\
\hline 77. Others (specify)-------------- & & & & & \\
\hline
\end{tabular}

* 1. Informed and gave correct information, 2 . Informed but gave wrong information, 3. Did not inform at all

B4. Now you tell me whether you have shared information about ECP with someone else? If yes, with how many women/men? Who are they, what is the relationship with you and where do they live?

(INSTRUCTION: Use code from Table 3 below)

Table 3: Who are the people you have informed?

\begin{tabular}{|c|l|l|l|l|}
\hline \multicolumn{2}{|c|}{ Relationship $^{\text {a }}$} & Place of residence & $\begin{array}{c}\text { What information you } \\
\text { have given to them? } \\
\text { (use code from 1st } \\
\text { column of table 2) }\end{array}$ & $\begin{array}{c}\text { Are you aware } \\
\text { whether she used } \\
\text { anytime } \\
\text { 1.Yes }\end{array}$ \\
\hline 1 & & & & \\
\hline 2 & & & & \\
\hline 3 & & & & \\
\hline 4 & & & & \\
\hline 5 & & & & \\
\hline
\end{tabular}


a 1. Neighbor, 2. Friends, 3. Sisters-in-law, 4. Sister and other close relatives, 5. Husband, 6. Senior relatives, 7. Other specify....

b 1. Same house hold, 2. Neighbor, 3. Same village, 4. Other village (ask distance)....

B5 (a) If husband is not mentioned in question 4. ASK, did you discuss about this method with your husband? What was his reaction? What did he say? What communication or exchange took place between him and you? Does he clearly understand the method? (INSTRUCTION: PROBE AND RECORD VERBATIM).

B5 (b) Did he become more relaxed or less careful in using FP methods, for example, now is he less careful to observe safe period, or practicing withdrawal or using condom or any other way? PROBE what?

B5 (c) After introduction of ECP has your husband behaved in any of the following way?

- $\quad$ Now, having sex during unsafe period more frequently than before $\quad$ Yes $1 \quad$ No2 Does not bring contraceptive in time or do not bring condom when he comes from out side unexpectedly.

Yes $1 \quad$ No 2

Not listening to the refusal of wife during unsafe period.

Yes 1 No 2

B5 (d) Well, women could also become relaxed. For example, wife may allow husband without resistance or encourage husband for sex even though she is not protected by any family planning method. She may feel that now she has ECP. Has it happened to you any time?

B6. In general what is your view about this method? Do you think this will be helpful to women? If yes, in what way? (INSTRUCTION: PROBE \& NOTE VERBATIM) If no, why not?

B7. Can this method be used as regular family planning method? $\quad$ Yes $1 \quad$ No 2 If no, why not?

If yes, why did you say so?

B8. Now, I am going to ask some questions about ECP. Could you please tell me:

\begin{tabular}{|c|c|}
\hline \multirow{2}{*}{\begin{tabular}{|l} 
Knowledge on \\
01. How this method works - prevents pregnancy or induces abortion?
\end{tabular}} & \multirow[t]{2}{*}{ Correct $=1$, Incorrect $=2$} \\
\hline & \\
\hline 02. When 1st dose of ECP must be taken? & \\
\hline 03. How many doses should be taken? & \\
\hline 04. What is the interval between doses? & \\
\hline 05. How many pills is each doses? & \\
\hline 06. What are the side-effects? & \\
\hline 07. What is to be done in case of vomiting 1 st dose within 2 hours of ingestion? & \\
\hline 08. How often ECP can be used? & \\
\hline 09. How effective is ECP? & \\
\hline 10. What method needs to be used immediately after use of ECP? & \\
\hline 11. Where is ECP available? & \\
\hline 12. When to come back to the regular FP method? & \\
\hline 13. When to come back for follow-up? & \\
\hline
\end{tabular}

B10. Now, could you please give me some more detailed information about each such unprotected sex such as (a ) What was the situation(s) When the last unprotected sex occurred? (b) What happened in the second and 3rd occasion? (c) What did you do to protect from unwanted pregnancy? 
(INSTRUCTION: Ask for each occasion how and why unprotected sex occurred. If more than 3 episodes of UPS, ASK question for the last three unprotected sex only. If no unprotected sex during last four months, ask for any unprotected sex that occurred after ECP introduction/receiving information. Women may not mention exact time of ECP taking, morning/evening).

\begin{tabular}{|c|c|c|c|c|c|c|c|}
\hline \multirow{2}{*}{$\begin{array}{l}\text { Episodes of } \\
\text { UPS sex } \\
\text { during last } \\
4 \text { months* }\end{array}$} & \multirow{2}{*}{$\begin{array}{c}\text { How and } \\
\text { why UPS } \\
\text { occurred? } \\
\text { Get detailed } \\
\text { story }\end{array}$} & \multirow{2}{*}{$\begin{array}{c}\text { When it } \\
\text { happened? } \\
\text { (Weeks or } \\
\text { months } \\
\text { before) }\end{array}$} & \multirow{2}{*}{$\begin{array}{c}\text { What did you } \\
\text { do to avoid } \\
\text { unwanted } \\
\text { pregnancy } \\
\text { from UPS? } \\
\text { Get detail** }\end{array}$} & \multicolumn{2}{|c|}{$\begin{array}{c}\text { If used ECP } \\
\text { ASK }\end{array}$} & \multirow{2}{*}{$\begin{array}{c}\text { Did you } \\
\text { succeeded } \\
\text { in avoiding } \\
\text { pregnancy? } \\
\text { Yes 1, No 2 } \\
\text { DK yet=3 }\end{array}$} & \multirow{2}{*}{$\begin{array}{c}\text { When used, } \\
\text { whether it } \\
\text { was with } \\
\text { her, if not } \\
\text { who } \\
\text { bought } \\
\text { it?*** }\end{array}$} \\
\hline & & & & \begin{tabular}{|c|} 
When \\
took 1st \\
dose \\
after \\
UPS \\
\end{tabular} & $\begin{array}{c}\text { When } \\
\text { took } \\
\text { 2nd dose } \\
\text { after } \\
\text { 1st dose }\end{array}$ & & \\
\hline $\begin{array}{l}\text { The most } \\
\text { recent UPS }\end{array}$ & & & & & & & \\
\hline $\begin{array}{l}\text { Next more } \\
\text { recent UPS }\end{array}$ & & & & & & & \\
\hline Next UPS & & & & & & & \\
\hline
\end{tabular}

*UPS=Unprotected sex,

** If other than ECP and mentioned OCP as the method, ask brand, dose, pills in each dose, interval and when started

*** Yes with me=1, I went to purchase it=2, No, husband brought it=3, Others brought it=4 -(specify)

B11. If used ECP. ASK ABOUT UNPROTECTED INTERCOURSE AND FP METHOD USE:

\begin{tabular}{|c|c|c|c|c|c|c|}
\hline $\begin{array}{l}\text { Episodes of } \\
\text { UPS sex } \\
\text { during last } 4 \\
\text { months }\end{array}$ & $\begin{array}{l}\text { B. } 11 \text { (a) How many } \\
\text { hours after the first } \\
\text { unprotected } \\
\text { intercourse you } \\
\text { used the ECP? } \\
\text { [INS: She may not } \\
\text { able to tell you } \\
\text { hour. Probe when } \\
\text { she took after the } \\
\text { UPS - next } \\
\text { morning, on the } \\
\text { same night, after 2- } \\
3 \text { days and so forth] }\end{array}$ & \begin{tabular}{|l|} 
B11 (b) \\
How many \\
intercourse \\
you had \\
before the \\
1st dose of \\
ECP? If \\
more than \\
one, check \\
on the \\
same day \\
or on \\
different \\
day/time.
\end{tabular} & $\begin{array}{l}\text { C11 (c) } \\
\text { During the } \\
\text { first and } \\
\text { second dose } \\
\text { of ECP, did } \\
\text { you have } \\
\text { unprotected } \\
\text { intercourse } \\
\text { again? Did } \\
\text { this occur } \\
\text { on the } \\
\text { same or } \\
\text { different } \\
\text { days/night? }\end{array}$ & $\begin{array}{l}\text { B11 (d) Why } \\
\text { could you } \\
\text { not avoid } \\
\text { UPS? Is it } \\
\text { because your } \\
\text { husband did } \\
\text { not } \\
\text { cooperate } \\
\text { with you? } \\
\text { (INS: } \\
\text { RECORD } \\
\text { VERBATIM) }\end{array}$ & $\begin{array}{l}\text { B11 (e) } \\
\text { Just } \\
\text { before you } \\
\text { had UPS } \\
\text { were you } \\
\text { using any } \\
\text { FP } \\
\text { method? } \\
\text { If yes, } \\
\text { which }_{\text {method?* }}\end{array}$ & $\begin{array}{l}\text { B11 (f) After } \\
\text { using ECP did } \\
\text { you start using } \\
\text { FP method } \\
\text { again? If yes, } \\
\text { which method? } \\
\text { Was there any } \\
\text { delay before you } \\
\text { started using } \\
\text { this method? If } \\
\text { yes, how much } \\
\text { delay (ask for } \\
\text { no. of days) } \\
\text { Why this } \\
\text { delay?* }\end{array}$ \\
\hline \multicolumn{7}{|l|}{$\begin{array}{l}\text { Next most } \\
\text { recent UPS }\end{array}$} \\
\hline \multicolumn{7}{|l|}{$\begin{array}{l}\text { Next more } \\
\text { recent UPS }\end{array}$} \\
\hline Next UPS & & & & & & \\
\hline
\end{tabular}

$* 1=$ Condom, $2=$ Oral pills, $3=$ =njection, 4=IUD, 5=Traditional methods (withdrawal, safe period, periodic abstinence, natural method), $6=$ Norplant, $7=$ Sterilization, $8=$ No methods 
B12. How many times have you used ECP in the last one month. (INSTRUCTION: If did not use in the previous one month, ask for the last 3 months. ASK what is the result of ECP use (Avoid or did not avoid possible pregnancy or do not known yet).

B13. If used ECP. ASKABOUT SIDE EFFECTS AND COMPLIANCE.

\begin{tabular}{|l|l|l|l|l|}
\hline Use of ECP & $\begin{array}{l}\text { B13 (a) Did you } \\
\text { experience any } \\
\text { side-effect due } \\
\text { to use of ECP? } \\
\text { If yes, what are } \\
\text { those? }\end{array}$ & $\begin{array}{l}\text { B13 (b) What } \\
\text { did you do } \\
\text { for the side- } \\
\text { effects? }\end{array}$ & $\begin{array}{l}\text { B13 (c) Did you have } \\
\text { vomiting within 2 hours } \\
\text { of 1st dose of ECP use? If } \\
\text { yes, what did you do for } \\
\text { that? Did you take } \\
\text { another dose for the 1st } \\
\text { dose? }\end{array}$ & $\begin{array}{l}\text { B13 (d) When you } \\
\text { vomited the 1st } \\
\text { dose, did you } \\
\text { take the second } \\
\text { dose after 12 } \\
\text { hours? If not } \\
\text { why? }\end{array}$ \\
\hline $\begin{array}{l}\text { Most recent use of } \\
\text { ECP }\end{array}$ & & & \\
\hline $\begin{array}{l}\text { Next more recent } \\
\text { use of ECP }\end{array}$ & & & & \\
\hline Next use of ECP & & & & \\
\hline
\end{tabular}

B14 (a) You have been educated about ECP and provided with ECP brochure. Did you receive brochure? (INSTRUCTION: If can't remember, show the brochure and then ask whether she got it or not. Write exact verbatim).

B14 (b) Did you read the brochure? If can't read then ask anybody read it for her. If anybody read it for you, who read it for you. Get detailed answers.

B15. Did you pay for the ECP? If yes, how much you have paid for one packet of ECP? Are you able to pay such amount?

B16. Do you have any concern about ECP. If yes, what are those-such as services by providers, method itself or price? 


\section{G uideline to Conduct FGD/Indepth}

Case Study $\mathrm{O} n$ Emer gency Contraception: Diagnostic Study

\section{A few things to remember while conducting FGD}

(1) FGD is a tool for data collection for studying PERCEPTION of the informants about some activities, behavior or issues in a societal context. It should NOT be used for studying participants OWN behavior.

(2) All questions should be addressed by asking "in your opinion" generally what women think or do in a certain situation. NEVER ask question "what YOU do". We are interested in their PERCEPTION and not their behavior.

(3) In contrast, when you do an in-depth interview/case study; focus is on that person, his/her opinion and behavior. Here we ask "what did YOU --------." In FGD we ask "what generally they (the other women in the community) do"

(4) As long as the women say that "I do this" or "I do not know what my neighbor is practicing" means informants have NOT understood your question. FGD does not focus on once individual action but on the informants perception, what generally community members do or how they would react to an event.

(5) Make sure that before asking any question, the informants know meaning of your key word. For example if "unprotected sex" is being discussed, all of them should have clear understanding what is unprotected sex. Special care should be taken to check the informants understanding of your questions.

(6) To get detailed and complete answers, probing and asking the same questions in different ways two or three times is useful, and encouraged.

(7) Never contradict with their response and say "it is wrong". In the study of assessing PERCEPTION there is no correct or wrong answers.

(8) As far as possible expand you notes on the same day, soon after completion of the FGD.

\section{INTRODUCTION}

Introduce yourself and explain the purpose of the today's meeting. The following points must be covered in your introduction.

- Self and note taker's introduction

- Your organization profile

- Purpose of today's meeting

- Interest in their perception on community/issues and not in their personal behavior

- Information obtained will be used for research purposes only and kept confidential

- Right to refuse to answer or participate in FGD

- Participants will not get any immediate benefit by participating in the FGD

- Permission to tape the conversation

- Introduction of participants with key variables (name, age, education, marital status, no. of children) 


\section{Getting Started}

1. What are some of the more important problems of this village/community?

2. What are the main problems women usually face in this village/community?

3. Do you think there are women who despite of not wanting children, often become pregnant?

4. In your opinion why such unwanted pregnancy occurs?

\section{Knowledge and Practice of Methods Used as Emergency Contraceptives}

A1(a) If a couple does not want any more children or wants after two years, what should the couple do? What methods can they use?

A1(b) If they do not use any family planning method what will happen?

A2(a) Why unsafe/unprotected sex takes place? Could you give some situation/examples when unsafe sex takes place?

A3(a) If a couple who does not want any more children or the woman does not want to become pregnant has sex without any family planning method, can such a couple do anything immediately after sex or within one or two days to avoid an unwanted pregnancy?

A3(b) How about an unmarried boy and girl who met and had sex without using any family planning method. Can they do anything immediately after sex or within two three days to avoid pregnancy?

A4 Now ask for EACH of the method the group has identified in A3 (a)-(c):

A4(a) How this is performed?

A4(b) To what extent is it effective?

A4(c) How commonly is it used?

(INS: If they express their inability to answer this question A4(c) ask ("d")

A4(d) How common is this knowledge among women that use of this method could AVOID pregnancy from unprotected sex?

A4(e) Does it have any side-effects?

A4(f) If yes, what?

A5(a) Could you tell me what all women do immediately after having intercourse- What are the common practices in the village?

(INS: Some of the examples are: cleaning with cloth, sleeping flat with face down, you washing, taking bath, passing urine, standing and walking etc. DO NOT read them but could give one or two examples to stimulate the discussion, if an answer to the question is not coming freely.)

(INS: At first make a list of all such acts by probing and repeating your question. Note that this question is a general question and irrespective whether it is safe or unsafe.)

A5(b) Now ask for each act or practice reported in A4(a)

Why this is done? What is the purpose of this practice?

(INS: Note that a probing like this "why" or for "what purpose" may give an idea whether these practices are used as emergency contraceptive measures i.e. "To avoid pregnancy." In all such cases go to Q\#A4 and ask A4 (a)-(e) for each practice.) 


\section{B. Acceptability of EC}

B1(a) Now a modern method like this (INS: show the packet) is available, which if women use within 2 or 3 days of an unprotected intercourse, it might prevent them from getting pregnant. Do you think women would like to know about this method or use it when such necessity arises?

B1(b) If NO, why not?

B2(a) Many of you said that women would use this method as emergency method to avoid pregnancy from unprotected sex. Could you tell me in which category or group of the women this method will be most popular? Or which groups of women will get more benefit from this method?

(INS: If the answer comes that generally aged women with two or three children, make sure that they have understood the question and not answering for abortion/MR of confirm/suspected pregnancy. We assume unprotected sex is more frequent among young and adolescents group. If they still say old couples with many children probe in detail why so.)

(Example of possible groups: Married-unmarried, young-middle aged-older women, women living with husband-husband visiting occasionally, all who face the problem. INS: However, do not read this example. Let them first come up spontaneously with some answers.)

B2(b) Why this particular group?

B2(c) Why other groups of women will be less benefited by this method?

B3(a) Would availability of this method (emergency contraceptive) reduce use of other family planning methods? (Check again that they understand what is this method)

B3(b) If yes, why do you think so?

B3(c) If no, why not? (Get as detailed answers as possible)

B4 Do you think that this method could be misused also? If yes, how? Who will misuse this method? (INS: Make them understand clearly what you mean by misuse) (INS: This might be misused by (i) married couples by using it as family planning method instead of using it as an emergency method or backup support (ii) husbands may stop using condom or become more careless towards pregnancy protection who is using 'safe period method' if Emergency Contraception becomes available (iii) It may increase premarital and/or extra-marital sex as they become confident that pregnancy from unprotected sex could be prevented)

B5(a) This method (INS: show the pills packet again) as I said could help women in AVOIDING pregnancy from unsafe intercourse. But it may not be available for free. Do you think women would be ready to pay Taka 15 for one course of the pills. (i.e. to protect women from one unprotected sex?)

(INS: If the general opinion (i.e. majority) of the informants is that women will pay Taka 15, then ask how about Taka 20? Will women pay 20 Taka to get this pills? Try again to assess what is the general response. Is it favourable or they (majority of women) are doubtful/negative to pay Taka 20. If still, in 
general, informants feel that women may pay even Taka 20, ask what will be the upper limit beyond which most of the women may not buy this product.) The answers may come in range. Discuss which will be more appropriate; the upper or lower bound of the range.

\section{Decision Making of Family Planning (OPTIONAL)}

D1 Did your husband (wife) talk with you about number of children you would like to have or his own preference about family size? If 'yes' at what stage of life, soon after marriage, sometime after marriage, after birth of 1st, 2nd ........child?

Who initiated the discussion on this issue?

If husband, why did you not initiate? [WOMEN ONLY]

How you think your husband would have reacted if you had initiated this discussion? [WOMEN ONLY] (FGD as well as case study)

D2 Repeat the full question given above (Q\#D1) for FP use. (FGD as well as case study)

D3(a) According to your opinion, between husband and wife who has the principal responsibility of using family planning?

D3(b) In your case what has happened? Who decided to use FP. At what stage of married life? [INDEPTH ONLY]

D4 If women, why? Husbands are equal partners.

D5 If male or both then why mostly women use contraceptives and not men?

D6 There are several male family planning methods like condom, vasectomy and withdrawal but men often do not use these methods and expect or advise their wives to use family planning method, why? Why do they not use male method? Probe for each method condom, withdrawal and vasectomy SEPARATELY.

D7 Often it is observed that men play only passive roles in family planning use by giving permission to their wives to use family planning but do not contribute much either in helping her to choose a method (by discussing with her) or in obtaining a method for her or cooperating in making contraception more effective (for example not having sex when women has forgotten to take pills). How do you explain such passive attitude of husband; though he also does not want any more children?

D8 Do you think women could ask her husband to use condom? If 'No' why not?

D9 Have you/your wife ever asked you/your husband to use condom? If yes, how did you/your husband react?

D10 If a woman refuses sex to her husband in such cases does husband have the right to beat her or have forced sex?

D11(a) Do you think woman has the right to refuse sex to her husband?

D11(b) Do you justify husband beating his wife for refusing sex to him? 



\section{EMERGENCY CONTRACEPTIVE PILLS (ECP)}

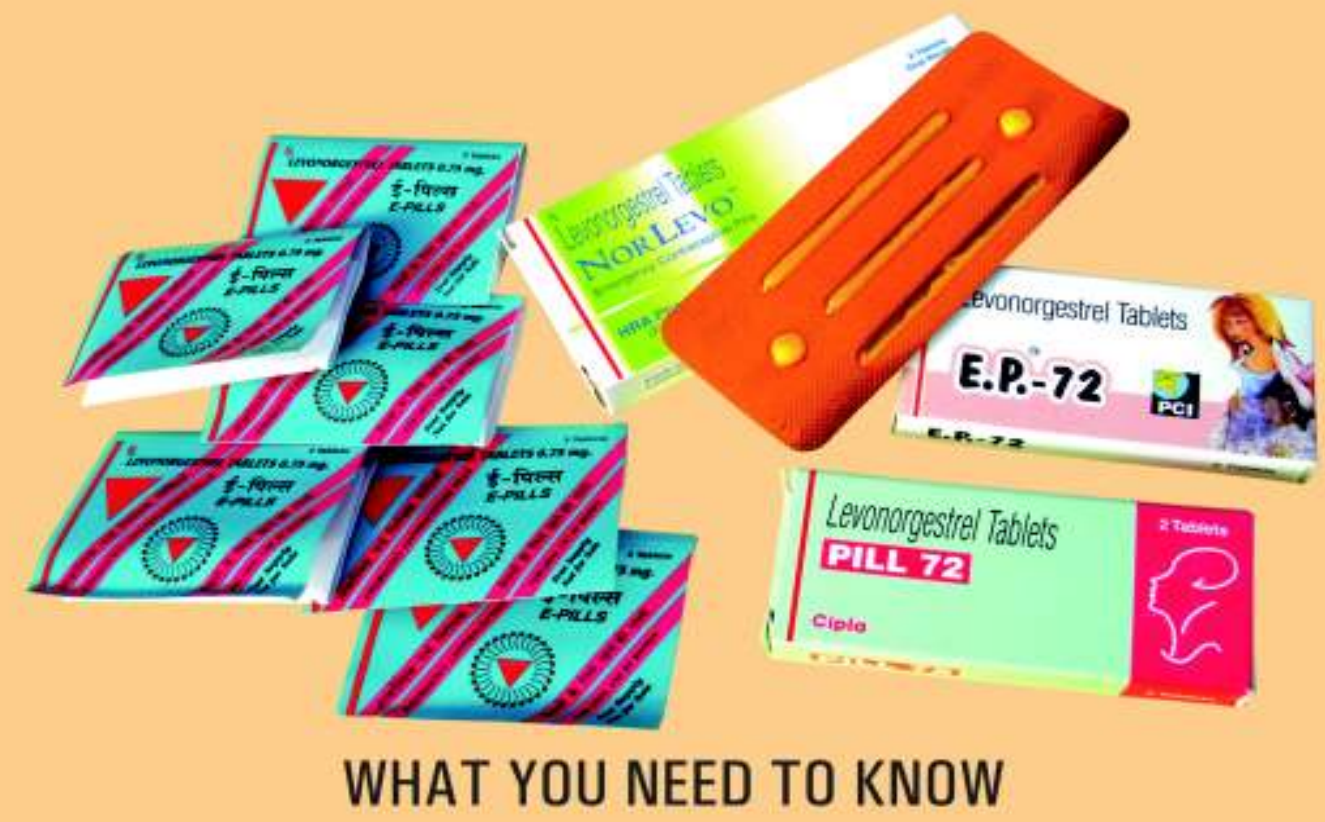

FRONTIERS

\section{Teaching}

\section{and IEC/BCC M aterials}





\section{Teaching And IEC/BCC M aterials $B$ angladesh}

\begin{tabular}{|c|c|c|c|c|c|c|c|c|c|c|c|}
\hline \multirow{3}{*}{ 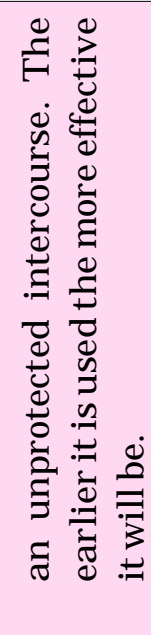 } & 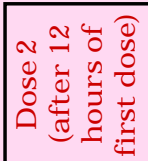 & 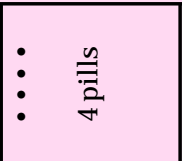 & 产 & $\begin{array}{l}\overline{0} \\
-1\end{array}$ & \multirow{3}{*}{ 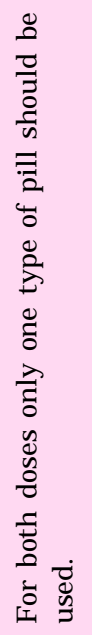 } & \multirow{3}{*}{\multicolumn{2}{|c|}{ 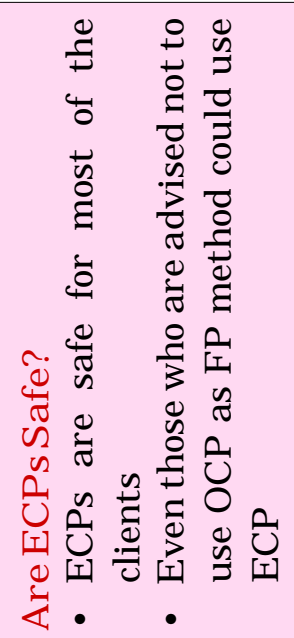 }} & \multirow{3}{*}{\multicolumn{2}{|c|}{ 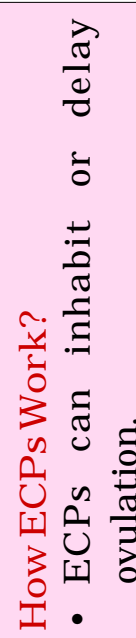 }} & \multirow{3}{*}{ 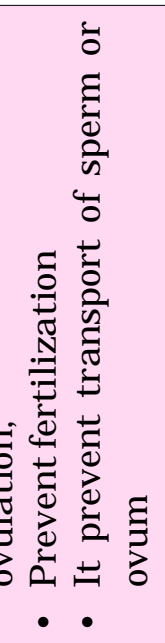 } & \multirow{3}{*}{ 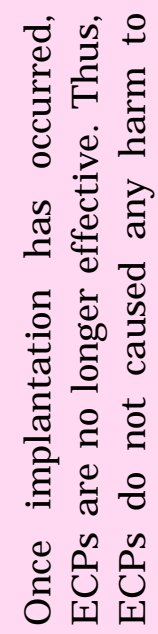 } \\
\hline & 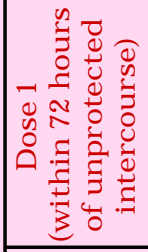 & $\vdots \quad \stackrel{0}{\bar{z}}$ & & - $\quad \begin{array}{l}\bar{a} \\
\overline{7}\end{array}$ & & & & & & & \\
\hline & 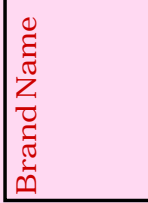 & 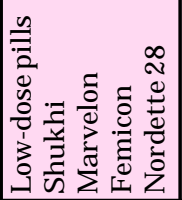 & 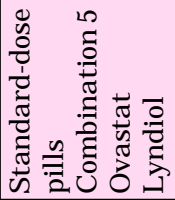 & 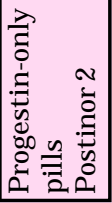 & & & & & & & \\
\hline
\end{tabular}

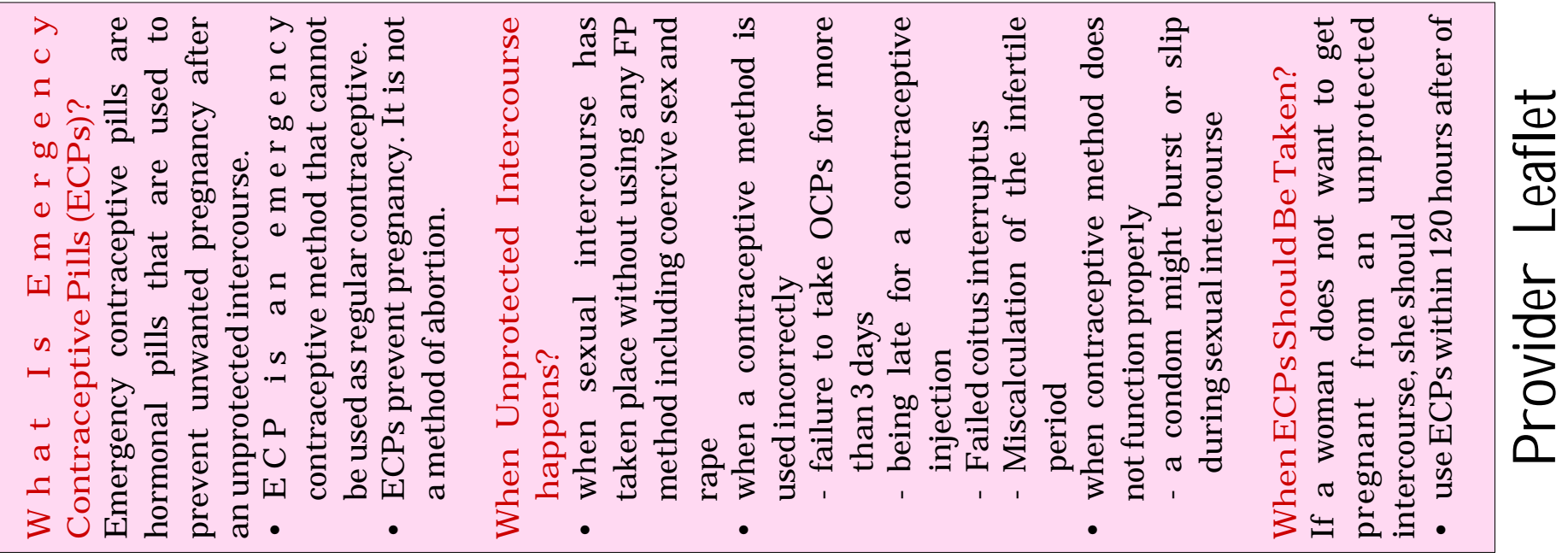
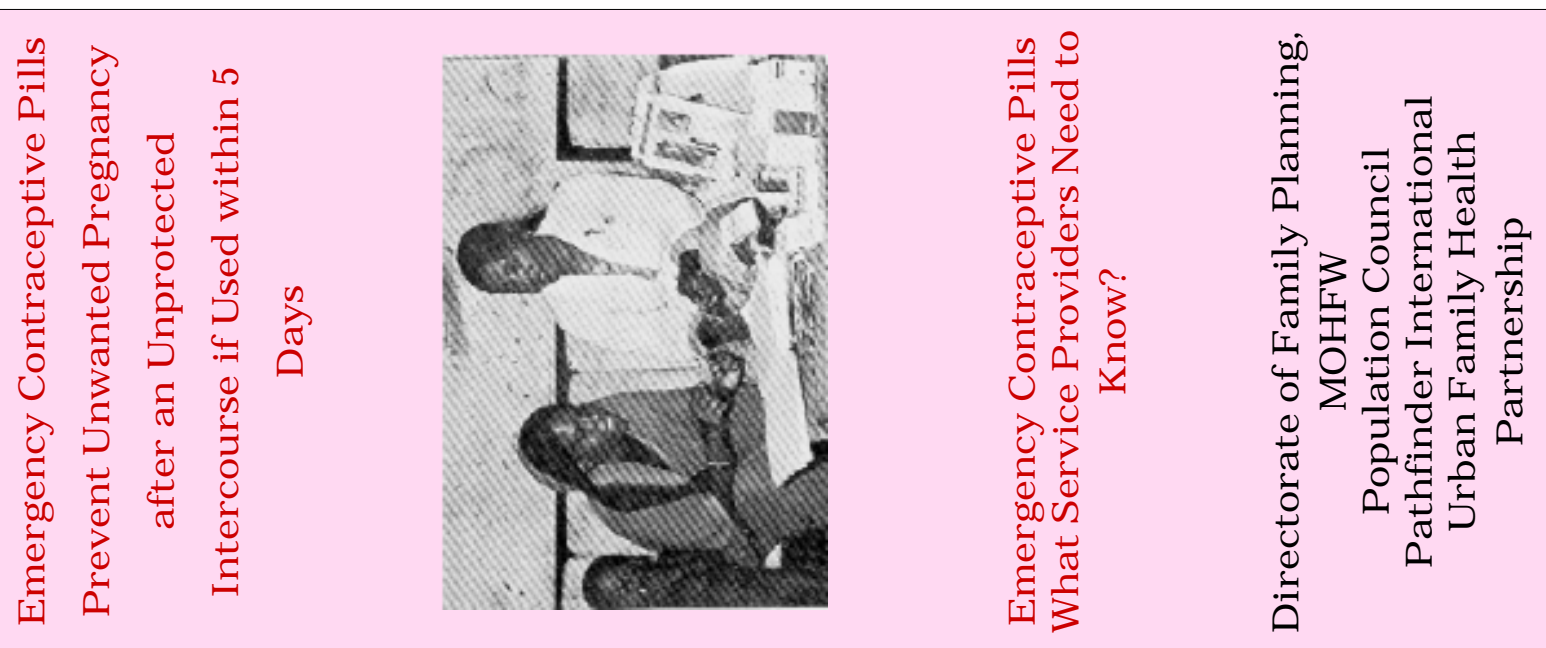


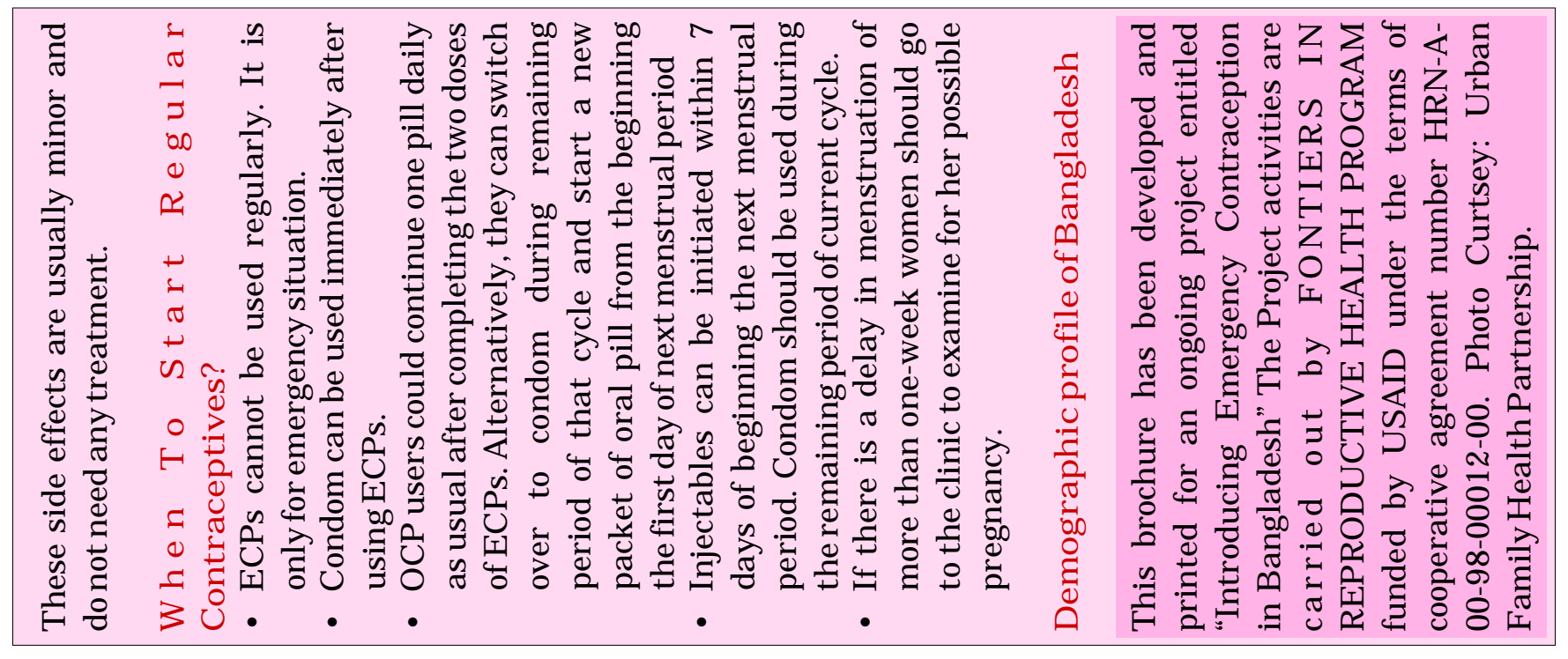

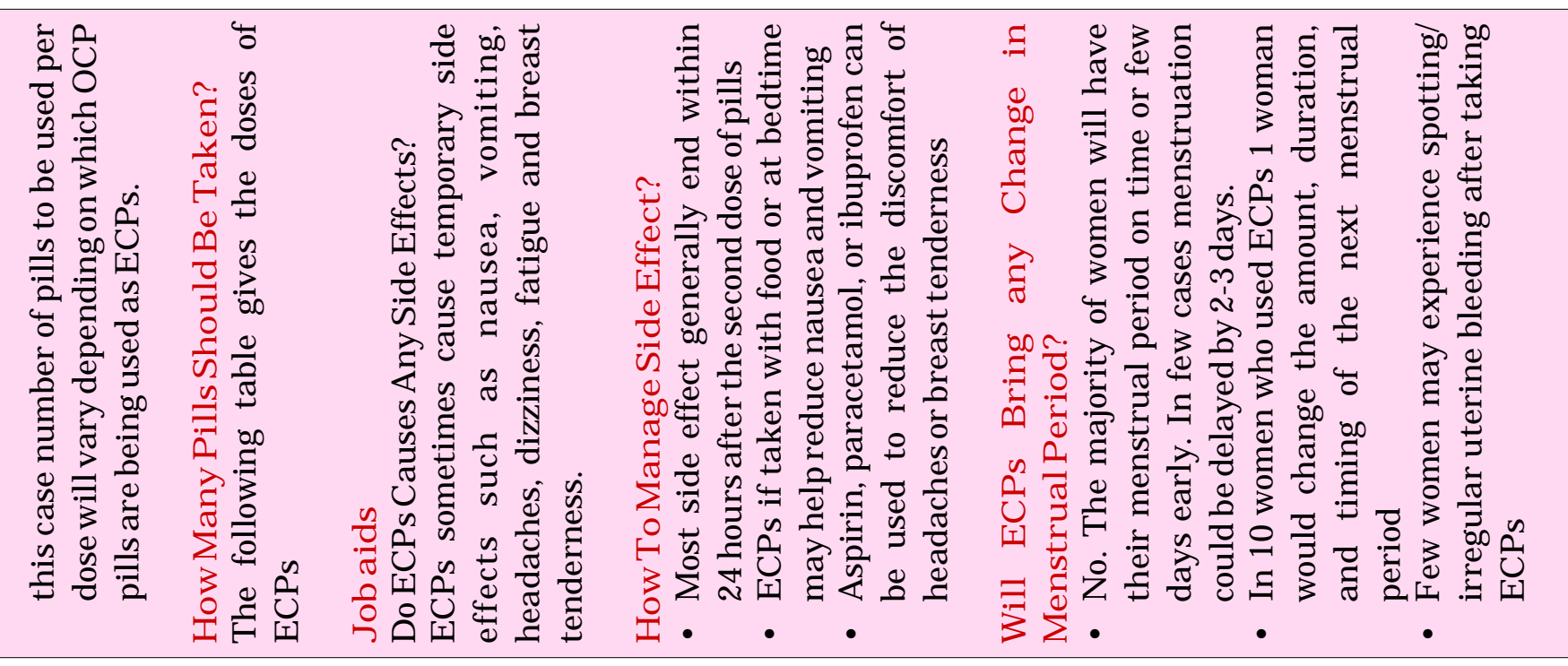

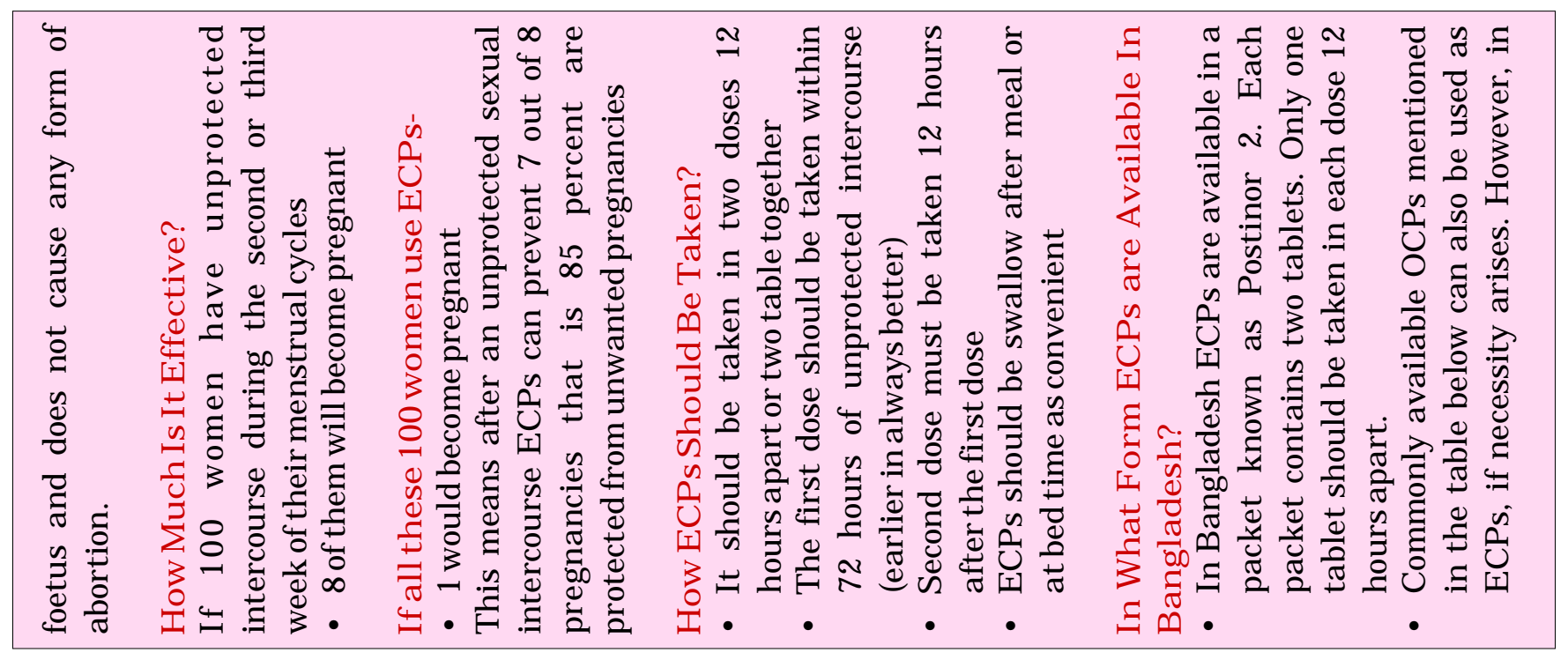




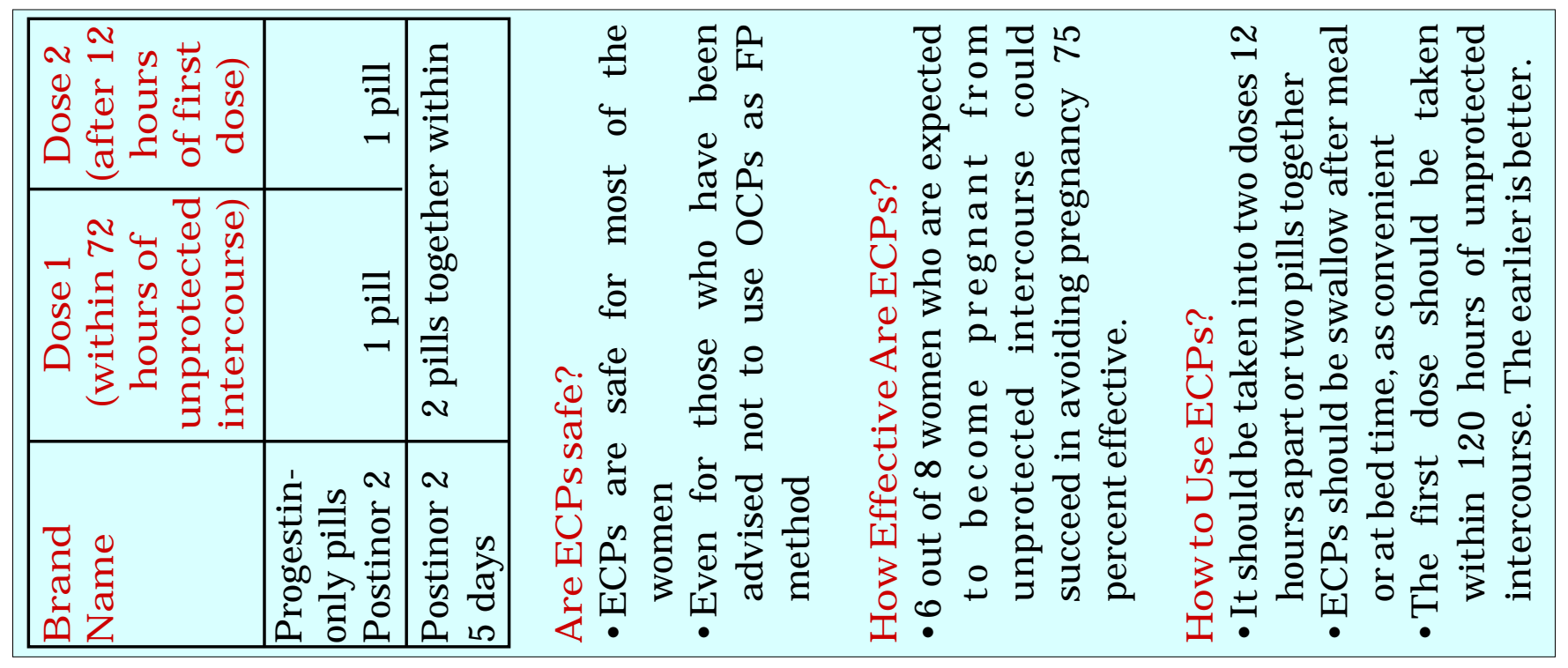

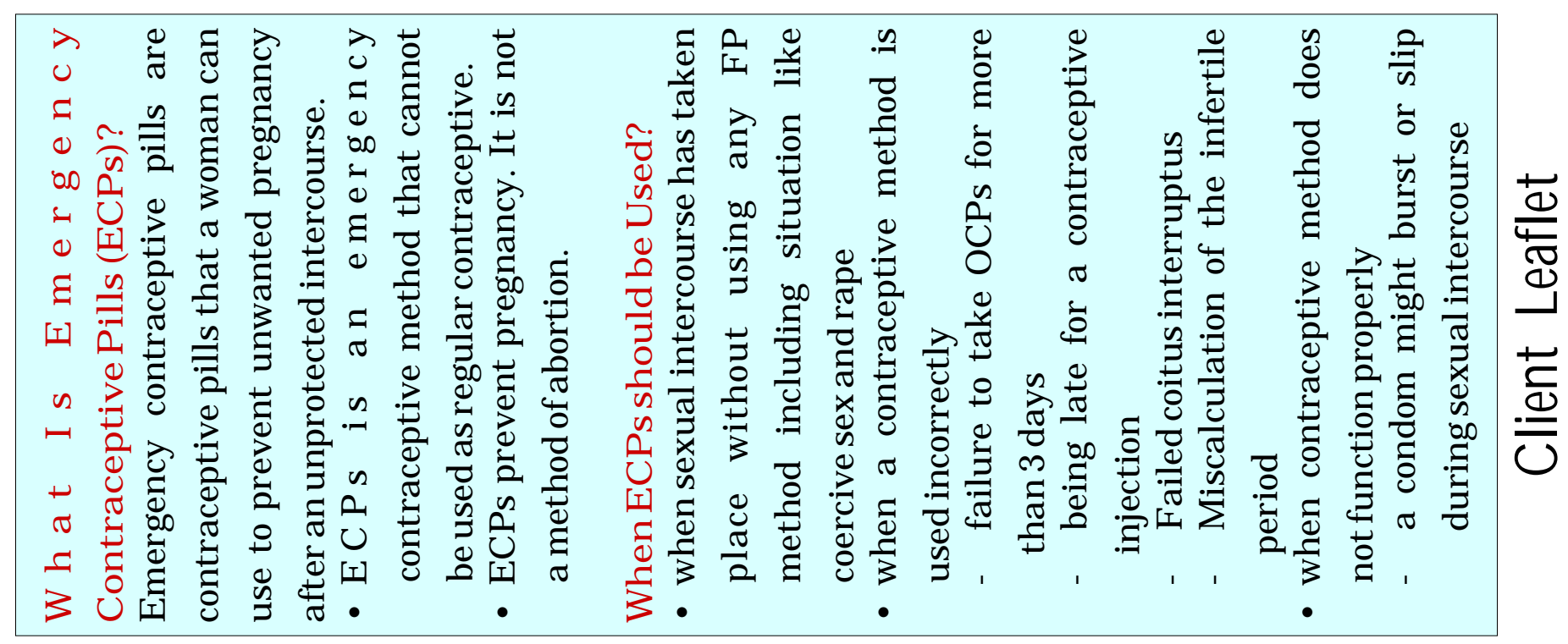
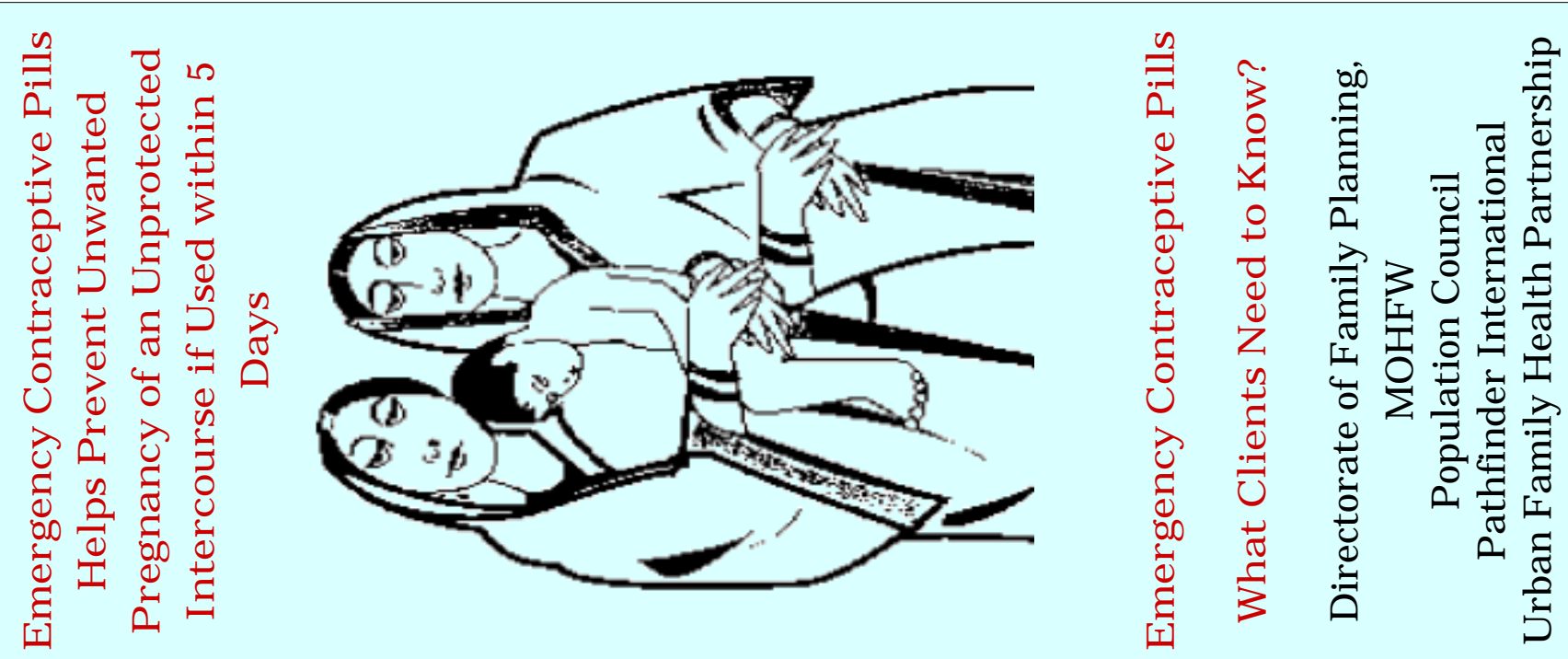


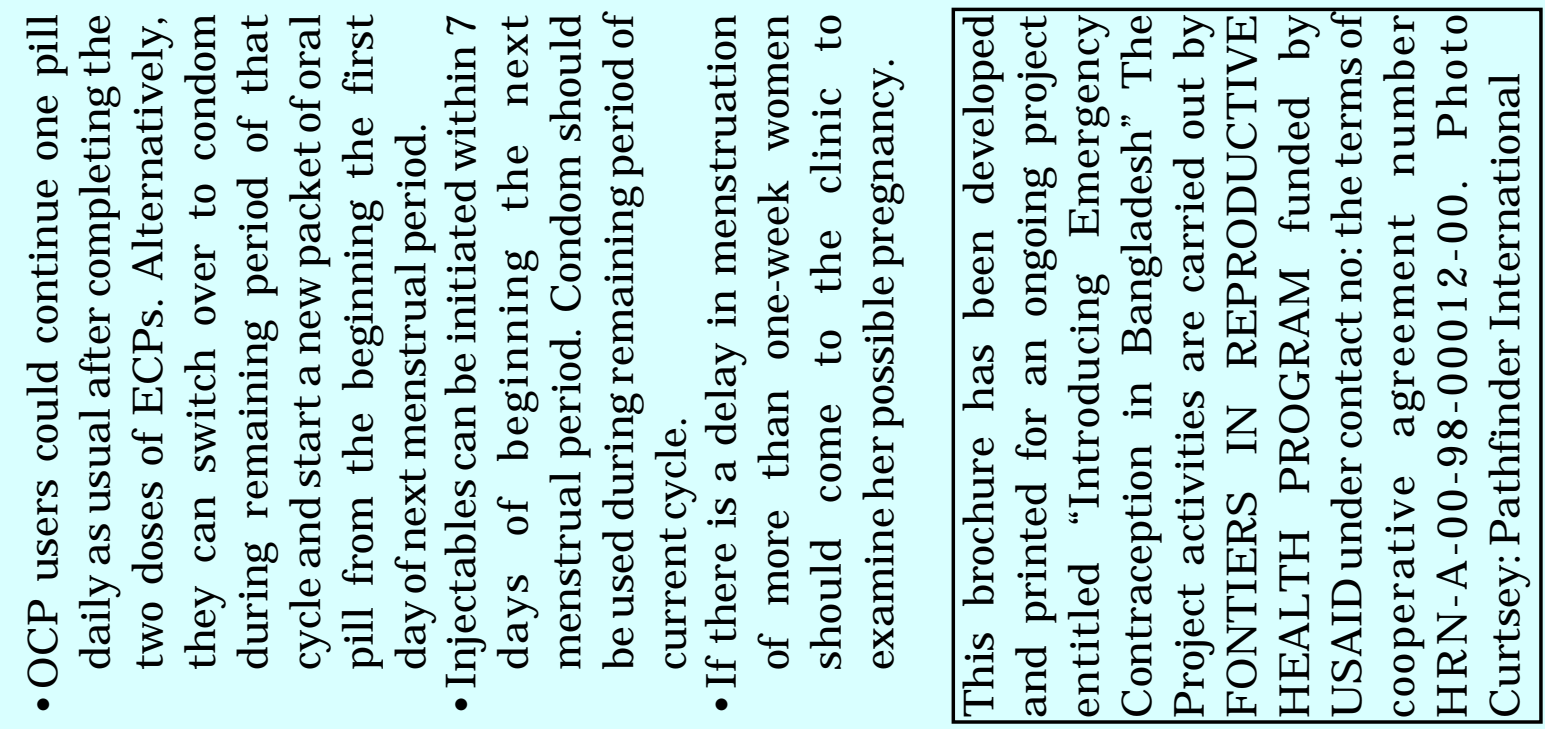

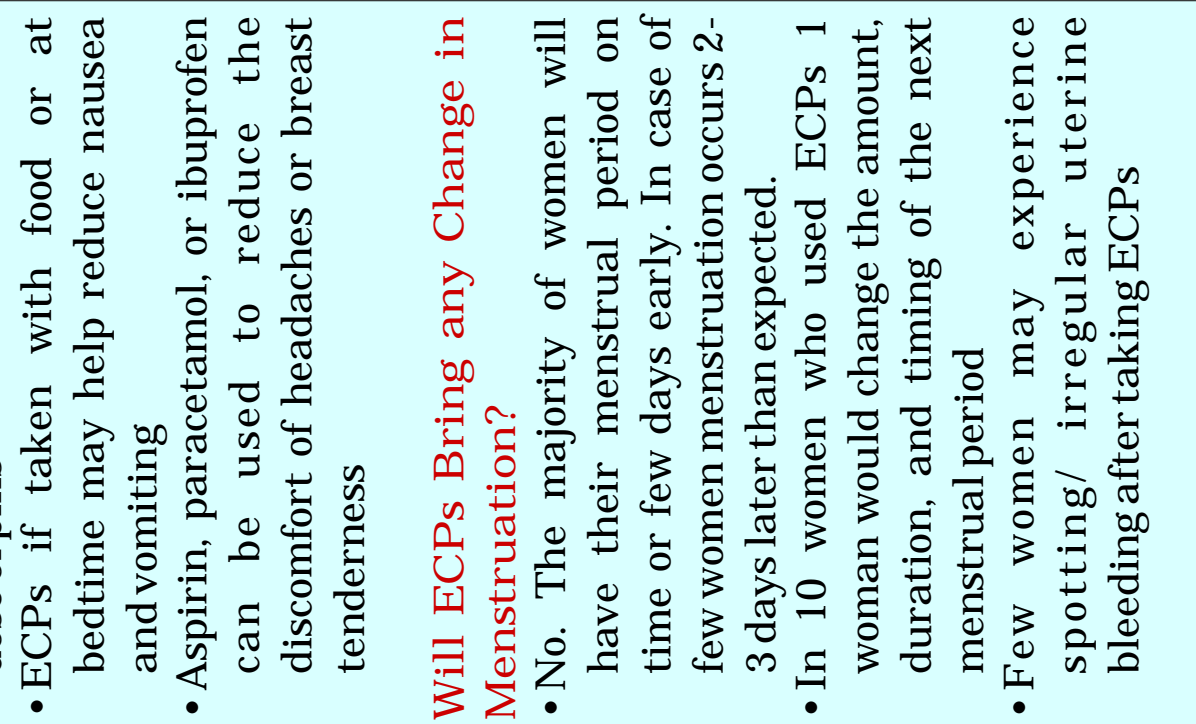

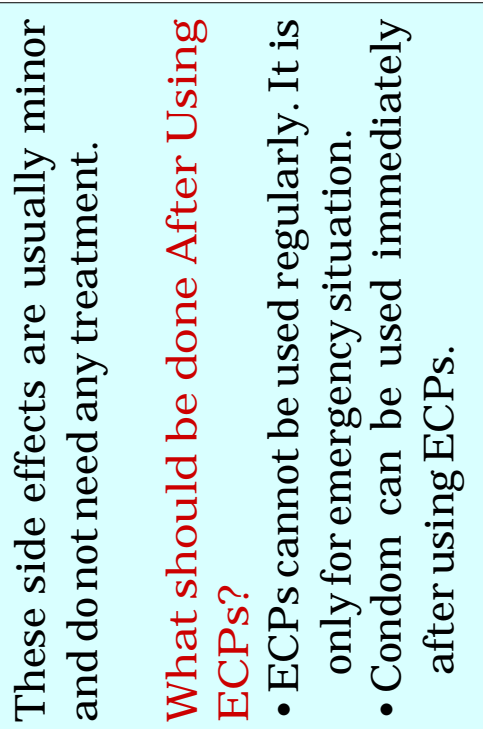

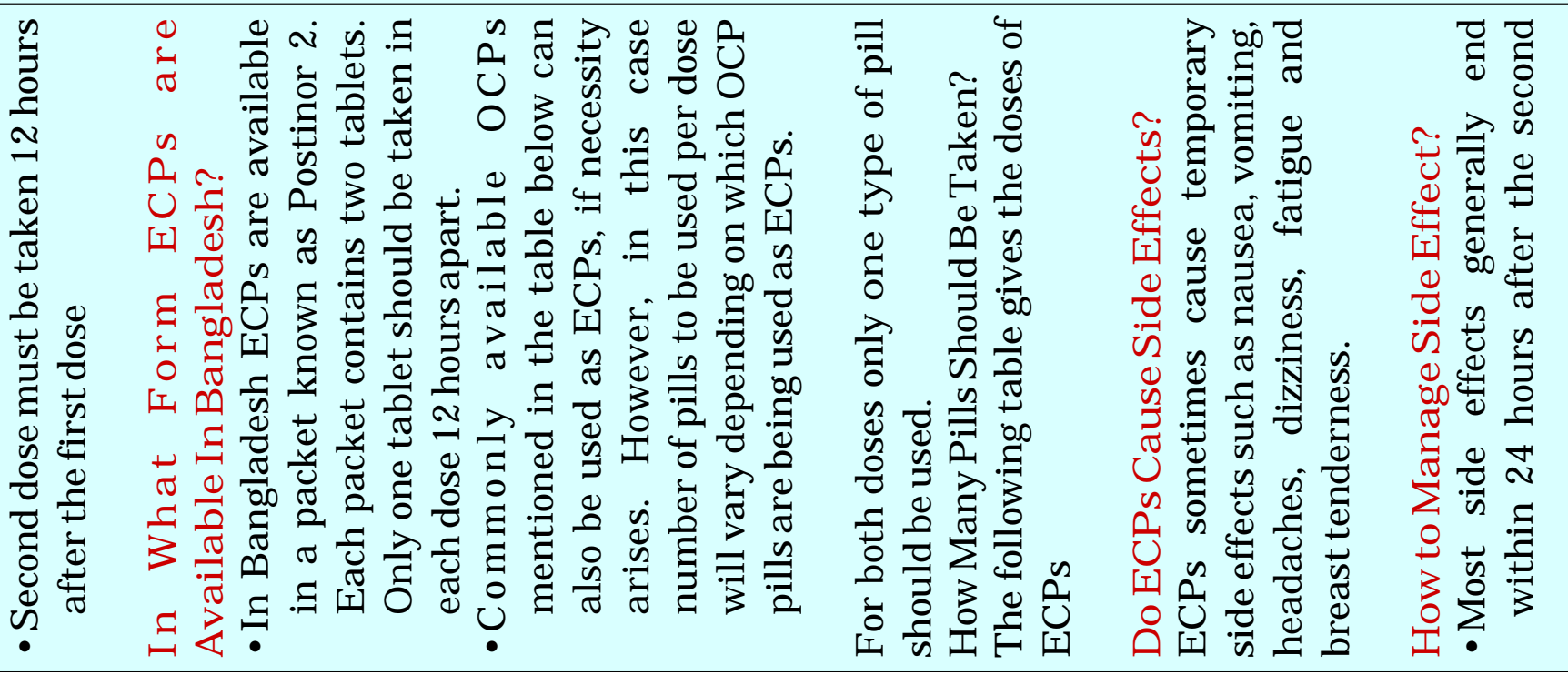




\section{Teaching And IEC/BCC M aterials India}

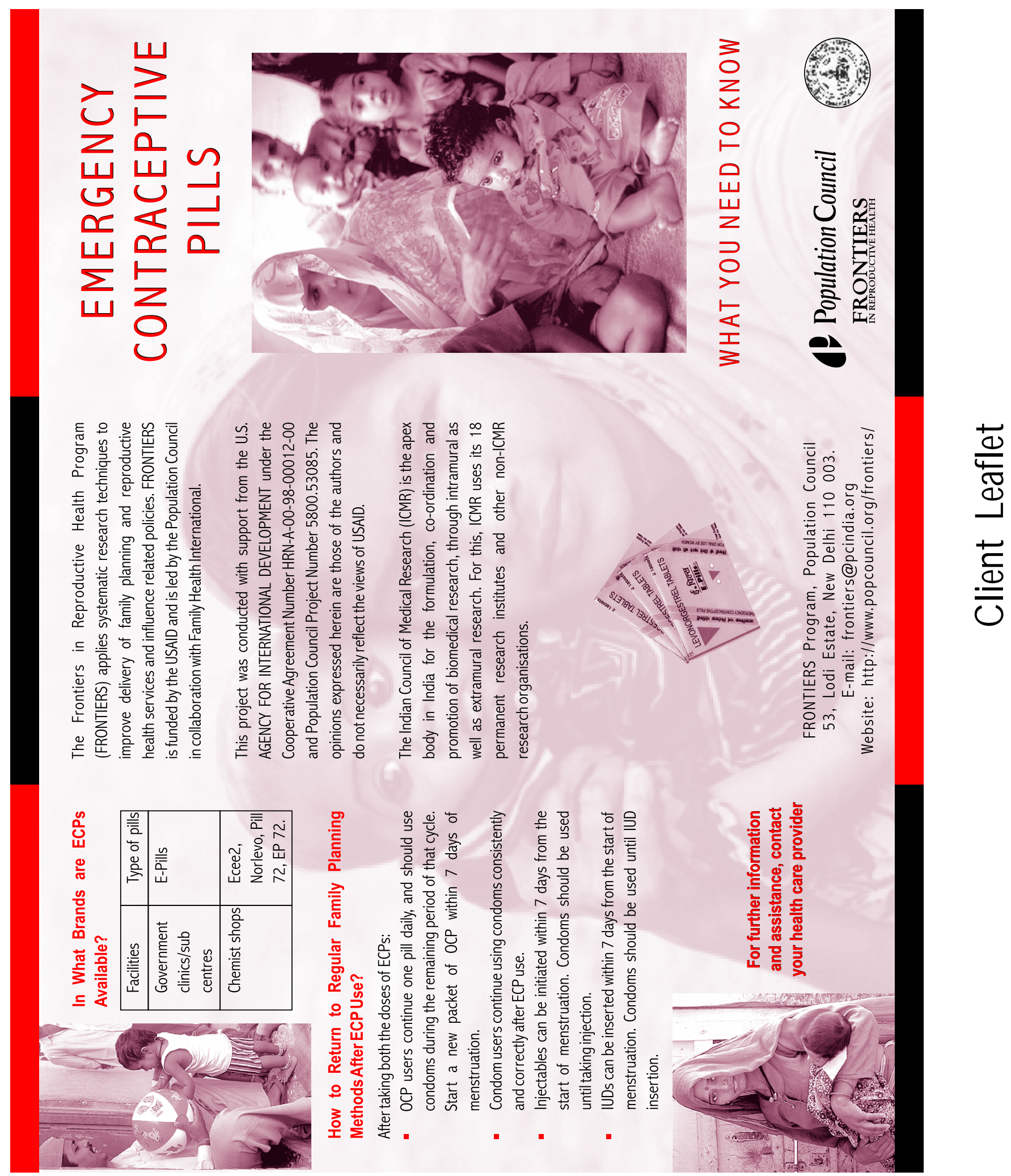




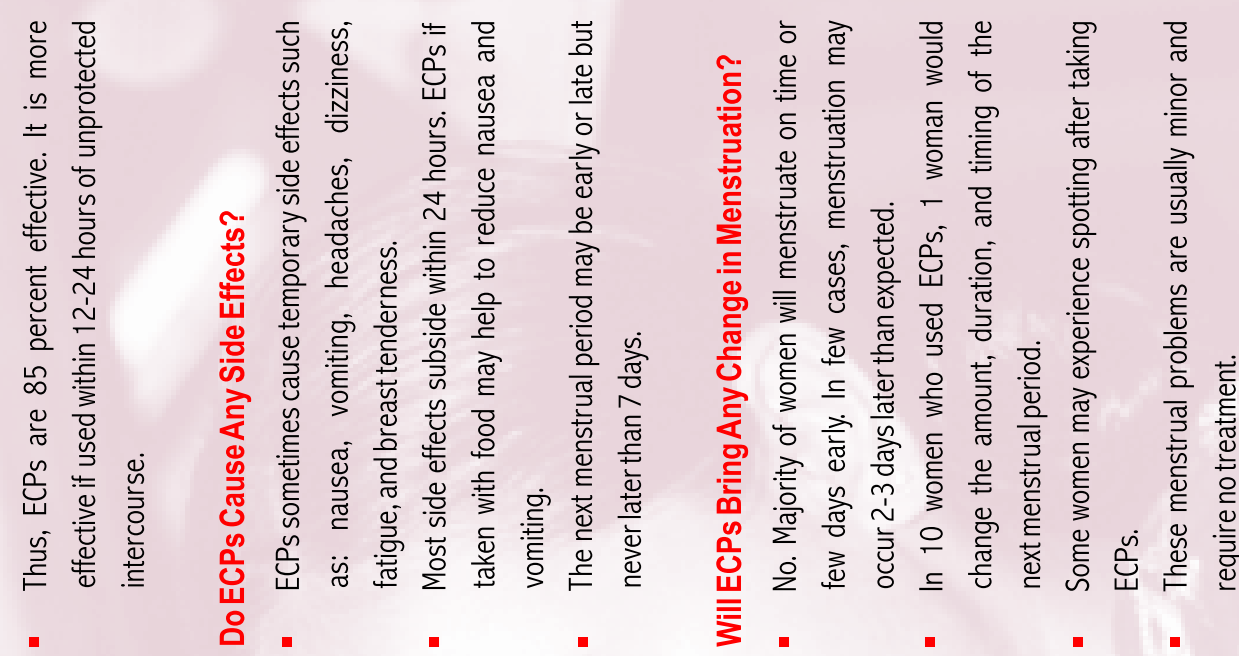

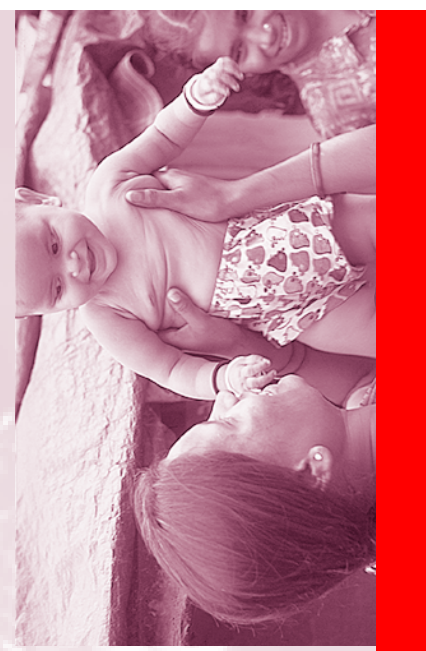

希 究

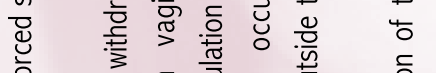

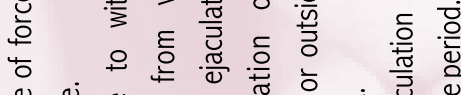

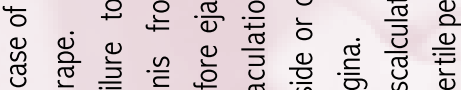

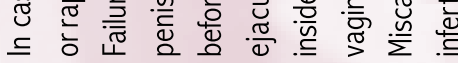

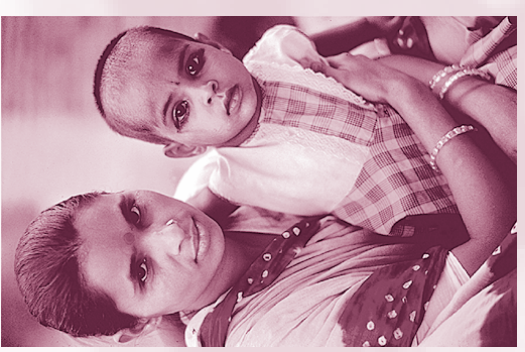

毫

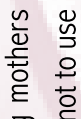

$\approx$ 造 尊

당

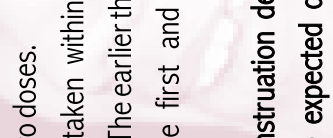

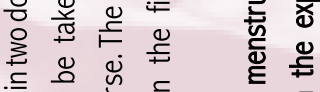

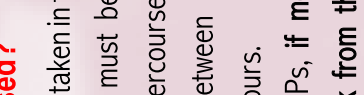

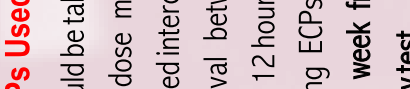

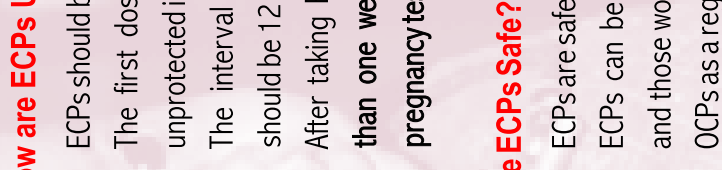

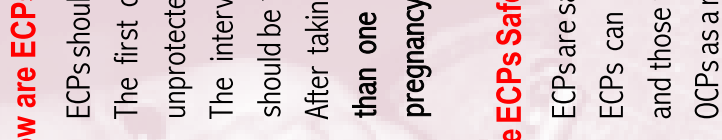

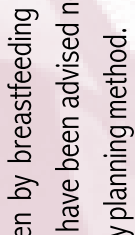

है

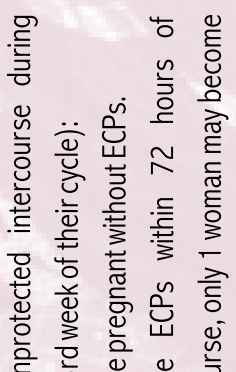

品 亏

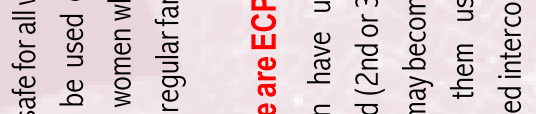

:

密

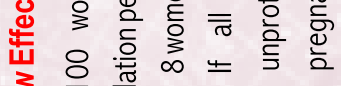

峞山.

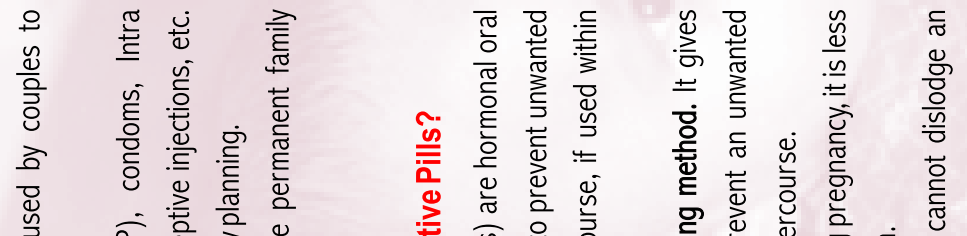

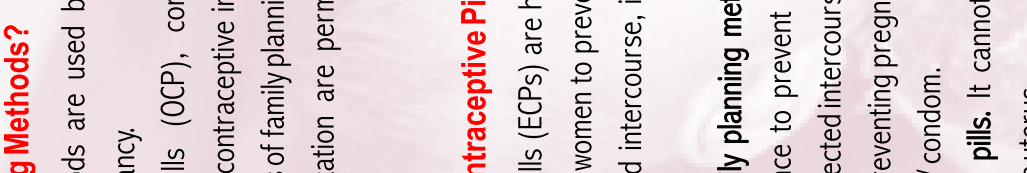
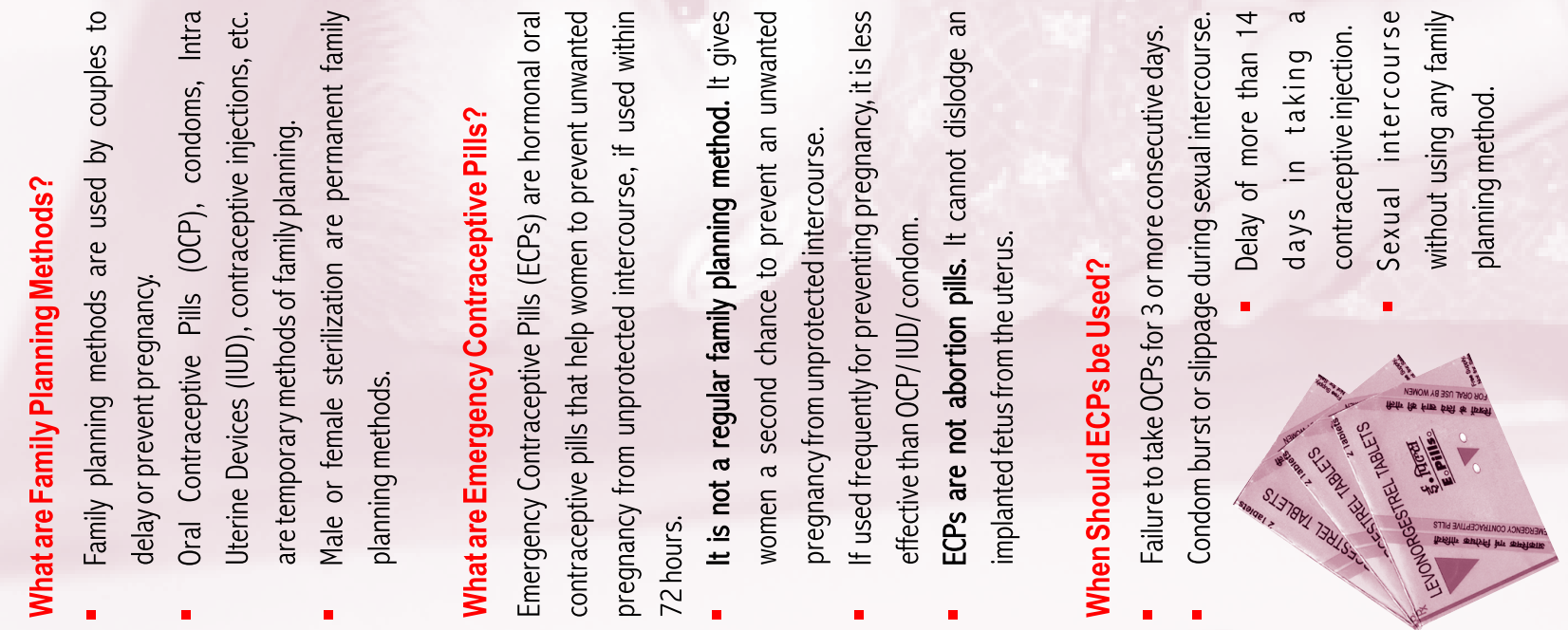


\section{What are Emergency Contraceptive} Pills (ECP)?

- Emergency Contraceptive Pills (ECPS) are hormonal oral contraceptive pills that help women to prevent unwanted pregnancy from unprotected intercourse if used within 72 hours

- ECP is not a regular family planning method. It gives women a second chance to prevent an unwanted pregnancy from unprotected intercourse

- If used frequently for preventing pregnancy, it is less effective than Pills/IUD/Condom

- ECPs are not abortion pills. It can not dislodge an implanted fetus from the uterus

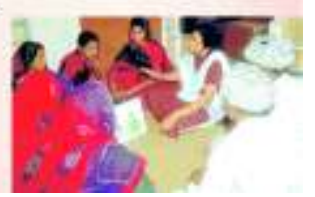

\section{How Effective are ECPs?}

- If 100 women have unprotected sex during ovulation period (2nd or 3rd week of their cycle)

- 8 women may become pregnant without ECPS

- If all of them use ECPS within 72 hours of unprotected intercourse;only 1 women may become pregnant

- Thus, ECPs are $85 \%$ effective. It is more effective if used within 12-24 hours of unprotected intercourse

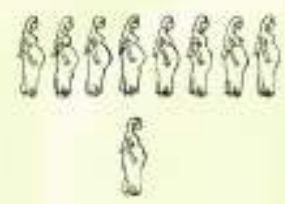

\section{A few pages from the ECP Flipchart}

\section{How should you use ECP?}

- ECPs must be taken within 72 hours of unprotected intercourse

- After taking ECPs, if menstruation gets delayed by more than one week from the expected date, go for a medical opinion/pregnancy test.

Dosage of ECP: Single dose of $1.5 \mathrm{mg}$ of Levonorgestrol to be taken within 72 hours of unprotected sex (one tablet of $1.5 \mathrm{mg}$ or 2 tablets of $0.75 \mathrm{mg}$ )

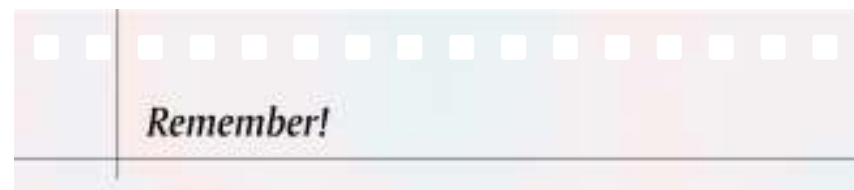

- ECP is for emergency use only. It is not a regular family planning method.

- If ECP is used frequently for preventing pregnancy, it is less effective than Pills/Injection/ Condom/ IUD

- ECP must be taken within 72 hours ( 3 days) of unprotected intercourse. The earlier the better

- The interval between the two doses should be 12 hours

- After taking ECPs, if menstruation delays for more than one week of the expected date, go for pregnancy test

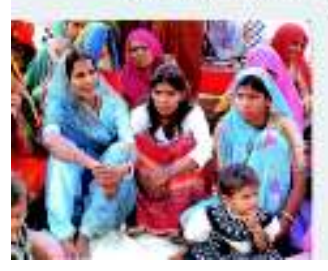

ECP are not abortion pills. It can not dislodge implanted fetus from the uterus 


\section{Poster on ECP}

यदि किसी गर्भनिरोधक का उपयोग न किया हो या गर्भनिरोधक असफल हो जाये तो क्या करें

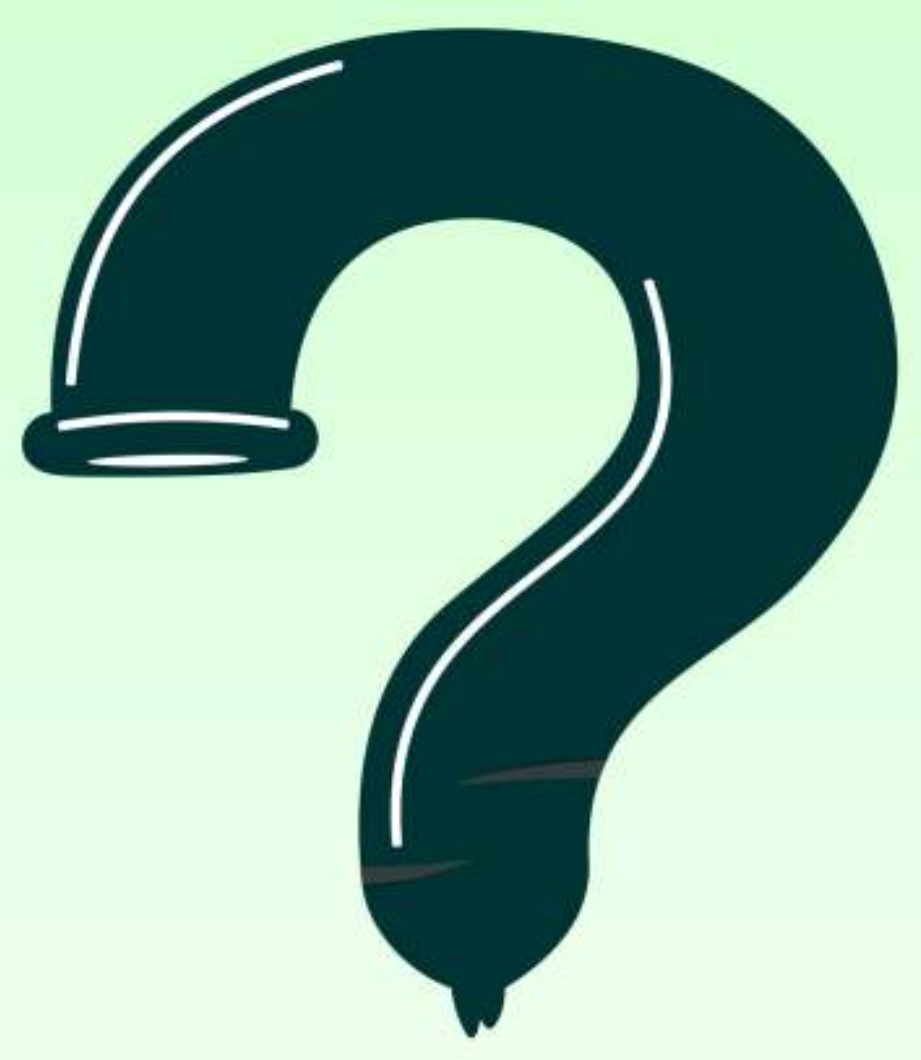

आपात्कालीन गर्भनिरोधक गोलियाँ अनचाहे गर्भ को रोकने में सहायक हैं; यदि इन्हें 72 घण्टे के अंदर लिया जाये। 


\section{Poster on ECP}
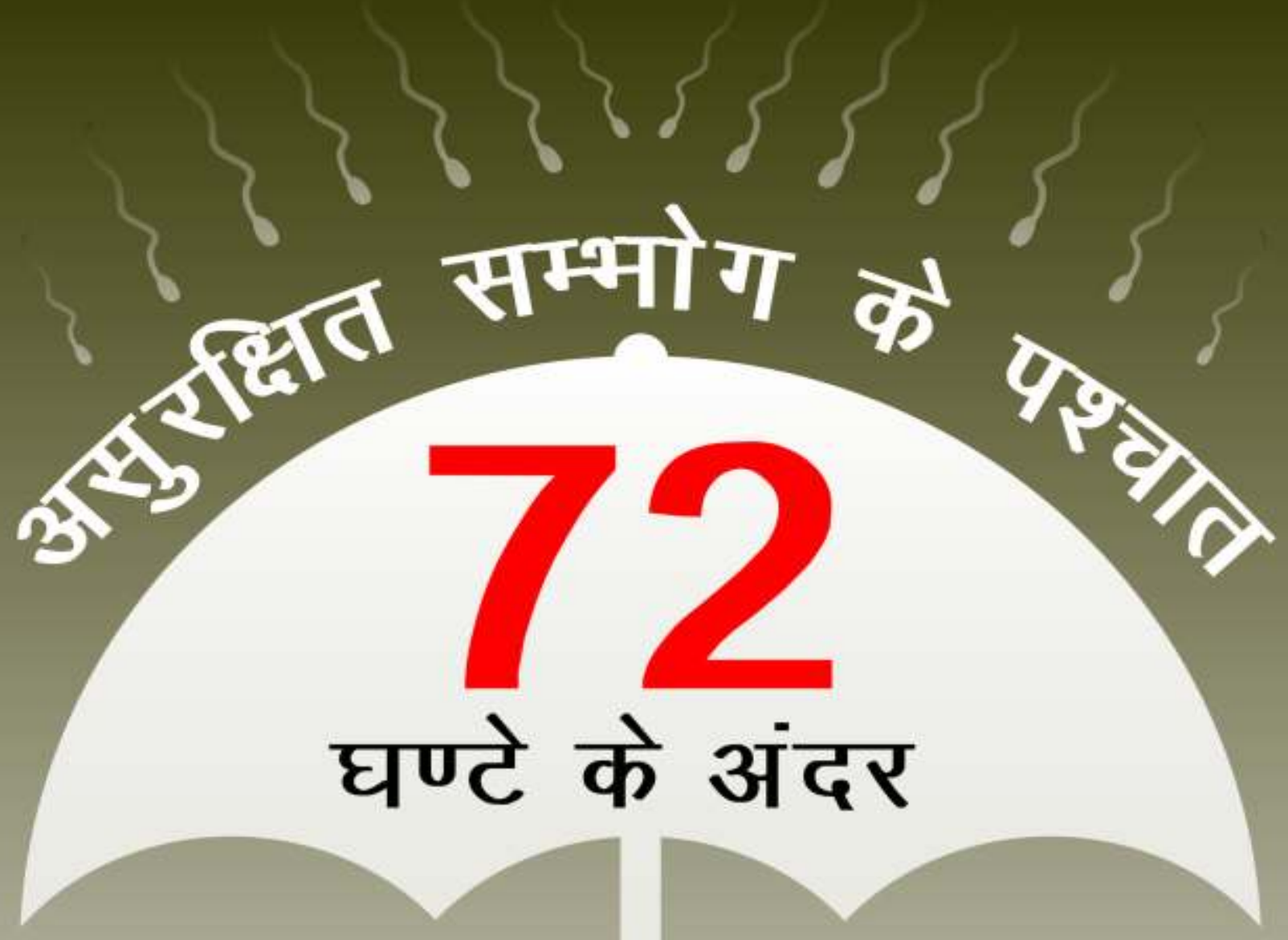

आपात्कालीन गर्भ निरोधक गोलियाँ लें और

अनचाहे गर्भ से बचें 


\section{Poster on ECP}

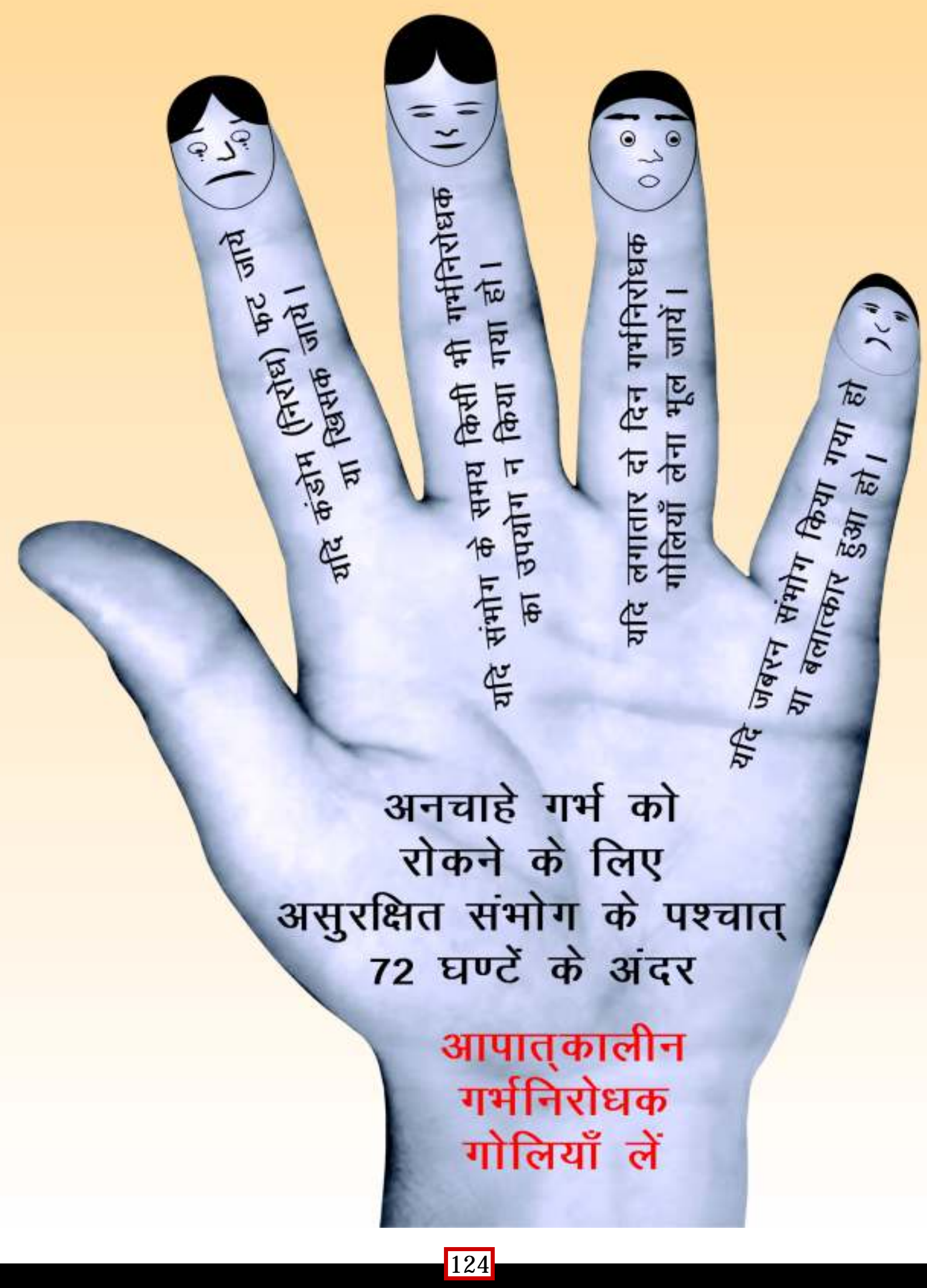




\section{Poster on ECP}

\section{अगर}

कंडोम (निरोध) फट जाये या खिसक जाये।

या

गर्भनिरोधक गोलियाँ लगातार 2 दिन लेना भूल जायें। या

किसी गर्भनिरोधक का उपयोग न किया गया हो।

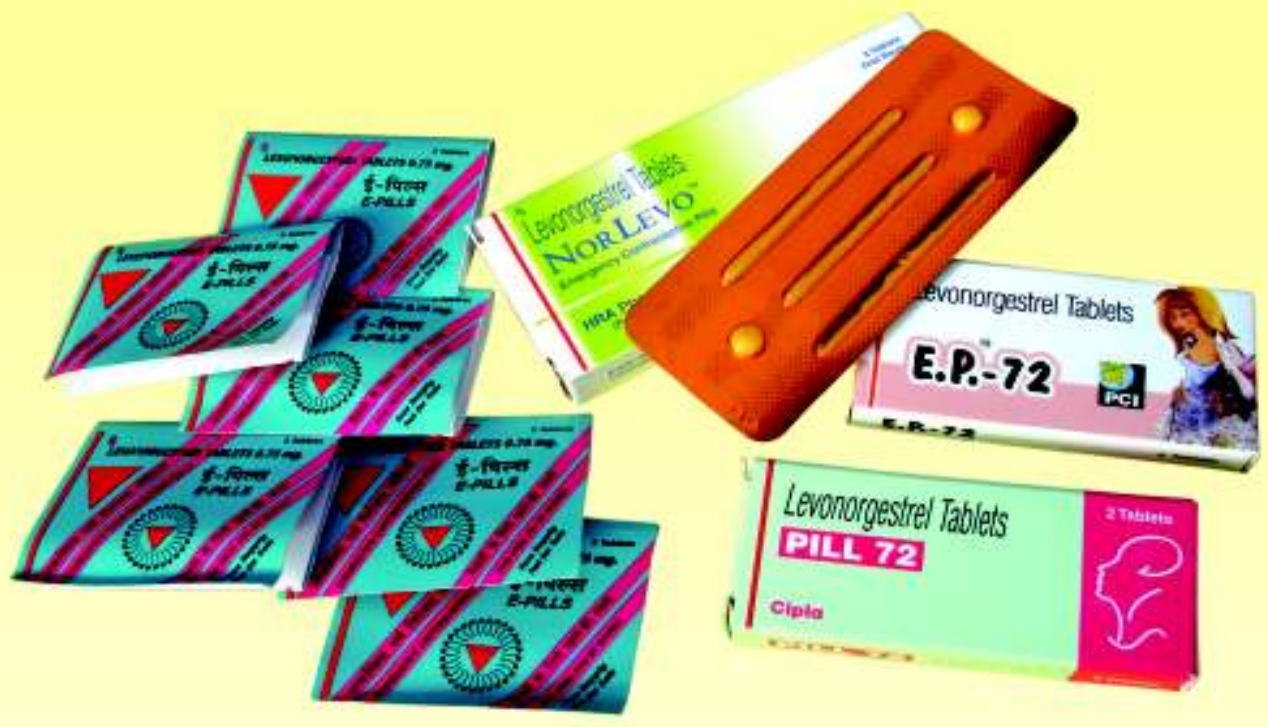

\section{तो:}

अनचाहे गर्भ को रोकने के लिए

72 घण्टे के अंदर

आपात्कालीन गर्भनिरोधक गोलियाँ लें। 



\section{Bibliography}

Akhter H. K. 1986. "Medical Practice After Legalization of Abortion: Bangladesh. Prevention and Treatment of Contraceptive Failure." In Honor of Christopher Tietze, edited by U Landy and S S Ratnam. New York: Plenum Press.

Alan Guttmacher Institute (AGI). 1999. Abortion Data from Reports of the Alan Guttmacher Institute. New York: AGI.

Bangladesh Bureau of Statistics. 2001. Population Census 2001: Preliminary Report. Dhaka: Bangladesh Bureau of Statistics.

Bangladesh Demographic and Health Survey 2003-2004. Dhaka: NIPORT, Mitra and Associates, and ORC Macro. 2004.

Center for Disease Control. 2004. "Fact Sheet: Abortion Surveillance." Atlanta: Center for Disease Control.

Consortium for Emergency Contraception. 2002. "Expanding Global Access to Emergency Contraception: A Collaborative Approach to Meeting Women's Needs." Seattle: Consortium for Emergency Contraception.

Cunningham F. Gary et al. 1997. "Williams Obstetrics [20th Edition]." Stamford: Appleton and Lange.

"Emergency Contraceptive Pills: Medical and Service Delivery Guidelines." Seattle: Consortium for Emergency Contraception. 2000.

"Emergency Contraceptive Pills: A Resources Packet for Health Care Providers and Program Managers." Seattle: Consortium for Emergency Contraception. 1996.

Ellertson C. et al. 2000. "Refining the Yuzpe Method of Emergency Contraception." New York: Population Council.

"Emergency Contraception: A Guide for Service Delivery." Geneva: WHO. 1998.

Family Health International. 1999. "Contraceptive Technology Updates Series." North Carolina: Family Health International.

"Gender Statistics in Brief, 1997." Dhaka: Bangladesh Bureau of Statistics. 1997.

Haishan Fu, Jacqueline E. Darroch, Taylor Haas and Nalini Ranjit. 1999. Contraceptive Failure Rates: New Estimates from the 1995 National Survey of Family Growth. Family Planning Perspectives, 31(2):56-63. 
Hatcher, Robert A., Ward Rinehart, Richard Blackbuurn and Judith S. Geller. 2001. "The Essential of Contraceptive Technology: A Handbook for Clinic Staff." Baltimore: Johns Hopkins School of Public Health, Population Information Program.

Henshaw, S.K.1990. "Induced Abortion: A World Review." Family Planning Perspectives, 22: 76-89.

International Consortium for Emergency Contraception. 2004. "Emergency Contraceptive Pills: Medical and Service Delivery Guidelines."

Islam Waliur and M. Shahadat Hossain. 1997. "Reproductive Health Status in Bangladesh, 1997." Dhaka: Bangladesh Bureau of Statistics.

"Improving Access to Quality Care in Family Planning: Medical E1igibility Criteria for Contraceptive Use." Geneva:WHO. 2002.

Kamal, H., A. Hussain, S.F. Begum, G.M. Kamal. 1993. "Prospects of Menstrual Regulation Services in Bangladesh: Results of an Operational Research." Dhaka: Bangladesh Association for Prevention of Septic Abortion (BAPSA).

Knowles, Jon and Marcia Ringel. 1998. "All about Birth Control." New York: Three Rivers Press, Pp169-170.

Letter. No:Pakaw-1/ECP/22/2001/248, date 31/12/2001, Ministry of Health and Family Welfare, Development 1 Branch; Government of Bangladesh. Dhaka: Ministry of Health and Family Welfare. 2001.

Ministry of Health and Family Welfare and National Integrated Population and Health Program (MHFW and NIPHP). 2000. "Contraception Manual." Dhaka: Ministry of Health and Family Welfare.

Ministry of Health and Family Welfare (MHFW). 2001. "Bangladesh National Strategy for Maternal Health." Dhaka: Ministry of Health and Family Welfare.

"Maternal Health Around the World"(wall chart). Geneva: WHO. 1997.

“Making Pregnancy Safer.” Delhi: WHO/SEARO. 2001.

Nayyar, Anjali. 2000. "Emergency Contraception: Know Your Option." New Delhi, India: Population Council.

NIPORT, Mitra and Associates and Measure/DHS+ ORC-Macro Internationals Inc. 2000. "Bangladesh Demographic and Health Survey 1999-2000." Dhaka: NIPORT, Mitra and Associates and Measure/DHS+ ORC-Macro Internationals Inc. 
NIPORT, Mitra and Associates, and ORC Macro Inc. 2001. "Bangladesh Demographic and Health Survey.” Dhaka: NIPORT, Mitra and Associates, and ORC Macro.

NIPORT, ORC Macro, Johns Hopkins University and ICDDR,B. 2003. "Bangladesh Maternal Health Services and Maternal Mortality." Dhaka: NIPORT, ORC Macro, Johns Hopkins University and ICDDR, B

"Preliminary Report: Bangladesh Maternal Health Services and Maternal Mortality Survey 2001." Dhaka: NIPORT, Mitra and Associates and Measure/DHS+ ORC-Macro Internationals Inc. 2001.

Pacific Institute for Women's Health. 2000. "A Clinician's Guide to Providing Emergency Contraceptive Pills." Los Angeles: Pacific Institute for Women's Health.

Paul, F.A., Van Look and Felicia Stewart. 1998. "Emergency Contraception." In Robert Hatcher et al., eds, Contraceptive Technology, pp. 277-95.New York: Ardent Media.

Physician for Reproductive Choice and Health (PRCH) and Alan Guttmacher Institute (AGI). 2003. "An Overview of Abortion in the United States." New York: PRCH and AGI.

Piaggio G., H. von Hetzen, D.A. Grimes and P.F.A. Van Look. 1999. "Timing of Emergency Contraception with Levonorgestrel or the Yuzpe Regimen." Lancet, 353: 721.

Planned Parenthood Federation of America. 1998. "Emergency Contraception Handbook." New York: Planned Parenthood.

Population Council 2005. "Emergency Contraception's Mode of Action Clarified" Population Briefs, vol. 11, no:2.

Population Reference Bureau. 2004. "2004 World Population Data Sheet.” Washington DC: PRB.

Population Reports. Series J No. 35, 36, 48 and 7. Washington: Population Reference Bureau.

Ransom, E. I. and Nancy V. Yinger. 2002. "Making Motherhood Safer: Overcoming Obstacles on the Pathway to Care." Washington: Population Reference Bureau.

Rochat, R.W., S. Jabeen, M.J. Rosenberg, A. R. Measham, A.R. Khan, M. Obaidullah and P. Gould. 1981. "Maternal and Abortion Related Deaths in Bangladesh, 1978-79." International Journal Gynaecology Obstetrics, 19: 155-64.

Royston, E. and S. Armstrong. 1989. "Preventing Maternal Deaths." Geneva: World Health Organization. 
"Reduction of Maternal Mortality: A Joint WHO/UNFPA/UNICEF/World Bank Statement." Geneva: WHO. 1999.

"Sharing Responsibility: Women Society and Abortion Worldwide." New York: The Alan Guttmacher Institute. 1999.

"Statistical Pocketbook of Bangladesh. Dhaka: Bangladesh Bureau of Statistics. 2000.

Segal, S. J. and k. D. LaGuardia. 1990. “Termination of Pregnancy: A Global View.” Balliere's clinical Obstetric and Gynecology, 4(2): 235-247.

Singh, Susheela, Josefina V. Cabigon, Altaf Hossain, Haidary Kamal and Aurora E. Perez. 1997. "Estimating the Level of Abortion in the Philippines and Bangladesh." International Family Planning Perspectives, 23: pp100-107 \& 144.

UNDP/UNFPA/WHO/World Bank Special Programme of Research, Development and Research Training in Human Reproduction. 2001. "Use of Emergency Contraception Pills could Halve the Induced Abortion Rate in Shanghai, China." Social Science Research Policy Briefs. Series 2. No 1.

UNFPA. 1997. “The State of the World Population 2004.” New York: UNFPA.

UNICEF. 1994. "Emergency Obstetric Care: Intervention for the Reduction of Maternal Mortality." Dhaka: Obstetrical and Gynaecological Society of Bangladesh.

United Nations. 1999. "World Abortion Policies." New York: United Nations, Population Division, Department of Economic and Social Affairs.

Von Hertzen H, Piaggio G, Ding J, Chen J, Song S, Bartfai G, et al. 2002. "Low Dose Mifepristone and Two Regimens of Levonorgestrel for Emergency Contraception: A WHO Multicentre Randomised Trial." Lancet, 360:1803-10.

Wilcox, A.J., C.R. Weinberg and D.D. Baird. 1995. "Timing of Sexual Intercourse in Relation to Ovulation: Effects on the Probability of Conception, Survival of Pregnancy, and Sex of the Baby." New England Journal of Medicine 199, 333:1517-21.

World Bank. 1995. "Bangladesh: From Stabilization to Growth." Washington, D.C.: The World Bank.

World Health Organization (WHO). 2004. "Unsafe Abortion- Global and Regional Estimates of the Incidence of Unsafe Abortion and Associated Mortality in 2000." 4th edition. Geneva: World Health Organization. 
World Health Organization/SEARO. 2002a. "Women's Health in South-East Asia." Delhi: World Health Organization/SEARO

"Women of South-East Asia: A health profile." Regional Publications, SEARO No. 34. Delhi: World Health Organization/SEARO. 2002b.

WHO/UNICEF/UNFPA. 2004. "Maternal Mortality in 2000: Estimates Developed by WHO, UNICEF and UNFPA." Geneva: Department of reproductive Health Research, WHO 

For More Information, Please Contact:

\section{Frontiers in Reproductive Health Program}

Zone 5A, Ground Floor, India Habitat Centre, Lodi Road, New Delhi 110003

E-mail: frontiers-india@popcouncil.org Website: http://www.popcouncil.org/frontiers/ 